\title{
Wound healing after myocardial infarction : focus on matrix metalloproteinases and the plasminogen system
}

Citation for published version (APA):

Creemers, E. E. J. M. (2000). Wound healing after myocardial infarction : focus on matrix metalloproteinases and the plasminogen system. [Doctoral Thesis, Maastricht University]. Datawyse / Universitaire Pers Maastricht. https://doi.org/10.26481/dis.20000616ec

Document status and date:

Published: 01/01/2000

DOI:

10.26481/dis.20000616ec

Document Version:

Publisher's PDF, also known as Version of record

Please check the document version of this publication:

- A submitted manuscript is the version of the article upon submission and before peer-review. There can be important differences between the submitted version and the official published version of record.

People interested in the research are advised to contact the author for the final version of the publication, or visit the DOI to the publisher's website.

- The final author version and the galley proof are versions of the publication after peer review.

- The final published version features the final layout of the paper including the volume, issue and page numbers.

Link to publication

\footnotetext{
General rights rights.

- You may freely distribute the URL identifying the publication in the public portal. please follow below link for the End User Agreement:

www.umlib.nl/taverne-license

Take down policy

If you believe that this document breaches copyright please contact us at:

repository@maastrichtuniversity.nl

providing details and we will investigate your claim.
}

Copyright and moral rights for the publications made accessible in the public portal are retained by the authors and/or other copyright owners and it is a condition of accessing publications that users recognise and abide by the legal requirements associated with these

- Users may download and print one copy of any publication from the public portal for the purpose of private study or research.

- You may not further distribute the material or use it for any profit-making activity or commercial gain

If the publication is distributed under the terms of Article $25 \mathrm{fa}$ of the Dutch Copyright Act, indicated by the "Taverne" license above, 


\section{Wound Healing after Myocardial Infarction}

Focus on Matrix Metalloproteinases and the Plasminogen System 
E.E.J.M Creemers, Maastricht 2000

ISBN 90-9013756.4

Basis vormgeving: Esther Creemers

Druk en omslagontwerp: Datawyse / Universitaire Pers Maastricht 


\section{Wound Healing after Myocardial Infarction}

Focus on Matrix Metalloproteinases and the Plasminogen System

\section{Proefschrift}

ter verkrijging van de graad van doctor

aan de Universiteit Maastricht,

op gezag van de Rector Magnificus,

Ptof. dr. A. C. Nieuwenhuijzen Kruseman,

volgens het besluit van het College van Decanen,

in het openbaar te verdedigen

op wrijdag 16 juni 2000 om 14.00 uur

door

Esther Elisa Johanna Maria Creemers

Geboren op 27 oktober 1969 te Geldrop 


\section{Promotores}

Prof. dr. M.J.A.P. Daemen

Prof. dr. J.F.M. Smits

\section{Co-promotor}

Dr. ir. J.P.M. Cleutjens

\section{Beoordelingscommissie}

Prof. dt. M. Borgers (voorzitter)

Prof. dr. V.W.M. van Hinsbergh (Universiteit Leiden)

Prof. dr. H.J.G.M. Crijns (Rijksuniversiteit Groningen)

Prof. dr. J.W. Cohen Tervaert

Prof. dr. L.H. Snoeckx

The studies presented in this thesis and the publication of this thesis were financially supported by the Netherlands Heart Foundation (grant NHS 94.012)

For financial support for the publication of this thesis, I also thank:

-Dr. Saal van Zwanenbergstichting 
Always look at the bright side of Life..

-Monty Python- 



\section{TABLE OF CONTENTS}

Chapter 1 Introduction 11

1 General: Introduction $\quad 12$

2 The extracellular matrix of the heart 12

3. Extracellulat matrix degrading enzymes 13

3.1 Cysteine and aspartic proteinases 13

3.2 Matrix metalloproteinases (MMPs) 14

3.2.1 The family members $\quad 14$

3.2.2 Protein structure of MMPs 16

3.2.3 Regulation of MMP activity 17

3.2.4 MMPs in disease $\quad 21$

3.3 The plasminogen system 23

3.3.1 Components of the plasminogen system 23

3.3.2 Regulators of the plasminogen system 27

3.3.3 Functions of the Plg system 28

4 Structural alterations of the heart after myocardial 31 infarction

4.1. Infarct healing 31

4.2 Architectural alterations of the heart after myocardial 32 infarction

5 Hypothesis 33

Chapter 2 Time-dependent lacalization of matrix metalloproteinases in $\quad 35$

the healing human heart after infarction

Chapter 3 Inhibition of matrix metalloproteinases attenuates left ventricular 47 remodeling, delays infarct healing and depresses cardiac function after myocardial infarction in mice

Chapter 4 Preliminary observations on the effects of adenoviral gene transfer 61 of a plasmin-inhibitor after myocardial infarction in the mouse

Cbapter 5 Distuption of the plasminogen gene in mice abolishes wound 69 healing following myocardial infarction 
Chapter 6 Inhibition of plasminogen activators or matrix metalloproteinases prevents cardiac rupture but impairs infarct healing and causes cardiac failure

Chapter 7 General discussion $\quad 97$

7.1 The role of matrix metalloproteinases in infarct healing 98

7.2 The role of tmatrix metalloproteinases in cardiac rupture 98

7.3 The role of the plasminogen system in infarct healing and cardiac rupture

7.4 Impaired healing and LV dilatation 101

$\begin{array}{ll}\text { 7.5 Impaired healing and cardiac function } & 102\end{array}$

7.6 Concluding temarks and outlook 103

References

105

Summary

Samenvating

123

Dankwoord

126

Carriculum Vitae 


\section{List of abbreviations}

\begin{tabular}{|c|c|}
\hline$\alpha_{2} \mathrm{M}$ & $a_{2}-$ macroglobulin \\
\hline ATF & aminoterminal fragment \\
\hline $\mathrm{bFGF}$ & basic fibroblast growth factor \\
\hline BPTI & bovine pancreas trypsin inhibitor \\
\hline BrdU & 5'-bromo-2'-deoxyuridine \\
\hline $\mathrm{BW}$ & bodyweight \\
\hline $\mathrm{CO}$ & cardiac output \\
\hline $\mathrm{ECM}$ & extracellular matrix \\
\hline EGF & epidermal growth factor \\
\hline H\&E & haematoxilin and eosin \\
\hline HW & heart weight \\
\hline IFN- $\gamma$ & interferon $\gamma$ \\
\hline IL-1 & interleukin-1 \\
\hline LV & left ventricle \\
\hline LVEDP & left ventricular end-diastolic pressure \\
\hline LVSP & left wentricular systolic pressure \\
\hline MAP & mean arterial pressure \\
\hline MI & myocardial infarction \\
\hline MMP & matrix metalloproteinases \\
\hline MT-MMP & membrane-type MMP \\
\hline $\mathrm{NF}-x \mathrm{~B}$ & nuclear factor kappa-B \\
\hline PAI & plasminogen activator inhibitor \\
\hline PDGF & platelet derived growth factor \\
\hline PIg & plasminogen \\
\hline PMNs & polymorphonuclear granulocytes \\
\hline $\mathrm{RT}-\mathrm{PCR}$ & reverse transcriptase polymerase chain reaction \\
\hline SEM & standard error of the mean \\
\hline SV & stroke volume \\
\hline TIMP & tissue inhibitor of metalloproteinase \\
\hline $\mathrm{TGF}-\beta$ & transforming growth factor $\beta$ \\
\hline $\mathrm{TNF}-\alpha$ & tumor necrosis factor- $\alpha$ \\
\hline TBS & tris buffered saline \\
\hline $\mathrm{tPA}$ & tissue-type plasminogen activator \\
\hline TUNEL & terminal transferase dUTP nick end labelling \\
\hline uPA & urokinase plasminogen activator \\
\hline UPAR & urokinase plasminogen activator receptor \\
\hline VEGF & vascular endothelial growth factor \\
\hline
\end{tabular}



Chapter 1

Introduction 


\section{GENERAL INTRODUCTION}

Ischemic heart disease may present as angina pectoris, acute myocardial infarction or sudden death and is still one of the most common causes of death in western Europe and in the USA. In the Netherlands, $14 \%$ of the deaths in 1997 was the result of ischemic heart disease ${ }^{41}$.

Myocardial infarction (MI) is defined as the prolonged interruption of coronary blood flow to the myocardrum. In the vast majority of patients, the underlying disease is atherosclerosis with obstructive coronary artery disease. Since early intervention after MI, such as reperfusion therapies, has been proven quite effective, the number of patients that survive an acute MI increases. As a consequence, more patients are at risk for the development of heart failure, a clinical syndrome with high morbidity and limited life expectancy. Understanding of the pathophysiology of heart failure following infarction is important for an adequate approach to therapy. Most studies on this subject have focussed on the limitation of muscle injury and the progressive ventricular dilatation that occurs in the months to years after infarction. In contrast, little attention has been paid to the healing process after infarction. Recent data, however point to the importance of the infarct itself as a potential target for intervention. The infarct appears to be more than just dead tissue and infarct healing turns out to be an active, and well controlled process. More importantly, interventions in infarct healing appear to affect the architecture of the heart, an important determinant of survival after infarction ${ }^{42}$. One of the determinants of left ventricular remodeling is damage to and loss of the myocardial extracellular matrix during the healing process after infarction ${ }^{43}$. This thesis focusses on the healing process after MI, with special attention to two enzyme systems that are able to degrade components of the extracellular matrix, i.e. the matrix metalloproteinases (MMPs) and the plasminogen system.

In this chapter, the composition of the extracellular matrix of normal hearts is described briefly. This is followed by a discussion on the four classes of extracellular matrix degtading enzymes. Speciall attention will be paid to the role of matrix metalloproteinases and the plasminogen system in a number of wound healing models. Then, an overview is given on the structural changes that occur in the heart after infarction. Finally, the aim of the present thesis will be outlined.

\section{THE EXTRACELLULAR MATRIX OF THE HEART}

The myocardium comprises of cardiomyocytes and a non-myocyte compartment (i.e. the interstitium), consisting of several different cell types and an extracellular matrix. Cardiomyocytes occupy approximately $70 \%$ of the volume of the myocardium but constitute only about one third of the cell population ${ }^{44}$. The non-myocytes are found in the cardiac interstitium and include fibroblasts, endothelial cells, vascular smooth muscle cells, macrophages and mast cells.

The extracellular matrix (ECM) forms the structural backbone of the heart and is composed of a complex of macromolecules, which can be divided in at least five major components: collagens, basement membranes, elastic fibers, proteoglycans and structural glycoproteins ${ }^{45}$. Interstitial collagens (type I and III), which are predominantly produced 
by (myo-) fibroblasts, form the major components of the extracellular matrix ${ }^{46}$. Type I collagen is a heterotrimer organized in thick bundles with an extreme tensile strenght. Thin type. III collagen fibers function as a center to which type I collagen and other collagen types can attach. The triple helix conformation makes interstitial collagens extremely resistant to degradation by all proteinases except specific types of collagenases. Type IV collagen is present in the basement membrane surrounding the cardiomyocyte. Together, the collagens surround and interconnect individual myocytes, groups of myocytes, muscle fibers, and muscle bundles ${ }^{47}$. Due to cross-linking of the collagen fibers, the network gains strength and provides stiffness to the myocardium ${ }^{43}$. The organization of the collagen fibers largly determines the mechanical property of tissues. In skin, for example, a complex three-dimensional weave of fibers provides multidirectional compliance, while in tendons the unidirectional organization of collagen fibers confers strength and stiffness parallel to the tendon's long axis.

\section{EXTRACELLULAR MATRIX DEGRADING ENZYMES}

The extracellular matrix (ECM) contains many biochemically distinct components. For this reason, the degradation of the ECM must involve the action of an array of proteolytic enzymes ${ }^{48}$. ECM degrading enzymes can be divided into intracellular functioning enzymes involving cysteine and aspartate proteinases and extracellular functioning enzymes involving metallo- and serine proteinases (Table 1). Although each of these four main classes of proteinases found in mammals may contribute to matrix degradation, increasing evidence suggests that the latter two systems predominate ${ }^{49}$. For this reason, we will focus on these two enzyme systems: the matrix metalloproteinases, collectively capable of degtading essentially all components of the ECM, and the serine proteinases, of which the plasminogen system is the best characterized. Cysteine and aspartatic proteinases will be briefly discussed.

\subsection{Cysteine and aspartic proteinases}

\section{Cysteinte proteinases}

In general, cysteine proteinases are intracellular enzymes, found in cytosol or lysosomes of various cell types, where they degrade proteins during phagocytosis. These enzymes ate optimally active at acidic $\mathrm{pH}$ and unstable at neutral or alkaline $\mathrm{pH}$ values. "They are inhibited by bivalent cations, in contrast to the metalloproteinases, which are activated by these compounds. In vitro studies have shown that some cathepsins degrade matrix proteins such as type I collagen, laminin and proteoglycans at acidic $\mathrm{pH}$. This led to the proposal that $1 y$ sosomal cysteine proteinases take part in the intracellular degradation of phagocytosed collagen ${ }^{50}$. Cathepsin $\mathrm{B}$, which is the major lysosomal cysteine proteinase, can also activate latent collagenases and may therefore have an additional rolle in $\mathbb{E C M}$ degradation $^{51}$. Although cysteine proteinases are lysosomal in origin, their release from living cells into the extracellular space has been described in a few pathological

Table 1. The four classes of proteinases 


\begin{tabular}{|c|c|c|c|c|}
\hline Proteinases & Location & Members: & Optimum pH & Inhibitors \\
\hline Cysteine & intracellular & Cathepsin $B, L, \mathbb{N}, S$ & $3-6$ & Cystatin, $\alpha_{2} M$ \\
\hline Aspartic & intracellular & Pepsin, renin, cathepsin D & $3-6$ & Pepstatin, $\alpha_{2} M$ \\
\hline Sexine & extracellullar & $\begin{array}{l}\text { Plasmin, uPA, } P A \text {, thrombin, } \\
\text { elastase, cathepsin } G\end{array}$ & 6.9 & $\begin{array}{l}\text { PAIs, aprotining } \\
\alpha_{2} M\end{array}$ \\
\hline Matrix metallo & extracellular & $\begin{array}{l}\text { Collagenases, gelatinases, } \\
\text { stromelysins, metalloelastase, } \\
\text { membrane-type MMPS }\end{array}$ & $6-9$ & IIMPS $_{3} \alpha_{2} M$ \\
\hline
\end{tabular}

$\alpha_{2} \mathrm{M}: \alpha_{3}$-macroglobulin

conditions. For example at sites of inflammation, cathepsins are released from macrophages ${ }^{52}$. It is possible that the acidic environment at sites of inflammation or nectosis favors the activity of cysteine proteinases ${ }^{48}$.

\section{Aspartic proteinases}

Pepsin, renin and cathepsin D are examples of aspartic type proteinases. These proteinases contain two aspartic residues at their active site. The optimum $\mathrm{pH}$ tange for their activity is 3-6. Pepsin is involved in the metabolistm of proteins in the intestine, renin converts angiotensinogen to angiotensin $\mathbb{I}$ and cathepsin $D$ is a glycoprotein found in lysosomes and is involved in the intracellular degradation of certain extracellular proteins ${ }^{53}$.

\subsection{Matrix metalloproteinases (MMPs)}

\subsubsection{The family members}

Matrix metalloproteinases (MMPs) are a family of zinc-containing endoproteinases that share structural domains, but differ in substrate specificity, cellular sources, and inducibility. The list of MMPs has lengthened rapidly in the past several years and by now, at least nineteen mammalian members have been cloned and identified. All MMPs share the following functional features: (1) they degrade ECM components; (2) they are secreted in a latent proform and require activation for proteolytic activity; (3) they contain $\mathrm{Zn}^{2+}$ at their active site; (4) they need calcium for stability; (5) they function at neutral $\mathrm{pH}$; and (6) they ate inhibited by specific tissue inhibitors of metalloproteinases (TIMPs).

Based on their substrate specificity and primary structure, the MMP family can be subdivided into 4 classes (see table 2). The first class, the collogenases includes MMP 1 
Table 2. Substrate specificity of MMPs

\begin{tabular}{lcl}
\hline Enzyme & MMP classification & Substrate \\
\hline $\begin{array}{l}\text { Collagenases } \\
\text { Interstitial collagenase }\end{array}$ & MMP-1 & $\begin{array}{l}\text { collagens I, II, III, VII and X, gelatin, entactin, } \\
\text { aggrecan } \\
\text { collagens I, II and III, aggrecan } \\
\text { Neutrophil collagenase }\end{array}$ \\
$\begin{array}{l}\text { collagen I, II and III, gelatin, fibronectin, } \\
\text { tenascin }\end{array}$ \\
laminin, \\
Collagenase-4
\end{tabular}

\section{Gelatinases}

Gelatinase A

MMP-2

Gelatinase B

MMP-9

gelatin, collagens I, IV, V, VII and X, fibronectin, laminin, aggrecan, tenascine- $C_{y}$ vitronectin gelatin, collagens IV, V and XIV, aggrecan, elastin, entactin, vitronectin

\section{Stromelysins}

Stromelysin 1

MMP-3

Stromelys in 2

MMP-10

Stromelysin 3

MMP-11.

\section{Membrane-type MMPs}

MT1-MMP

MMP-14

MT2-MMP

MMP-15

MT3-MMP

MMP-16

MTAMMP

MMP-17

MT5 MMP

$?$

\section{Others}

Matrilysin

MMP-7

Macrophage elastase

MMP-12

Unnamed $^{3}$

MMP-19

Enamlysin

MMP-20

gelatin, fibronectin, laminin, collagens III IV IV, IX and $\mathrm{X}$, tenascine- $\mathrm{C}$, vitronectin collagen IV, fibronectin, aggrecan fibronectin, gelatin, Laminin, collagen IV and aggrecan

${ }^{1,2}$ and ${ }^{3}$ refer to reference numbers 
(interstitial collagenase), MMP-8 (neutrophil collagenase) and MMP-13 (collagenase-3), which can all cleave fibrillar collagens (type I, II and III collagen). Because they are tightly apposed and highly cross-linked fibrils, type I, II and III collagens are known to be extremely resistant to cleavage by most proteinases. Collagenases cleave fibrillar collagens at unique sites in the triple helix at $3 / 4$ from the $N$-terminal end, generating $3 / 4$ and $1 / 4$ collagen fragments. Due to thermal degradation and loss of stability, these fragments unfold their triple helix and fall apart into fragmented single $\alpha$-chains, the so-called gelatins. In the mouse, MMP-13 appears to be the primary collagenase. Group 2, the gelatinases (MMP-2 and MMP-9) is well-known for its ability to degrade these gelatins. Gelatinases are also capable of degrading type IV collagen in basement membranes. The third group constitutes the strometysins (MMP-3, -10 and -11), so named because they are active against a broad spectrum of ECM components, including proteoglycans, laminin, fibronectin, vitronectin and some types of collagens. Group 4 contains the membrane-yype MMPs (MT-MMPs), which degrade several ECM components and are also able to activate other MMPs.

This substrate based subdivision of MMPs turned out to be useful in the past, however as mote is known about the enzymatic activities and substrates (table 2), its usefulness becomes less clear. The most important reason for this is that the substrate profiles of the enzymes do indeed differ, but this difference is often more gradual than absolute. For example, it was assumed for a long time, that the cleavage of intact fibrillar collagens was limited to the action of collagenases. Recent evidence however, demonstrated that gelatinases, formerly thought of as having substrate specificity for denatured collagens (gelatins) only, are able to cleave interstittal collagens as well ${ }^{5,55}$. It is therefore suggested that, due to their ability to initiate and continue the degradation of filorillar collagens, gelatinases play a more important role in the remodeling of collagenous $E C M$ than has been previously thought $\mathrm{t}^{56}$.

\subsubsection{Protein structure of MMPs}

Each member of the MMP family is the product of a different gene. Analysis of the nucleotide sequences and protein structure of the individual MMPs however, reveals that these enzymes contain four basic, distinctive and well-conserved domains (Figure 1). The functional properties of these domains provide insights into the mode of action of the enzymes. 'The first domain is the 'signal peptide'. This domain targets the enzyme for secretion, but is subsequently removed and therefore not present in the latent enzyme. The 'propeptide domain' determines the latency of the proenzyme and is removed when the enzyme becomes activated. Maintenance of latency of the propeptide is achieved by folding of this propeptide domain such that the highly conserved Cys residue in the propeptide domain blocks the zinc molecule in the active site ${ }^{48,57,58}$. Cleavage of this propeptide induces conformational changes and renders the zinc molecule available for catalytic reactions. The third domain, the 'catalytic domain' contains the zinc binding region (HEXGH) and is responsible for the enzymes proteolytic activity. The precise sequence of the catalytic domain in activated MMPs has been found to be critical for the extent of activity. The fourth domain, the "hemopexin domain' has sequence similarity to hemopexin and vitronectin and is found in all MMPs except matrilysin. In collagenases, 


\section{Protein structure of MMPs}

A

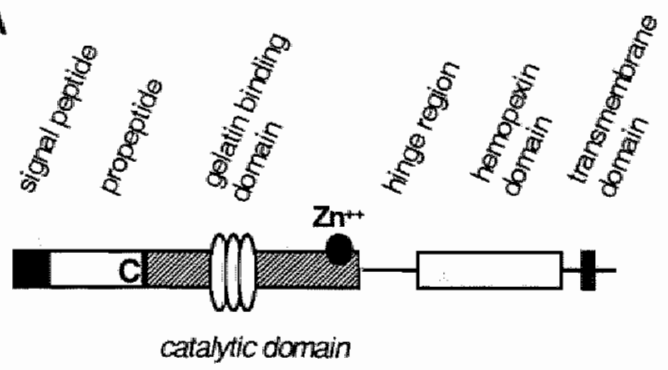

B

Collagenases

Gelatinases

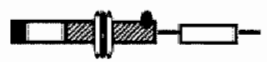

Stromelysins

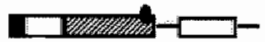

Membrane-type

MMPs

Matrilysin
Figure 1 - Basic domain structure of MMPs

Panel A: MMPs contain at least three homologous protein domains: "the signal peptide", a domain that targets the enzyme for secretion, the "propeptide domain", which is removed when the enzyme becomes activated and the "catalytic domain' which contains the zinc binding region and is responsible for the enzyme"s proteolytic activity. Pond B: Structural differences between the different classes of MMPs. In gelatinases, the catalytic domain contains the "gelatin binding domain", which has homology to the collagen binding domain of fibronectin. The hemopexin" domain has been shown to play a functional role in substrate binding and interactions with TIMPs. Finally, membrane-rype MMPs contain a transmembrane domain in the C-terminal end (Modifed from Matriviand

this domain appears to determine substrate specificity, while in getatinases the hemopexin domain is involved in interactions with specific MMP inhibitors, the tissue inhibitots of metalloproteinases (TIMPs) ${ }^{55}$. The catalytic and hemopexin domains are connected by a flexible linker peptide or "hinge region", which is of variable length. An additional domain has been demonstrated in the gelatinases. Within their catalytic domain, gelatinases contain three fibronectin type II repeats, which are thought to facilitate binding of the gelatinases to their substrate ${ }^{\text {sh }}$. Finally, the MT-MMPs possess a unique transmembrane domain which anchors MT-MMPs to the cell surface ${ }^{61}$.

\subsubsection{Regullation of MMP activity}

Since MMPs, once activated, are collectively capable of degrading the complete ECM, it is important that the activity of these enzymes is kept under tight control. The activity of MMPs is controlled at the following three levels: transcription, activation of the latent proenzymes and inhibition by their endogenous inhibitors, the TIMPS. 
Table 3. Effects of cytokines and growth factors on MMP and TIMP expression

\begin{tabular}{|c|c|c|}
\hline & MMPs & TIMPs \\
\hline$\overline{T N E}+d^{6}$ & + & $+/-*$ \\
\hline EGE & + & + \\
\hline $\mathrm{PDGF}$ & + & + \\
\hline $\mathrm{BFGF}$ & 4 & $\mathrm{ND}$ \\
\hline LL-1 & + & + \\
\hline $1 L-6$ & + & + \\
\hline VEGF & + & ND \\
\hline $\mathrm{CD} 40^{10}$ & + & ND \\
\hline phorbol esters & $H$ & + \\
\hline conticosterroids & - & ND \\
\hline rétinoic acid & - & + \\
\hline heparim & - & ND \\
\hline $1 L-4^{n}$ & - & - \\
\hline $\operatorname{TGF}_{-\beta} \beta^{3, \mathrm{~B}}$ & MMP-2,-9: +, MMPP-1,-3:- & - \\
\hline$\llbracket F N \sim Y^{12,13}$ & $+1-{ }^{n}$ & ND \\
\hline
\end{tabular}

The given effects of cytokines on MMP expression compromise most members of the MMP family and exceptions for certain members of the MMP family are not given. Adapted from Mauviel et al. ${ }^{14}$ and Gomez et $\mathrm{al}^{15}$, unless stated otherwise. + , upregulated; -, downregulated; $\mathrm{ND}$, not determined; *, dose dependent; ${ }^{\prime \prime}$, cell type specific.

\section{Regulation of MMP expression}

The expression of most MMPS is generally found at low levels in normal adult tissue but is upregulated during certain physiological and pathological remodeling processes. Induction or stimulation at the transcriptional level is mediated by a vatiety of inflammatory cytokines, hormones and growth factors (see table 3), such as interleukin-1 (1L-1), IL-6, tumor necrosis factor- $\alpha$ (TNF- $\alpha$ ), epidermal growth factor (EGF), platelet derived growth factor (PDGF), basic fibroblast growth factor (bFGF) and CD40 ${ }^{10,62}$. Other factors, like corticosteroids, retinoic acid, heparin and IL-4 have been demonstrated to inhibit MMP gene expression ${ }^{63}$. Not all MMPs react similarly to the same stimuli. For example TGF- $\beta$ stimulates MMP-2 and MMP-9 but inhibits MMP-1 and MMP-3 synthesis ${ }^{14}$. In the case of interferon-gamma (IFN- $\gamma$ ), the impact on MMP expression is cell-type specific. Whereas IFN- $\gamma$ increases MMP-1 expression in keratinocytes, it decreases MMP-1 expression in macrophages and fibroblasts ${ }^{13}$

It has turned out that the promoter region of most MMP genes contain the following common sites important for transcriptional regulation: a TATA box, one or more copies of the tumor promoter-responsive element (TRE) and the polyoma virus enhancer Abinding protein-3 (PEA3) site ${ }^{14,60,64,65}$. The position of these elements relative to the transcription start site differs between the different MMPs, which may partly account for their heterogeneous expression pattern $s^{66}$. The TRE element in the promoter binds to the transcription factor AP-1, a dimer of oncogene proteins, while the PEA-3 binding site interacts with members of the ETS-family of transcription factors. It has been 
demonstrated that extracellular stimuli such as IL-1, IL-6, bFGF and TNF a induce transcription of MMPs, via activation of the AP-1 transcription factor complex ${ }^{\text {is } 56}$. Ghucocorticoids and retinoic acid have been shown to block binding of AP-1 to TRE; which explains the inhibition of these factors of MMP expression ${ }^{14,67}$ (Table 3). Transcriptional induction of MMPs is enhanced by AP-1, but it does entirely depend on it ${ }^{66}$. Analysis of the MMP-9 promoter has identified another transcription factor binding site: the nuclear factor kappa-B (NF-xB) site. Bond et. al demonstrated an absolute requirement of $\mathrm{NF}-\varkappa \mathrm{B}$ in the upregulation of MMP-9 by inflammatory cytokines in both rabbit and human dermal fibroblast ${ }^{68}$. The promoter of the MMP-2 gene lacks the PEA3 site, but contains two copies of a GC box for binding of transcription factor SP1. This unique promoter profile of MMP-2 might explain the fact that this MMP is constitutively expressed, whereas other MMPs are mainly inducible ${ }^{69}$.

\section{Activation mechanisms of latent $M M P_{5}$}

Although transcriptional regulation is essential for MMP production, matrix degradation requires the latent enzymes to be activated by proteolytic cleavage. Thee different activation mechanisms have been described: (1) stepwise activation, (2) activation at the cell surface by MT-MMPs and (3) intracellular activation ${ }^{5}$.

The first step during stewsise actwation of MMPs often involves proteinases such as plasmin, trypsin, chymase, elastase or kallikrein. Of these proteinases, plasmin is thought to be the most potent physiological activator in two ${ }^{70}$. Plasmin attacks the proteinase susceptible-region in the 'propeptide domain' of the MMP, which induces conformational changes in the propeptide and renders the activation site to be readily cleaved by a second proteinase, usually a $\mathrm{MMP}^{5}$. The generation of plasmin from plasminogen by the action of plasminogen activators (PA) occurs largely at the cell surface, where both plasminogen and urokinase PA are bound to plasminogen binding sites and urokinase PA receptors ( $\mathrm{UPAR}$ ), respectively (see also figure $3 \mathrm{c}$ ).

Cell sarface activation of MMPs is considered to be important for pericellular degradation of the ECM during cell migration (see figure 2). Besides the plasminogen system, also other enzymes are capable of activating MMPs at the plasma membrane. In 1994, Sato et al cloned a membranc-type MMP (MT1-MMP) and identified it as an activator of proMMP-2 on the plasma membrane ${ }^{61,71}$. Currently five MT-MMPs have been cloned and it has been demonstrated that MT-MMPs also actrvate other MMPs ${ }^{5,72}$. The first evidence that members of the MMP family are ativated intracelutarly came from Pei and Weiss in $1995^{73}$. They demonstrated that stromelysin 3 (MMP-11) could be activated by the Golgiassociated subtilisin-like proteinase, furin, and could be secreted as an active enzyme. Subsequently, Sato et al. reported that MT1-MMP, expressed in $\mathbb{E}$. coli was also activated by furin, indicating that MT-MMPs are also likely to be activated intracellularly ${ }^{74}$. The precise mechanism of intracelluat activation and the contribution to extracellular MMP activity has not been cllarified yet.

\section{Endogenous MMP inbibitors}

Fully activated MMPs can be inhibited by interaction with naturally occurring, specific inhibitors, the TIMPs. TIMPs are expressed by a variety of cell types and are present in most tissues and body fluids. At present, the TIMP gene family consists of four 


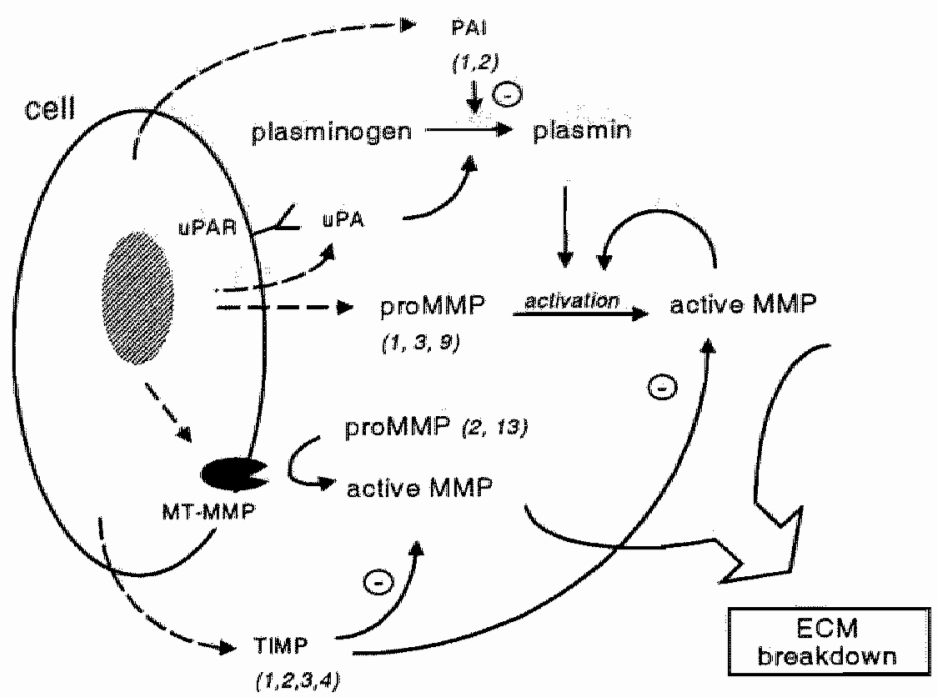

\section{Figure 2 - Activation pathways of proMMPs}

MMPs are secreted in latent form by numerous cell types. These latent MMPs can be activated by plasmin, which is the active component of the plasminogen system and by active MMPs (including membrane type-MMPs, MT-MMPs). Cell surface activation of latent MMPs by the plasminogen system and by MT-MMPs is considered to be important for pericellular degradation of the ECM during cell migxation. Activated MMPs can be inhibited by interaction with naturally occuring, specific inhibitors, the TIMPs. Components of the plasminogen system are explained in more detail in figure 3. Numbers between brackets represent the MMP numbers involved. (Adapred from Nagases)

structurally related members, TIMP $-1,-2,-3$ and -4 . TIMPS bind non-covalently to active MMPs in a 1:1 molar ratio. Inhibiton is accomplished by their ability to interact with the zinc-binding site within the catalytic domain of active MMPs. There is a certain degree of specificity in the activity of different TIMPs towards distinct members of the MMP family. Whereas TIMP-1 potently inhibits the activity of most MMPs, with the exception of MMP-2 and MT1-MMP, TIMP-2 is a potent inhibitor of most MMPs, except MMP-9. In addition, TIMP-2 can form a complex with MT1-MMP at the cell mernbrane, which possibly plays a regulatory role in the proteolytic activation of MMP-2. TIMP-3, insoluble and bound to the ECM, has been shown to bind MMP-1, $-2,-3,-9$ and -13 . TIMP-4 inhibits MMP-1, $-3,-7$ and -9 and shows a high level of expression in adult human cardiac tissue ${ }^{75,76}$. Transcriptional regulation of TIMPs is mediated by factors such as phorbol esters, IL-1 and IL-6 $6^{14}$ (see table 3). Since these factors stimulate both TIMP and MMP expression, they might have a minor effect on the total proteolytic activity. TGF- $\beta$ on the other hand has a more complex impact on the regulation of proteolytic activity. In this regard, TGF- $\beta$ upregulates the expression of MMP-2, MMP-9 and TIMPs, while it decreases the expression of MMP-1 and $-3^{14}$. 
Although the role of TIMPs is clearly important in the prevention of matrix degradation by MMP's, recent developments in TIMP research suggest that TIMP-1 and 2 are multifunctional proteins with more diverse biological actions. It was reported that TIMP-1 and TIMP-2 exhibit growth factor-like activity and can inhibit angiogenesis ${ }^{77}$, whereas TIMP-3 has been implicated in apoptosis ${ }^{80}$

In additon to the TIMPs family, there are also several other naturally occurring inhibitors of MMPs, of which $\alpha$-macroglobulin is the most prominent. This macroglobulin is a large $(750 \mathrm{kDa}$ ) protein produced by the liver. It can inluibit all 4 classes of proteinases, not just MMPs. However, the latge size of $\alpha$-macroglobulin may exclude it from many sites of connective tissue turnover. This may limit its effectiveness as an inhibitor.

\subsubsection{MMPs in disease}

Proteolytic degradation of ECM is an essential feature of repair and remodeling during wound healing in various tissues (e.g. skin, vessel, heart). MMPs may be involved in various tasks during wound healing: 1) degradation of ECM components; 2) promotion of cell migration, by helping to clear a path through the ECM; 3) initiation and promotion of angiogenesis; 4) remodeling of newly synthesized connective tissue; and 5) regulation of activities of certain growth factors, like TNF $\alpha$, TGF $\beta$ and IL $-1 \beta^{81,82}$.

Studies using synthetic MMP inhibitors have providled more insights into the role of MMPs in the pathogenesis of several diseases. Most MMP inhibitors used these days are representatives of a chemical class, the hydroxamates ${ }^{83}$. Inhibition is accomplished by binding of the hydroxamic group to the zinc atom present in MMPs. MMP inhibitors have been succesfully applied in the following animal models of inflammation and cellular invasion: 1) in cancer, administration of the broad spectrum MMP inhibitor Batimastat $(\mathrm{BB}-94)$ prevented tumor cell invasion and metastasis in mice $\left.{ }^{84}, 2\right)$ in arthritis, it was recently shown that the MMP inhibitor Ro 32-3555 prevented cartilage breakdown in both theumatoid arthritis and osteoarthritis in rats ${ }^{85}, 3$ ) during dermal wound healing in rats, broad range inhibition of MMP activity by Ilomastat (GM6001) resulted in an enllanced wound strength due to a decreased inflammatory response ${ }^{8.6}$, 4) in thioglycollate-induced peritonitis in the mouse, Ilomastat reduced the cellular infiltrate into the peritoneum ${ }^{87}$. Due to the positive outcome of the first clinical trials using synthetic MMP inhibitors in the treatment of comeal ulcers and lung cancet ${ }^{13}$, it is feasible that MMP inhibitors will be used in the future for other clinical indications. So far, however, disadvantages of these potent broad range MMP inhibitors include poor bioavailability and carcinogenic properties of degradation products of the hydroxamate compounds $s^{83}$.

\section{MMPs in vascular diseases}

Also in vascular diseases MMP inhibitors have been suggested for therapy. In this regard the btoad range MMP inhibitor Batimastat limited the expansion of experimental abdominal aortic aneurysms in rats and interfered with the inflammatory response seen in these ancurysms. Attenuation of the inflammatory response correlated with areas of elastin preservation ${ }^{88}$. Other investigators have focussed on the role of MMPs and the effect of MMP inhibition during neointima formation, which is regarded as a wound 
healing response of the vessel wall in response to injury. In balloon catheter-injured tat arteries, administration of the brond range MMP inhibitor llomastat (GM6001), resulted in a $97 \%$ dectease in the number of smooth muscle cells that migrated into the neointima, which retarded intima formation ${ }^{8 \%}$. Strauss ef al. found that broad range MMP inhibition by Ilomastat inhibited both collagen degradation and synthesis in balloon catheter-injured tabbit arteriest. This led to attenuated neointima formation and the authors concluded that MMPs have an integral role in collagen tumover during the healing response of the vessel wall ${ }^{\text {po }}$. Local overexptession of TIMPs by adenoviral constructs, another approach to inhibit MMP activity, has also succesfully been applied to inhibit smooth muscle cell migration in balloon injured rar arteries". "IMP-1 overexpression reduced smooth muscle cell function and increased elastin accumulation in the carotid intima ${ }^{91,22}$, while in another study it prevented aortic aneurysm degeneration and rupture in a rat model ${ }^{93}$. TIMP-2 overexpression led to a significant reduction in neointima formation in a human saphenous veins organ culture model $\|^{34}$. In conclusion, these studies indicate that MMPS play an important rolle in the pathogenesis of several vascular diseases. Increased proteolytic activiry by MMPs can weaken the vessel wall, which might result in aneurysm formation, while at the same time, increased proteolytic activity facilitates migration of inflammatory cells and smooth muscle cells into the injured area, which can result in neointima formation or plaque formation/rupture during atherosclerosis.

\section{MMPs in cardiac diseases}

In 1975, Montfort and Perez-Tamayo demonstrated that collagenase was present in notrnal myocardium. Collagenase was located in the interstitium, in the neighbourhood of its substrate, fibrillar collagen ${ }^{95}$. It is now known that myocardial MMPs are produced by fibroblasts-like cells, inflammatory cells and probably also cardiomyocytes ${ }^{36,97}$, that they are predominantly present in their latent form ${ }^{98}$ and that they are increasingly expressed and activated during several pathological states of the heart. For example, in patients with dilated cardiomyopathy, elevated MMP-1, and -2 activity was associated with fibrillar collagen degradation". The consequences of increased MMP activity on cardiac performance have been studied in transgenic mice overexpressing myocardial collagenase. At an age of six months, these mice exhibited left ventricular hypertrophy and hypercontractillity

Several studies have demonstrated increased activity of MMP-1, $-2,-3$ and -9 in humans, at and porcine hearts after myocardial infarction ${ }^{96,101-105}$. Although the data on the exact time course of post infarction myocardial MMP activity is diverse, it becomes. more and more cleat that MMP activation starts early (<1day post MD) ${ }^{102}$. Upregulation of MMP activity after infarction strongly suggests an involvement of MMPs in the wound healing response of the heart. In this regard, MMPs might be involved in the following processes during infarct healing: 1) early ECM degradation; 2) cell migration (inflammatory cells, fibroblasts); 3) angiogenesis; 4) remodiling of mewly synthesized connective tissue and 5) the regulation of growth factor activities. Just recently, Rohde et al have demonstrated that in vivo MMP inhibition attenuates early left ventricular dilatation after experimental myocardial infarction in mice ${ }^{106}$.

TIMP expression in the infarcted heart has also been studied. One study in rats revealed increased "TIMP -1 expression as early as 6 hours after infarction, reaching a peak at day $2^{\%}$. Another study, using cardiac tissue of patients with ischemic cardiomyopathy 
(ICM), demonstrated a decrease in TIMP-1, -3 and -4 expression, while TTMIP-2 expression was unchanged ${ }^{107}$. Taken together, these two studies suggest that TMPs are upregulated during the acute inflammatory phase of infarct healing and downregulated during later stages. The underlying mechanism remains unexplored.

\subsection{The plasminogen system}

The serine proteases include plasminogen (Plg), plasminogen activators (PA), leukocyte elastase and cathepsin $G$ (Table 1). Of these, the plasminogen system is the best characterized. Plasmin, the active component of the plasminogen system, was originally known as fibrinolysin because of its ability to dissolve blood clots, which is a major physiological function of the plasminogen system in the circulation ${ }^{48}$. Since plasmin has a broad trypsin-like substrate specificity it can also degradle several ECM components, including fibronectins, laminins and the protein core of proteoglycans. It does not degrade native collagens and elastin, but can degrade gelatins. A relevant feature of plasmin is the proteolytic amplification that it can achieve by activating several matrix metalloproteinases ${ }^{48}$. The activity of the plasminogen system is regulated by Plg activators (PA) and an assortment of Plg and PA cell surface receptors and inhibitors (see figure 3C). Due to its direct and indirect proteolytic activity, the plasminogen system participates in a variety of (patho)biological processes such as embryonic development, reproduction, wound healing and cancer. In cardiovascular disorders, the plasminogen system contributes to the pathogenesis of thrombosis, atherosclerosis and restenosis ${ }^{108}$. The ability of plasmin to dissolve blood clots is also the basis for its clinical application. After myocardial infarction, for example, recanalization of the occluded blood wessel is often achieved by early administration of plasminogen activators.

\subsubsection{Components of the plasminogen system}

\section{Plasminogen}

Plasminogen is the proenzyme form of the serine protease plasmin. It is produced in the liver and in the seminiferous tubules of the testis, and present at high concentrations in the circulation $(\sim 2 \mu \mathrm{M})$. In humans $\sim 40 \%$ of the Plg is extravascularly located ${ }^{\circ}$. Although high-affinity plasma membrane binding sites (receptors) for Plg have not yet been characterized, low-affinity binding sites appeat to be present in the ECM and on the cell surface $^{48}$. Plg is a $90 \mathrm{kDa}$, single chain glycoprotein contaning a C-terminal protease domain, five homologous triple loop disulfide-linked structures, known as kringle domains, a signal peptide and a preactivation peptide (figure $3 \mathrm{~B}$ ). The kringle domains are involved in the binding of Plg to fibrin, $\alpha_{2}$-antiplasmin, thrombospondin, annexin II and $\alpha$-elonase ${ }^{10,111}$, the signal peptide targets Plg fot secretion and is not ptesent in circulating $\mathrm{Plg}$, and the pre-activation domain is important in regulating the conformation and activation properties of the native enzyme ${ }^{111,112}$. Proteolytic digestion of plasmin, 


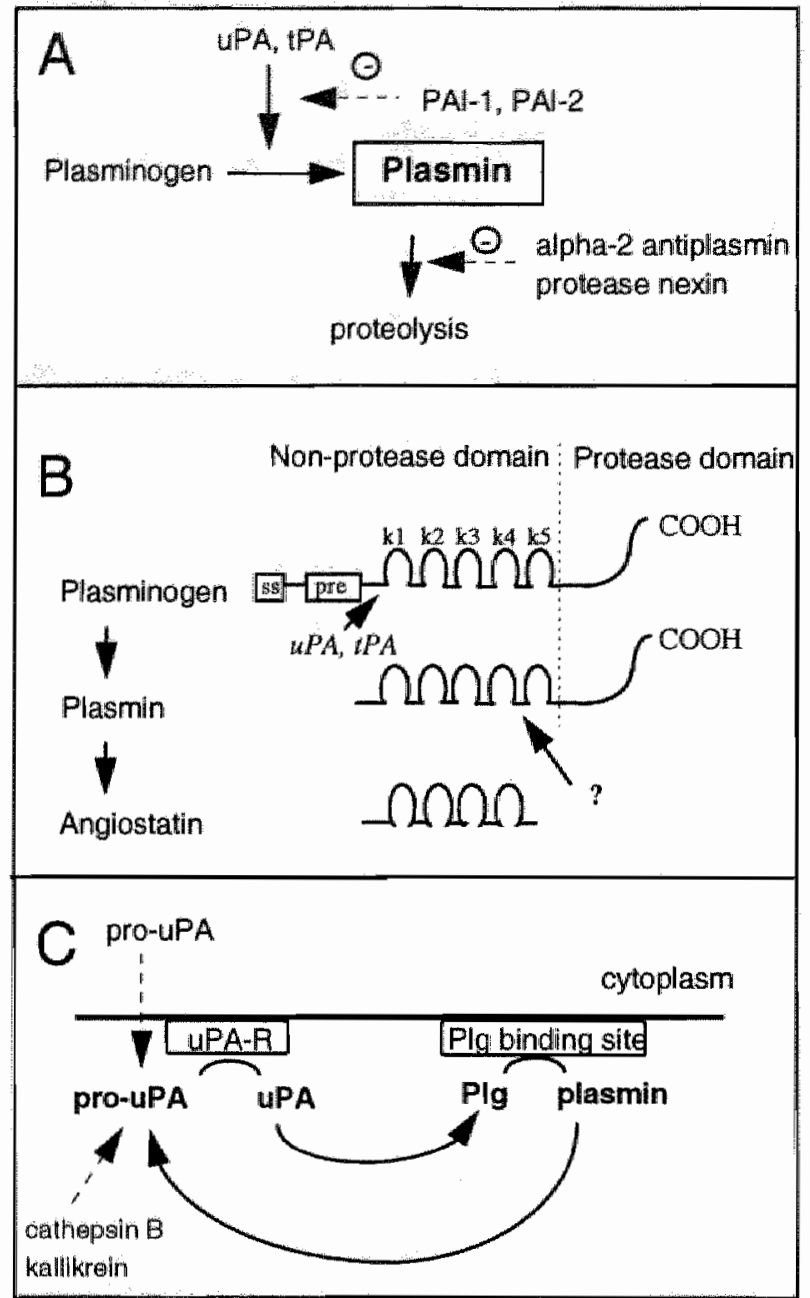

Figure 3 - Components of the plasminogen system

A) Activators and inllibitors of the plasminogen system. B) Schematic structures of plasminogen (Plg) and its cleavage products. The nonprotease region of $\mathrm{Plg}$ contains a signal sequence (SS), absent in circulating $\mathrm{Plg}$, a preactivation peptide (pre), cleaved off by uPA or $\mathrm{PAA}$ to form proteolytic active plasmin, and 5 triple-disulfide bridged kringle structures, involved in anchoring $\mathrm{Plg}$ to fibrin and other proteins. Digestion of plasmin, between kringle 4 and 5 results in the formation of angiostatin, a potent natural inhibitor of angiogenesis. Enzymes responsible for the in vivo production of angiostatin are currently unknown. C) Positive feedback mechanism of pro-uPA and $\mathrm{Plg}$ activation on the cell surface. Since Plg is present at high concentrations, pro-uPA synthesis and secretion is the rate limiting step in the formation of plasmin.

between kringles 4 and 5 results in the formation of angiostatin, a circulating potent natural inhibitor of angiogenesis ${ }^{113,14}$ (figure $3 \mathrm{~B}$ ).

\section{Plaswinogen activators $(P A s)$}

The term plasminogen activator (PA) is restricted to two enzymes, the urokinase type and tissue-type $P A$ (uPA and $t P A$ ), which are serine proteases that convert Plg to plasmin. Because of the high concentrations of plasminogen in virtually all tissues, the production of small amounts of $\mathrm{PA}$ can result in high local concentrations of plasmin and other proteinases ${ }^{115} . \mathrm{P}^{\mathrm{A}} \mathrm{A}$ and $\mathrm{UPA}$ are the products of distinct genes and are secreted by a broad range of cell types ${ }^{16,48}$.

uPA was first found in urine at relatively high concentrations $(200-300 \mathrm{ng} / \mathrm{ml})$ and was 
later identified in human plasma at a level of about $2-5 \mathrm{ng} / \mathrm{m}^{116}$. After secretion, $u P A$ can bind to the UPA receptor in its inactive, pro-uPA form. The bound zymogen is then activated by proteolytic cleavage (figure 3C). Interaction of uPA with its receptor has at least two important consequences: 1) concentration of enzyme activity on the cell surface and 2) acceleration (16 fold) of plasminggen activation ${ }^{16,48}$. Conversion of pro-uPA to active $\mathrm{uPA}$ is achieved by trace amounts of plasmin, thereby generating a positive feedback mechanism of pro-uPA and Plg activation (figure $3 \mathrm{C}$ ). In addition, it was demonstrated that cathepsin B, kallikrein and Factor XIIa can activate pro-uPA ${ }^{16}$. However, the presence of relatively high concentrations of Plg in all tissues implicates plasmin as the most important activator of pro-uPA ${ }^{48}$. Interestingly, Plg and $\mathrm{uPA}$ are often colocalized, either on the cell surface and/or in the ECM, which has underlined the importance of $\mathrm{uPA}$ in cell migration and recruitment through ECM proteolysis.

$\mathrm{tPA}$, a $70 \mathrm{kDa}$ glycoprotein, is primarily involved in fibrinolysis and thrombolysis via its specific affinity for fibrin ${ }^{117}$. $\mathrm{tPA}$ is synthesized as a single chain molecule and its catalytic activity increases as a result of plasmin-mediated cleavage to a two chain molecule. Several cellular binding sites for $\mathrm{tPA}$ have been described. Some of these are clearly involved in the clearance (in particular by the liver) of the enzyme, wheteas others localize $t P A$ to the plasma membrane ${ }^{16}$. In this regard, annexin II has been identified as a tPA receptor on human endothelial cells which localizes plasmin generation on the vessel wall ${ }^{15,118,119}$. Besides binding to fibrin and annexin II, tPA also binds heparin, fibronectin, laminin, $\alpha$-enolase and denatured protein $\mathrm{s}^{115,120}$. The precise function of these latter binding sites is currently unknown.

\section{Plasminagen actitiator inbibitors (PAIs)}

The enzymes of the PA/plasmin system are tightly controlled by special serine protease inhibitors (serpins): the plasminogen activator inhibitors PAI-1 and PAI-2. PAI-1 is the major serpin in plasma and the most efficient inhibitor of both uPA and tPA. It is secreted as an active inhibitor by a broad range of cell types, but is rapidly converted to an inactive latent form. PAI-1 in plasma is predominantly bound to an abundant plasma protein, vitronectin, which stabilizes PAI in its active form. Vitronectin is also present in the ECM of many tissues and it may serve to localize PAJ-1 function to specific sites ${ }^{13}$. PAI-2 is a relatively stable molecule and found predominantly in monocytes and macrophages, in the placenta, and in the plasma of pregnant women ${ }^{12 t}$. It is an efficient inhibitor of $\mathrm{UPA}$, but only a poor inhibitor of tPA. PAI-2 exists both as a secreted and an intracellular protein. The function of intracellular PAI-2 is unknown, although it has been proposed to play a role in regulating apoptosis ${ }^{122,123}$. In addition, two other, less specific, serpins have been identified: protease-nexin I and $\alpha_{2}$-antiplasmin. Whereas protease-nexin $I$ inhibits uPA, plasmin and thrombin, $\alpha_{2}$-antiplasmin is a plasmin inhibitor in plasmá.

\section{The $u P A$ receptor (uPAR)}

The receptor for uPA belongs to the family of glycosylphosphatidylinositol (GPD) glycolipids, which are known for their ability to anchor a variety of proteins to the external surface of cells ${ }^{124}$. Cell types expressing uPA receptors (uPAR) include monocytes/macrophages, polymorphonuclear granulocytes (PMNs), fibroblasts, endothelial cells and keratinocytes ${ }^{16}$. Receptor-bound $\mathrm{uPA}$ remains active at the cell 
quiescent cell adhesion cell detachment

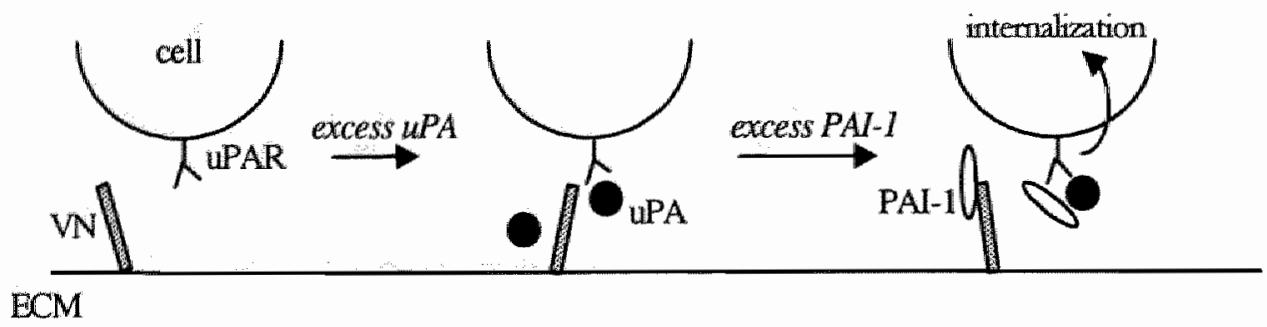

Figure 4 - Model for the regulation of UPAR dependent cell adhesion and release by PAI-1 and uPA (Adapted from Deng et.af)

surface with a half-llife of about 6 hours. However, once uPA/uPAR is complexed with one of its inhibitors, the complexes ate rapidly internalized and degtaded ${ }^{125}$. Since UPAR does not have a transmembrane domain and is therefore not directly coupled to an intracellular adaptor, the major function of uPAR was generally assumed to be focussing proteolytic activity to the cell surface. In addition, recent studies have demonstrated that $\mathrm{PPA}$ and $\mathrm{PPAR}$ have other activities, independent of the function of UPA as a proteinase. For example, uPAR may regulate cellular adhesion and migtation by associating with the extracellular domains of integrins and by binding directly to vitronectin, an abundant ECM glycoprotein ${ }^{126,127}$ (figure 4).

lnterestugly, binding of uP. to the receptor has recently been shown to mediate signal transduction to the cestinterior, including proten tyrosine phosphorylation, diacylglycerol formation and the activation of a serine whase ${ }^{128}$. A soluble form of uPAR (suPAR) exists in plasma, yet ots orgin is unknown. $s u P A R$ by itself is thought to directly mediate intracelluhat signaling by intencting with target proteins in the plasma membrane ${ }^{129}$. Together the above emphasizes the role of uPAR in proteolysis, cell migration, cell adhesion, chemonxis and mitogenesis.

\section{Angiostatin}

Angiostatin was identified as a $38 \mathrm{kDa}$ internal fragment of Plg that encompasses the first four kringles of the molecule ${ }^{13}$ (figure $3 \mathrm{~B}$ ). It is one of the most potent naturally occurring inhibitors of angiogenesis ${ }^{114}$. Although the enzymatic mechanism by which angiostatin is generated in wiwo is unknown, recent studies have demonstrated that the cleavage of plasmin to yield angiostatin in vitro can be catalyzed by MMP-3, $-7,-9,-12$, uPA, plasmin and plasmin reductase ${ }^{114,40-13}$. The mechanism by which the antiangiogenic effects of angiostatin are mediated is probably threefold: 1) the potential loss of plasmin activity that results from plasmin conversion to angiostatin may contribute to reduced 
proteolytic activity and therefore reduced cell migtation ${ }^{134}, 2$ ) angiostatin may induce a direct arrest in mitosis ${ }^{135}$ and 3) angiostatin might increase the lievel of apoptosis ${ }^{136}$. The latter two effects might be mediated by a recently discovered angiostatin receptor: $\alpha / \beta$. ATP synthase ${ }^{137}$. Together, these data indicate that the Plg system can act both as a positive and a negative regulator of angiogenesis, respectively through its proteolytic degradation of the ECM surrounding endothelial cells and through the formation of angiostatin $^{138}$. The generation of an endogenous angiogenesis inhibitor from a large precursor protein is a recurrent theme in the inhibition of angiogenesis. One theory about the physiological function of this dual effect of the Plg system is the following: when angiogenesis is initiated, proteolytic degradation of the ECM is a prerequisite for endothelial cell migration and proliferation. Once new blood vessels have been formed, they may require angiogenic inhibitors to control the overgrowth of blood vessels ${ }^{139}$.

\subsubsection{Regulators of the plasminogen system}

As described in the above paragraphs, plasmin activity is stringently regulated by $P A s$, PAIs and specific receptors on the cell surface. These regulators are by themselves subject to regulation at the level of gene expression and, in case of the UPA and IPA, also by activation. The homones, cytokines and (growth) factors listed in table 4 regulate plasminogen activation by modulating the level of synthesis. During inflammation and wound healing, various cytokines are synthesized and secreted by invading inflammatory cells. These cytokines are thought to be involved in the regulation of the activity of the plasminogen system under these circumstances. Indeed, IFN- $\gamma$ has been demonstrated to be a positive regulator for the induction of $\mathrm{uPA}$ and its receptor ${ }^{22}$, while interleukin-10, a known anti-inflammatory cytokine, induced a decrease in uPA expression in monocytes ${ }^{37}$. Corticosteroids are also negative regulators of the plasminogen system in many cell types: they decrease $\mathrm{UPA}$ transcription and $\mathrm{UPA}$ receptor expression, while at the same time they often increase the expression of the PAI-1 gene ${ }^{16}$. Modifications in the organization of the cytoskeleton has also been found a trigger for uPA expression in vitro ${ }^{140}$. This suggests that during differentiation and/or migration of cells, changes in cell shape are direct regulators of proteolytic activity. Substantial evidence comes from cancer research, where transformed cells in general have less organized cytoskeletal structures and at the same time produce higher amounts of $\mathrm{UPA}^{140}$. The complexity of the transcriptional regulation of the plasminogen system is further illustrated by the effects of TGF- $\beta$ and bFGF on endothelial cells. Both factors enhance PAT-1 and UPA mRNA and

protein synthesis, however in the case of $\mathrm{TGF}-\beta$ the overall balance is shifted towards antiproteolysis, while in tesponse to bFGF the net effect is enhanced proteolysis ${ }^{16}$.

A growing body of evidence indlicates that the renin-angiotensin system interacts with the plasminogen system ${ }^{35,141}$. Clinical trails have indicated that the use of angiotensin converting enzyme (ACE) inhibitors among patients with myocardial infarction reduces the rate of coronaty thrombosis and consequently the incidence of recurrent myocardial infarction ${ }^{142}$. Moreover, the DD polymorphism of the human ACE gene is associated with enhanced levels of PAI-1. The underlying mechanism for these observations is the stimulation of PAl-1 expression by angiotensin $I^{143}$. Besides the fact that $A C E$ inhibitor 
Table 4. Transcriptional regulation of components of the plasminogen system

\begin{tabular}{|c|c|c|c|c|}
\hline Regulators & UPA & $\mathbf{P A}$ & PAl-1 & UPAR \\
\hline \multicolumn{5}{|l|}{ Postive regulators } \\
\hline DFGF & + & + & + & + \\
\hline TNF $=\alpha^{19-21}$ & + & + & + & + \\
\hline $\mathbb{L}-1 \mathrm{z}$ & + & + & + & + \\
\hline IFN-Y & + & $=$ & $-1=$ & + \\
\hline NEOF & + & + & + & + \\
\hline thrombin ${ }^{17}$ & + & + & + & + \\
\hline $\mathrm{PMA}^{28,20}$ & + & + & + & + \\
\hline bradykinin $^{30}$ & & & & + \\
\hline prostaglandin $\mathrm{E}$ & 4 & & & \\
\hline Granulocyte-CSF & & & + & \\
\hline \multicolumn{5}{|l|}{ Negative regulators } \\
\hline corticosteroids $^{16,33}$ & - & $=$ & + & - \\
\hline TGF $-\beta^{116,19,94}$ & $+1-$ & $=$ & + & + \\
\hline angiotensin $\|^{35}$ & & & + & \\
\hline IL $-10^{97}$ & $\infty$ & & & \\
\hline hypoxia ${ }^{38,39}$ & - & - & + & + \\
\hline
\end{tabular}

+, stimulates expression; - , inhibits expression; $=$, no effect. If two effects are given for one component of the Plg system, these effects are cell-type specific.

treatment reduces the formation of PAI-1, the positive influence of ACE inhibitors on fibrinolysis might be exacerbated by preventing the degradation of bradykinin, which is a stimulator for $\mathrm{PA}_{\mathrm{A}}$ production ${ }^{30}$.

\subsubsection{Functions of the plasminogen system}

The plasminogen system has been claimed to play a role in a variety of biological phenomena, including blood clot dissolution, reproduction, embryogenesis, cell invasion and angiogenesis. In addition, the plasminogen system might participate in pathologies such as thrombosis, restenosis, atherosclerosis, neoplasia, metastasis, wound healing and inflammatory disorders ${ }^{177}$. The way in which components of the plasminogen system mediate these processes is generally based on the proteolytic activity of plasmin. Plasmin can degrade fibrin and several ECM components, activate or liberate growth factors from the ECM and activate other matrix-degrading proteinases (such as MMPs) ${ }^{15,144}$. Several studies have linked the plasminogen system to the regulation of cell migration. Cell migration was associated with increased expression of uPA, Plg, UPAR and PAI-1, with uPA and UPAR usually being localized at the leading edge of the migrating cells $\mathrm{s}^{145,146}$. In addition, cell migration was reported to be inhibited by antibodies against UPA and enhanced by plasminogen activation ${ }^{146}$. 


\section{Regulation of cell migration}

Nearly all motile cells in vivo require a surface of ECM proteins in order to move Cell migration proceeds through extension of the leading cytoplasmic edge, a process which involves adhesion, mediated by integrios and their ECM ligands. This adhesion of a cell to the ECM is thought to provide guidance and traction for pulling the cell body forward. In order for cells to migtate, adhesion must be reversible to allow detachment (figure 4). It is, for example, known that integrins that form very tight contacts with the ECM can even limit cell migtation. Detachment of cells from focal adhesive sites is thought to occur by several mechanisms, including cell-surface proteolysis, alterations in integrin conformation, and shedding of attachment sites ${ }^{147}$.

In particular, the matrix protein vitronectin has been shown to induce cells to adhere and migrate faster than they do on many other matrix proteins. The integrins $\alpha_{\mathrm{v}} \beta_{3}$ and $\alpha_{w} \beta_{5 y}$ collectively called the vitronectin receptors, are expressed by highly motile cells such as metastatic tumor cells and cells involved in wound healing. These integrins are generally not expressed by normal cells in vivo; however, in response to injury they are rapidly upregulated ${ }^{148}$. Considerable evidence indicates a direct link between the plasminogen system and virronectin during cell migration. In addition to binding $u P A$, UPAR functions as an adhesion receptor for vitronectin (figure 4). It was demonstrated that UPAR collocalizes with integrins at the leading edge of migrating cells and that $\mathrm{UPAR}$ can form complexes with other integrins to provide an indirect connection between uPAR and the cytoskeleton ${ }^{127,145}$. Furthermore, the fact that vitronectin can be degraded by plasmin, emphasizes the link between the plasminogen system, integrins and vitronectin during cell migration. Taken together, the above observations indicate that the plasminogen system may provide both cell-surface-associated protease activity and may be involved in cell adhesion.

It is proposed that PAI-1 plays a central regulatory role in cell migration. Evidence was provided that the balance between cell adhesion and cell detachment is governed by PAI$1^{40}$. By blocking the generation of plasmin activity on the cell surface, PAI-1 prevents detachment of cells from their surrounding ECM, thereby inhibiting cell migtation. This effect of PAI-1 was actually seen in a model of vascular wound healing in PAI-1 deficient mice. In those mice, increased cell migration accelerated neointima formation ${ }^{149}$. In contrast to this role of PAI-1, several in vitro studies have provided evidence that PAI-1, independent of its action as a protease inhibitor, prevents cell adhesion ${ }^{40,146,150}$. The proposed underlying mechanism is based on observations which show that PAI 1 binds to both uPAR and vitronectin ${ }^{151}$. Binding of PAI-1 to vitronectin stabilizes this serpin in its active conformation and prevents binding of $\mathrm{UPAR}$ expressing cells to vitronectin (Gigure 4). Indeed, PAI-1 effectively competes with uPAR for vitronectin binding, thereby preventing the adhesion of cells to vitronectin. In vitro, low concentrations of PAI-1 can ewen release $U 937$ cells from their attachment to vitronectin and promote celliular motility $^{153}$. By binding to vitronectin, PAI-1 also inhibits vitronectin-integrin binding, an effect which is reversible by $\mathrm{UPA}^{146}$. Another mechanism that PAI-1 uses to promote detachment of cells is binding to UPA/uPAR complexes, which leads to internalization and subsequent degradation of the receptor complex ${ }^{152}$. Taken together, in specific situations binding of PAI-1 to vitronectin and/or the UPA/uPAR complex actually can promote cellular migration by abrogating stable interactions with vitronectin ${ }^{151}$. It might be true that this stimulatory effect of PAI-1 only occurs when cell migration is mediated 
by uPAR and vitronectin interactions. This effect of PAI-1 probably explains why high PAI-1 levels correlate with a poor prognosis for many cancers ${ }^{153}$. During vascular wound healing the uPAR appeared not to be involved in cell migration, which might explain the inhibitory role of PAI-1 on neoiritima formation in this model ${ }^{149,154}$.

\section{Plasmin and growth factor itteractions}

Besides degrading ECM components and activating MMPs, plastmin can also activate or liberate growth factors from the ECM. Several lines of experimental evidence indicate that the release of bFGF from the cell surface and ECM can be mediated by plasmin ${ }^{155}$. This process of growth factor mobilization is of particular importance for the biological activity of bFGF because it permits bFGF to diffuse in the tissue and to interact with its receptors. Plasmin also releases VEGF from the ECM or cell surface. Released VEGF is active as an endothelial cell mitogen and has a role in angiogenesis. Mobilization of bFGF and VEGF from the ECM in its turn stimulates UPA, uPAR and MMP expression from endothelial cells, providing a positive feedback mechanism for ECM proteolysis ${ }^{156}$. TGF$\beta_{1}$, a potent inhibitor of cell proliferation, migration and proteinase production is also actived by plasminin ${ }^{157}$. Active TGF- $\beta_{1}$ counteracts the effects of $b F G F$ on vascular endothelial cells by down-tegulating uPA and MMP expression and by stimulating PAI-1 and TIMP production. As a consequence, plasmin formation is blocked, active MMPs are inhibited, and MMPs are no longer activated. However, this blockade of ECM proteolysis also turns off the plasmin-mediated activation of TGF- $\beta_{1}$. When no more active TGF- $\beta_{1}$ is present, the effects of $\mathrm{bFGF}$ on endothelial cells becomes dominant and proteinase production increases again ${ }^{115}$. The local inhibition of extracellular proteolysis is thought to permit the deposition and assembly of ECM components by newly formed capillairies.

\section{Transgenic mouse models of the plasminogen system}

The generation of genetically modified mice with deficiencies in the main components of the Plg system have provided new insight in the role of this system in vivo. Plasminogendeficient (Plg- $/ \cdot$ ) mice survive embryonic development but because they develop spontaneous fibrin deposits due to impaired thrombolysis, suffer retarded growth and reduced fertility and survival. The Plg-/- phenotype is very similar to the combined tPA/-uPA-/- phenotype, which suggests that there is no additional pathway for physiological plasminogen activation in mice ${ }^{\text {s58. }}$. The role of the Plg system has been studied in several models associated with wound healing and inflammation.

Vascular wound healing. The functional role of the Plg system in neointima formation has recently been studied in a model of arterial injury ${ }^{159}$. In $P \lg -/$ - and uPA-/ - mice, neointima formation was significantly impaired as a consequence of delayed removal of necrotic debris, reduced leukocyte infiltration and smooth muscle cell migration ${ }^{159,160}$. Surprisingly, in $\mathrm{TPA}-/$ - and uPAR-/ mice, the degrees of intima formation after injury were similat as in their wild-type controls ${ }^{154,160}$. Those data confirm a tole for Plg and uPA, but not $\mathrm{PAA}$ and uPAR, in cell migration and neointima formation. Another study by Carmeliet et al. showed that PAI-1 deficiency resulted in accelated neointima formation and that PAI-1 overexpression inhibited this response of the vessel wall. The authors concluded that PAI-1 plays an inhibitory role in vascular wound healing by affecting cellular migration ${ }^{149}$.

Dermal wornd bealing. Plg-/- mice suffered delayed and impaired closure of skin wounds, 
which was mainly due to reduced keratinocyte migration. Surprisingly, these skin wounds had an abundant intiltration of macrophages, neutrophils and fibroblast-like cells and a pronounced neovascularization ${ }^{161}$.

Inflammation of the peritonewm. Ploplis et al. directly characterized the involvement of plasminogen in the inflammatory response of the peritoneum. They found that monocyte and lymphocyte tecnuitment was diminished in Plg/-mice. However, Plg appeared not to play a role in the recruitment of neutrophils into the peritoneum and in the phagocytic action of macrophages ${ }^{162}$.

Taken together, the effects of an absent Plg gene during wound healing processes in different tissues are diverse. The role of the Plg system in healing tissue might therefore depend on environmental conditions, involving the cell types present and the concentration of other proteinases and PAIs in the injured tissue. No data are available on the expression or function of the PIg system during myocardial wound healing.

\section{STRUCTURAL ALTERATIONS OF THE HEART AFTER INFARCTION}

\subsection{Infarct healing}

The repair process of the heart after myocardial infarction is considered a wound healing response, since it resembles the response of parenchymatous tissue to ischemic injury. Cardiomyocyte swelling and necrosis are early characteristics of an infarct. Myocyte necrosis is followed by an acute local inflammatory response. Within 6-8 hours after the onset of infarction, PMNs migrate into the infarcted area. Granulacyte infiltration is followed by an influx of other inflammatory cells, like lymphocytes and macrophages, which help to resotb the necrotic tissue. It is also in this period that degradation of ECM components takes place. Although there are some diverging results in the time course and nature of collagen injury in the acute phase postinfarction, there is agreement that the onset of collagen damage is early and extensive ${ }^{43}$. Morphologic and biochemical evidence has been presented to indicate that collagenolysis begins within a few hours after myocardial infarction ${ }^{163}$. Approximately four days after infarction new $\mathrm{ECM}$ proteins are synthesized. This marks the onset of the formation of granulation tissus, in which (myo) fibtoblasts start to proliferate and migrate, and new vessels are being formed. Extensive collagen deposition and collageh cross-linking increase the tensile strength of the infarct in the last phase of infarct healing, the period of scar tissue formation ${ }^{164}$. The time frame for these events is species-dependent. For example in humans, complete healing of the infarct, including the formation of mature scar tissue takes about 6 months, while in rabbits infarct healing is accomplished already after 4 weeks ${ }^{165}$.

Compared to other wound healing models, cardiac wound healing has several unique characteristics such as 1) the sustained presence of myofibroblasts in the infarcted myocardium $^{166}$, of which the orientation seems to be actively regulated by the WntFrizzled pathway, 2) the assumption that cardiomyocytes are terminally differentiated cells, which have lost the ability to divide. Myocardial healing is therefore independent of cardiomyocyte regeneration, but depends on the formation of granulation tissue, 3 ) another unique feature of cardiac wound healing is the thythmic contraction of the noninfarcted myocardium, which puts a cyclic stretch on the healing wound. 


\subsection{Architectural alterations after myocardial infarction}

Myocardial infatction leads to complex architectural alterations involving both the infarcted and noninfarcted myocardium. Dilatation and thinning, allso called "infarct expansion", are the most prominent structural changes in the infarct region ${ }^{167}$. Patients exhibiting extensive infarct expansion after myocardial infarction are more likely to experience complications such as the development of congestive heart failure, aneurysm formation, and myocardial rupture ${ }^{168}$.

Thinning of the infarctzone occurs early, against a histopathological background of evolving necrosis, edema and acute inflammatory cells, a period in which the affected myocardium is especially prone to mechanical deformation. Late thinning of the infarctzone occurs after about 3 weeks, when collagen has been deposited in the infarctzone ${ }^{169 \%}$. The extent of ventricular dilatation after infarction is related to the magnitude of the initial damage (infarct size), to the extent of the inflammatory response (infarct healing) and to ventricular wall stress. In addition, experimentally induced collagen degradation in normal myocardium has been reported to cause increased chamber compliance and $\mathrm{LV}$ dilatation ${ }^{170,171}$. Although ventricular dilatation after infarction can be viewed as an initial compensation mechanism to maintain stroke volume after the loss of contractile tissue, the balance can be exceeded in which increased cavity volumes can promote further dilatation and ventricular dysfunction.

Increasing evidence indicates that interference in the healing process after infarction can alter LV remodeling. Administration of glucocorticosteroids and nonsteroidal antiinflammatory agents in experimental infarct models during the acute phase of infarct healing resulted in thinner infarcts and enhanced ventricular dilatation ${ }^{172-174}$. In patients, anti-inflammatory therapy, given during the early infarction period, resulted in a higher prevalence of left ventricular aneurysm formation and congestive heart failure during follow-up ${ }^{\text {t75 }}$

\section{HYPOTHESIS}

As discussed in the previous paragraphs, indirect evidence suggests an involvement of proteinases, including the metalloptoteinases and plasminogen system, in the repair process of the heart after myocardial infarction. MMPs are known to be upregulated in the heart after infarction, but their localization and function during the healing process are largely unknown. The ability of MMPs to degrade interstitial collagens and other components of the extracellular matrix may suggest that MMPs contribute to the process of infarct expansion. On the other hand, increasing evidence indicates a role for MMPs in cell migration. This predicts a role for MMPs in the healing process after myocardial infarction.

No information is available in literature on the expression or function of components of the plasminogen system during infarct healing. However, since plasmin is an important activator for most MMPs, the plasminogen system might be a main regulator of MMP activity during infarct healing. 
The first hypothesis of the present thesis is that proteinase activity, in particular of MMPs and plasmin, is a main regulator of the wound healing process after myocardial infarction. Second, we hypothesized that interference in this healing process modulates LV remodeling and cardiac function.

\section{Outline of this thesis}

Thus the aim of the present thesis is to investigate the roles of MMPs and the plasminogen system on infarct healing, LV remodeling and cardiac function after myocardial infarction. The model system used is the chronic myocardial infarction in the mouse. This murine model of chronic myocardial infarction offers an opportunity to study this wound healing process under standardized conditions. In addition, recent developments in gene-targeting and transgenic technologies make it suitable for studying the role of candidate genes in the healing process after myocardial infarction.

In the first experimental chapter (chapter 2), we studied the localization and time course of MMP-1, $-2,-3$ and -9 immunoreactivity in cardiac autopsy tissue of patients who died after myocardial infarction. A subgroup of patients, who developed cardiac rupture after infarction was included to test the hypothesis that MMP over-activation contributes to rupture of the heart following infarction. In chapter 3, we describe the expression and activity of MMPs in the murine model of myocardial infarction and we investigated the effects of a pharmacological intervention, using a broad-range MMP inhibitor, on infarct healing, $\mathbb{L V}$ remodeling and cardiac function in the mouse infarct model. In chapter 4, we used an adenoviral construct, expressing a plasmin inhibitor to study the role of plasmin after myocardial infarction in mice. In chapter 5 , the impact of the plasminogen system on infarct healing was studied in plasminogen deficient mice. In chapter 6, we investigated the effects of plasminogen activators and matrix metalloproteinases on cardiac rupture, infarct healing and cardiac function. In chapter 7 , the findings of the experimental chapters are discussed and put into context. 



\section{Chapter 2}

Time-dependent localization of matrix metalloproteinases in the healing human heart after infarction 


\section{SUMMARY}

In the present study, we examined the localization and time course of matrix metalloproteinase immunoreactivity (MMP-1, -2, -3 and -9) in hearts of 36 patients who died after myocardial infarction. A subgroup of 14 patients, who developed cardiac rupture after infarction was included to test the hypothesis that MMP overexpression contributes to cardiac rupture following infarction. In normal hearts, $M M P-1,-2$, and -3 immunoreactivity was observed in smooth muscle cells, endothelial cells and cardiomyocytes, while MMP-9 immunoreactivity was absent in normal myocardium. In the first 12 hours after infarction, MMP-1, -2 and -3 immunoreactivity decreased. This was mainly due to disappearance of MMP immunoreactivity from ischemic cardiomyocytes. 12-24 Hours after infarction immunoreactivity increased again as a result of infiltration of MMP-containing inflammatory cells into the infarcted myocardium. Additionally performed double immunohistochemistry revealed that these MMP-containing inflammatory cells were polymorphonuclear leukocytes and macrophages. The presence of $M M P_{s}$ in large numbers of inflammatory cells may imply an important role for these cells in the collagen degradation process early after infarction. In subsequently developing granulation tissue (5-14 days after infarction), MMPs were present in fibroblast-like cells, smooth muscle cells and endothelial cells, which may suggest a role for MMPs in the structural remodeling process and angiogenic response of the infarcted myocardium during wound healing.

In conclusion, the data show a transient decrease of MMP immunoreactivity in early infarct healing. This was due to loss of MMPs from ischemic cardiomyocytes. The immunoreactivity increased again due to infiltration of MMP containing inflammatory cells into the infarcted myocardium. No differences in localization of MMIPS were found between the infarct and rupture group. 


\section{INTRODUCTION}

The myocardium contains a structural protein network, largely composed of type I and III fibrillar collagens. These collagens give strength and stiffness to the heart by connecting myocytes to each other, and myocytes to coronary capillaries ${ }^{45}$. Collagen turnover in cardiovascular tissue is a highly regulated, dynamic process $46,17 \%$ and abnormalities in either collagen synthesis or degradation in the heart can alter the collagen network and consequently influence myocardial structure and function. For example, a relatively small increase in the amount of collagen increases the stiffness of the heart, leading to decreased compliance and therefore diminished diastolic filling ${ }^{177}$, whereas a reduction of the collagen concentration or impairment of collagen cross-linking decteases the force-generating capacity of the myocardium ${ }^{178}$.

Myocardial infarction is associated with rapid fibtillar collagen degradation in the infarct zone of the rat heart, which starts within a few hours after ischemia and lasts for several days. Takahashi et al ${ }^{163}$. observed a $25 \%$ decrease in total collagen content as early as one hour after infarction. This decrease was due to an increased collagen degradation. The collagen content further decreased to $50 \%$ after 3 hours of persistent ischemia. In porcine myocardium, damage to collagen fibrils was seen as soon as 40 minutes after ischemia ${ }^{104}$. This early collagen loss is not compensated by increased collagen synthesis since deposition of new collagen fibers in the infarct zone was first visible 4-7 days after infarction ${ }^{179}$. This indicates a net loss of collagen in the infarct zone in the first days after infarction.

Loss of collagen integrity in the infarcted myocardium can result in infarct expansion, a rapid process, which starts within 24 hours and reaches its peak at 5.7 days after myocardial infarction in the tat ${ }^{43,167}$. Infarct expansion and left ventriculat dilatation are believed to form the basis for congestive heart failure and cardiac rupture ${ }^{180}$.

The enzymes responsible for collagen degradation are a family of matrix metalloproteinases (MMPs). The regulation of MMP activity is normally under stringent control at three levels: 1) through gene expression, 2) through extracellular activation of latent MMPs and 3) by binding to tissue inhibitors of metalloproteinases (TIMPs) ${ }^{48}$. Interstitial collagenase (MMP-1), neutrophil collagenase (MMP-8) and collagenase-3 (MMP-13) are the main proteinases able to cleave native fibrillar type I and III collagen triple helices, thereby generating two smaller fragments approximately $3 / 4$ and $1 / 4$ the size of the original molecule. Recent data do indicate that also $72 \mathrm{kDa}$ gelatinase (MMP-2) has the ability to (partially) degtade type I"collagen ${ }^{55}$. Due to thermal degradation and loss of stability, these $3 / 4$ and $1 / 4$ fragments unfold their triple helix conformation. The so formed gelatins can be degraded into oligopeptides and amino acids by gelatinases (MMP2 and MMP-9), stromelysin-1 (MMP-3) and serine proteases ${ }^{44,45}$.

Montfort and Pérez-Tamayo ${ }^{95}$ were the first to demonstrate collagenase in the normal rat myocatdium. Collagenase was present in the interstitial spaces between myocardial fiber bundles in the neighbourhood of its substrate, fibrillar type I and III collagen. In normal myocardium MMPs largely reside in their latent form ${ }^{\% 6}$. We tecently described a transient increase in MMP-1, -2 and -9 activity in the infarcted left ventricle of the rat starting at day 2 and peaking at day 7 after myocardial infarction ${ }^{96}$. In the same study it was found that fibroblast-like cells contained the mRNA of MMP-1. Also in dilating failing human hearts, secondary to previous infarction and in pacing-induced supraventricular tachycardia, which leads to congestive heart failure in pigs, the MMP 
activity was found to be enhanced ${ }^{181,182}$

Since there is no information about the localization of MMPs in the human infarcted myocardium, we examined the localization of MMP-1, $-2,-3$ and -9 in a time course of healling myocardium. A subgroup of patients who developed cardiac rupture after infarction was included to test the hypothes is that MMP immunoreactivity was even more increased in ruptured hearts.

\section{MATERIALS AND METHODS}

\section{Case selection.}

Tissue blocks of human transmural myocardial infarctions, obtained during autopsy, were retrieved from the archives of the Department of Pathology of the University Hospital of Maastricht. For inclusion into this study, the duration from the first clinical signs of myocardial infarction to the demise of the patient had to be known. Infarct duration was. also estimated histologically ${ }^{251}$ "Early infarcts ( $<24$ hours) were classified on the basis of the following histological characteristics: eosinophilia of necrotic cardiomyocytes, coagulation necrosis and stretching and waviness of the myocardial fibers at borders of infarcted areas. Inflammatory cells were barely seen in these early infarcts. Infarcts of 1-5 days are characterized by signs of acute inflammation (e.g. infiltration of polymorphonuclear leukocytes (PMNs) into the necrotic myocardium and the removal of necrotic cardiomyocytes). Infarct durations of 6-14 days were recognized by the ingrowth. of granulation tissue.

A patient was included into the study if the dinical and histological postinfarction survival time were in agreement. Based on these criteria a totall number of 36 infarct cases and an additional non-infarct control group with no cardiac history of any kind ( $\mathrm{n}=5$ ) were selected and classified.

\section{Infarce group}

This group included 22 patients with non-ruptured myocardial infarction. For inclusion, the post-infarction time of the patient had to be less than two weeks, since most of the collagen degradation takes place within the first two weeks. The samples were divided into three groups. Group A contained hearts with post-infarction periods of 6 to 24 hours $(\mathrm{n}=9)$. In addition, this group included one patient with a post-infarction survival time of less than 6 hours. Hearts in group $B$ had post-infarction periods between 1 and 5 days $(n=8)$. Group $C$ included heart tissue from patients who died between 6 and 14 days after infarction $(n=5)$.

\section{Cardiac rupture group}

This group comprised 14 patients who died of cardiac rupture after infarction. The time span between the onset of myocardial infatction and cardiac rupture (MI-rupture period) in these patients was between 6 hours to 14 days. Group A contained 5 hearts with MIrupture periods of less than 24 hours. Group B included 8 hearts with MI-rupture periods of 1 to 5 days and group $C$ consisted of only one heart with a MI-rupture period of 10 days. To examine potential differences in MMP localization between the rupture and infarct group, we compared tissue sections from the two groups. For this purpose, hearts 
from the rupture and infarct groups were matched on the basis of post-infarction surwal times. Subsequently, MMP localization and staining intensities were compared.

\section{Contral group}

The control group contained normal cardiac tissue of frve age matched autopsy cases, without clinical or histological evidence of cardiac disease.

\section{Immunohistochemistry}

Mouse monodlonal antibodies, raised against human MMP-1, MMP-2, MMP-3 and MMP-9 were obtained from Oncogene Science, Inc. In Western blotting, ELISAs and immunohistachemistry, the tested antibadies appeared to be highly specific in sections of various tumor tissues and in sera and synovial fluids of patients with osteoarthritis. ${ }^{13}, 184$. An important limitation of the antibodies is that they do not discriminate between the active and llatent form of the enzymes ${ }^{183}$.

The method for immunostaining was based. on the product performance guide, supplied with the anti-MMP antibodies. Briefly, parallel paraffin sections $(4 \mu \mathrm{m})$ were deparaffinized, hydrated and washed with Tris buffered saline, $\mathrm{pH} 7.5$ (TBS). Subsequently, each antibody was applied to parallel sections. Sections were incubated with the primary antibodies for $1 \mathrm{~h}$ at room temperature (RT) in the following dilutions: MMP-1, 1:30; MMP-2, 1:20; MMP-3, 1:15; MMP-9, 1:30. Only for the MMP-9 immunostaining a microwave pretreatment step was needed (before adding the primary antibody): these sections were treated by boiling in $0.01 \mathrm{M}$ citrate buffer ( $\mathrm{pH}$ 6.0) for 10 min in a mictowave oven (750 Watt) and allowed to cool down for $15 \mathrm{~min}$ at RT. After washing with TBS, biotinylated sheep anti mouse IgG (Amersham, dilution 1:250) was applied to each section and incubated for $1 \mathrm{~h}$ at RT. Subsequently, sections were washed and incubated with alkaline phosphatase coupled $A B C$ reagent (DAKO) for 30 min at RT. Alkaline phosphatase activity was visualized using New Fuchsin substrate (BioGenex), resulting in a red precipitate. The sections were counterstained with haematoxylin, dehydrated and aqueously mounted. As negative controls, myocarclial sections were used, omitting the incubation step with the primary antibody.

\section{Phenotyping of MMP producing intlammatory cells}

Double immunohistochemistry was performed to identify the types of inflammatory cells that contained MMP-1, MMP-2, MMP-3 and MMP-9. Antibodies against CD68 (DAKO) and CD15 (Becton Dickinson) were used to identify MMP-1, $-2,-3$ and -9 containing macrophages and polymorphonuclear leukocytes (PMNs), respectively.

MMP-1, $-2,-3$ or -9 were first localized using the above described protocol for MMP immunohistochemistry. After the MMP visualization step with the New Fuchsin substrate, sections were rinsed in distilled water. Subsequently, sections were pretreated with $0.1 \%$ pepsin (Bochringer) in $0.1 \mathrm{~N} \mathrm{HCl}$, pH 2.0 for $30 \mathrm{~min}$ at $\mathrm{RT}$ and washed with TBS. The sections were incubated for $45 \mathrm{~min}$, with the antibody against CD15 (1:250) or CD68 (1:100). After washing, biotinylated sheep anti mouse IgG was applied to each section and incubated for $1 \mathrm{~h}$ at RT. Sections were washed with TBS and incubated with alkaline phosphatase coupled $A B C$ reagent for 30 min at RT. After washing, alkaline phosphatase was visualized by incubation with $100 \mu \mathrm{l}$ fast blue substrate $(0.2 \% \mathrm{~W} / \mathrm{v}$ fast blue-BB-salt (SIGMA)) which was freshly dissolved in fast blue buffer. (Fast blue buffer: 
$0.2 \%$ w/v naphtol-phosphate (SIGMA), $5 \% \mathrm{v} / \mathrm{v}$ dimethylformamide (AnalaR), $0.3 \%$ w/v levamisol (SIGMA) in $100 \mathrm{mM}$ tris-HCl, $\mathrm{pH} 8.5$ ). Sections were washed with distilled water and aqueously mounted. No haematoxylin counterstaining was used.

\section{RESULTS}

\section{Time course of MMP-1, MMP-2, MMP-3 and MMP-9 immunoreactivity after myocardial infarction}

Through the complete time course after infarction, as well as in normal hearts, MMP-1, -2 and -3 immunoreactivity was observed in vital cardiomyocytes (see figure 1a-c), smooth muscle cells, fibroblast-like cells, endothelial cells and inflammatory cells. MMP-9 was only observed in inflammatory cells. Perivascular tissue contained MMP- $1,-2$ and -3 . Adipocytes, inflammatory cells and fibroblast-like cells were mainly responsible for the MMP $-1,-2$ and -3 immunoreactivity in these ateas. Because similar immunoreactivity patterns were observed for MMP-1, -2 and -3 , only MMP-1 stainings are shown (figure 1 $a, b, c, g$ and $h$ ).

Less than 24 bowrs after infartion. In infarcted tissue of 6-12 hours, MMP-1, -2 and -3 immunoreactivity decreased due to loss of staining in ischemic cardiomyocytes. Already in the earliest available infarct (less than 6 hours), the disappearance of MMP immunoreactivity from ischemic cardiomyocytes was clearly visible (figure $1 \mathrm{~b}$ ). Between 12 and 24 hours after infarction, MMP immunoreactivity increased again in the infarcted area. This was due to infiltration of the first MMP-1, $-2,-3$ and -9 containing PMNs into the infarcted myocardium.

$1-5$ days after infartion. The infiltration of inflammatory cells, predominantly PMNs, peaks 3-4 days after infarction. Since MMP-1, -2, -3 and -9 immunoreactivity was located in PMNs this resulted in high MMP immunoreactivity during this period (figure $1 \mathrm{~d}$ and $\mathrm{i}$ ). In tissues with post-infarction periods of mote than 4 days, a granular MMP-9 staining was observed in the interstitium between the necrotic myocytes (figure 1e). Macrophages, that were present in infarcts of at least 5 days old, frequently contained MMP-1, $-2,-3$ and -9 as well (figure $1 \mathrm{i}$ ).

MMP double stainings with a PMN or a macrophage marker demonstrated that MMP immunoreactivity in PMNs and macrophages was heterogeneously distributed. PMNs and macrophages in the centre of the infarct did not, or to a lesser extent contain the studied MMPs. At the border of the infarcts, but also in the neighbourhood of vessels, the majority of the PMNs and macrophages contained all the studied MMPs. An example of a MMP-1/PMN matker and a MMP-3/mactophage marker double staining is shown in figures $\mathrm{l} i$ and $1 \mathrm{j}$, respectively.

In non-infarcted areas of the infarcted myocardium, MMP-9 containing inflatmmatory cells were detected inside vessels (figure $1 \mathrm{f}$ ).

6.14 days after infartion. This period is characterized by the development of granulation tissue. Within this granulation tissue, inflammatory cells, predominantly PMNs, disappear and fibroblasts begin to proliferate and to produce extracellular matrix components. Considerable numbers of MMP-1, -2 and -3 containing fibroblast-like cells and endothelial cells could be detected in this granulation tissue (figure $1 \mathrm{~g}$ ). Macrophages, 
present in granulation tissue frequently contained all the studied MMPs.

In severall patients, besides a recent infarct, also signs of older infarcts could be demonstrated. These previous infarctions ( $>4$ weeks) manifested itself as fibrotic scar tissue, in which fibroblast-like cells contained MMP-1, -2 and -3 (figure 1h). MMP-9 could not be detected in these fibroblast-like cells.

\section{Differences in MMP localization between rupture and infarct group}

To compare the localization of MMPs in ruptured and non-ruptured infarcted hearts, tissue samples of the two groups were matched according to postinfarction survival times. Also in the ruptured hearts, MMP immunoreactivity was increased compared to normal hearts. However no qualitative differences were observed in the localization of MMP-1, $2,-3$ and -9 between the cardiac rupture and infarct group. The global staining intensities of the antibodies against MMP-1, $-2,-3$ and -9 were also similar in both groups.

\section{DISCUSSION}

\section{Normal human myocardium}

In normal myocardium, MMP-1, -2 and -3 immunoreactivity was observed in smooth muscle cells, some endothelial cells and in vital cardiomyocytes. The synthesis of MMPs by cardiomyocytes has been corroborated in a recent animal study, where MMP expression and activity were found in adult porcine cardiomyocytes ${ }^{97}$.

\section{MMP immunoreactivity, the first 12 hours after infarction}

The observation that MMP-1, -2 and -3 immunoreactivity decreased as early as a few hours after infarction in the ischemic cardiomyocytes suggests MMP leakage from these myocytes into the extracellular space. This MMP release might result in increased MMP-1, -2 and -3 plasma levels shortly after infarction. An increase in plasma levels of other proteolytic enzymes, like metalloendopeptidase (MMP-7) and cathepsin B has indeed been shown to occur within 24 hours after infarction ${ }^{185}$. Early release of MMPs from cardiomyocytes and a possible concomitant increase in plasma MMP levels might have an effect on collagen degradation in the heart or in other tissues early after infarction, prowided that the MMPs become activated directly after release. In this view, it was remarkable that this period of $\mathrm{MMP}$ release from cardiomyocytes correlated with the period in which a decrease in collagen content was observed in rat, porcine and human infarcted myocardium ${ }^{104,163,196}$. Whether MMPs released from ischemic cardiomyocytes are involved in this eatly collagen degradation remains speculative, since plasma MMP levels were not measured and MMP-1, -2 and 3 immunoreactivity could not be detected in the interstitium a few hours after infarction. 

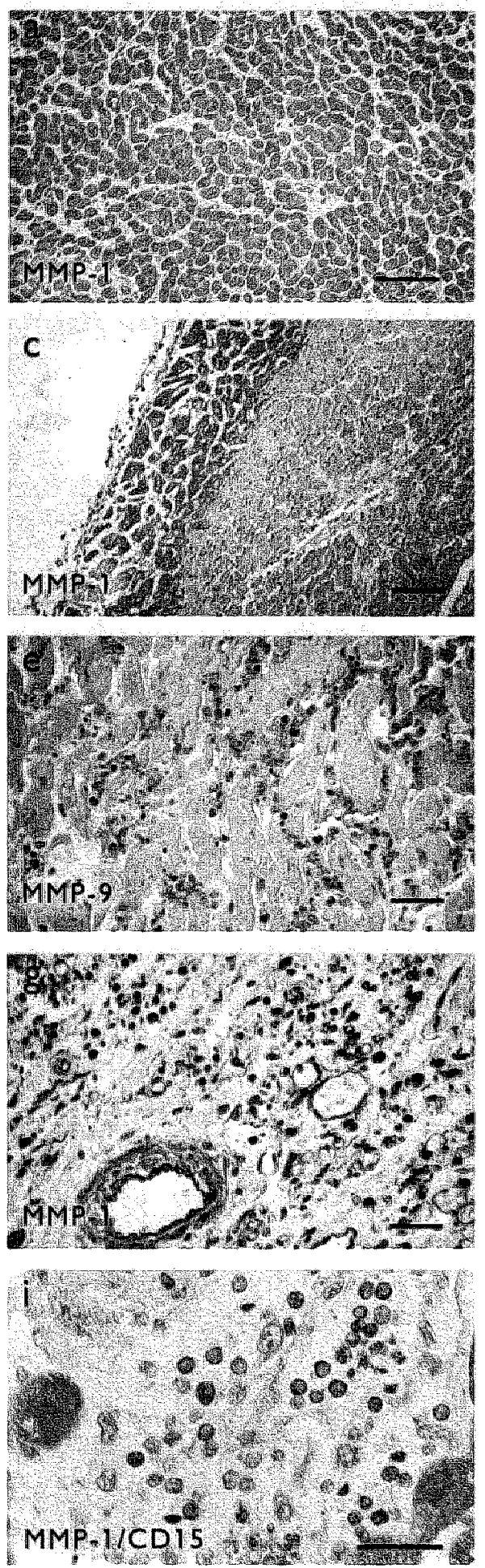
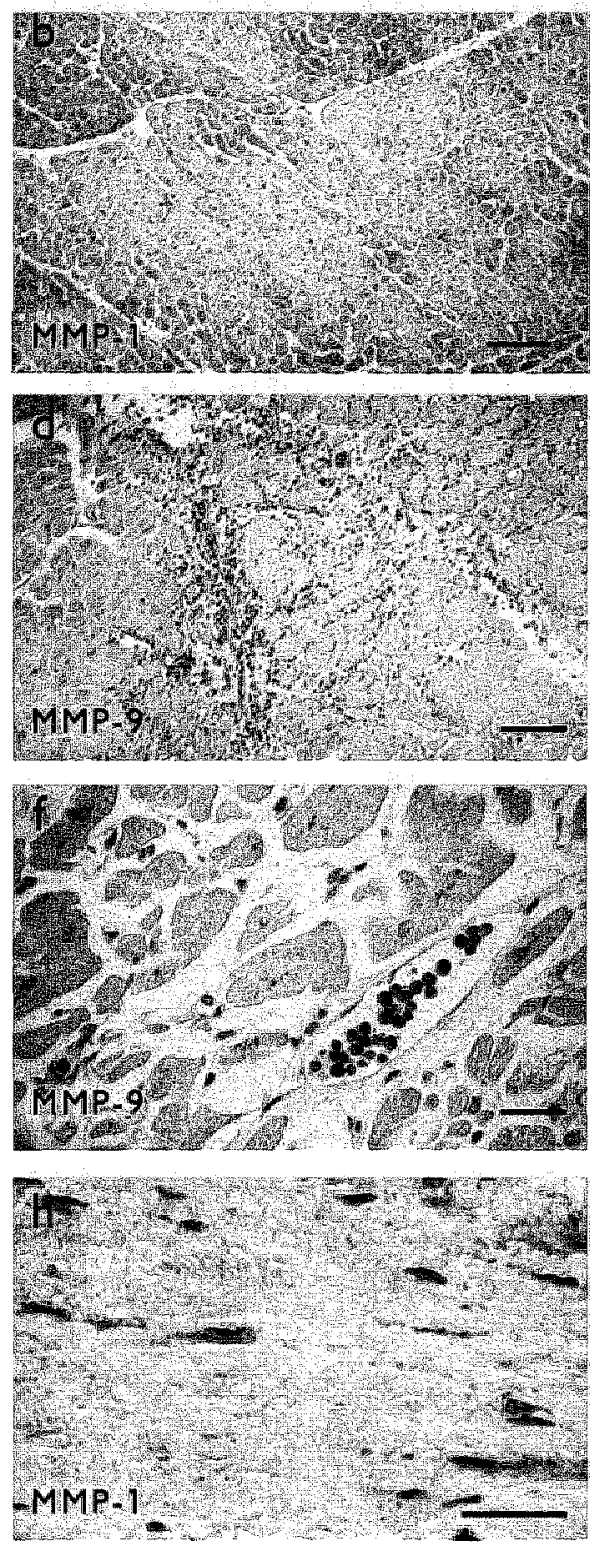

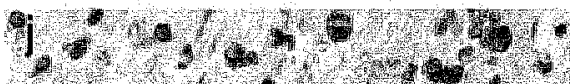

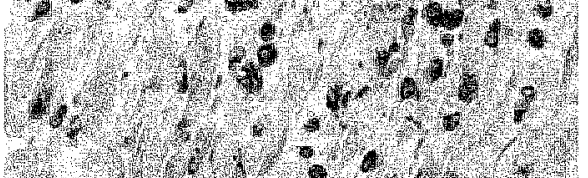

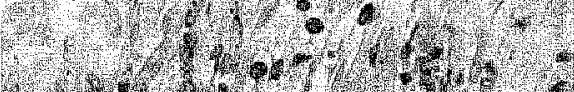

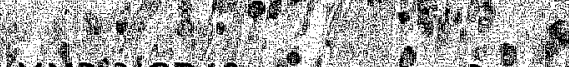

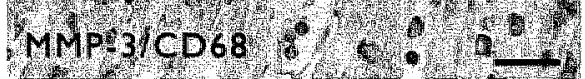




\section{MMP immunoreactivity in the inflammatory phase of wound healing}

After the initial loss of MMP-1, -2 and -3 from necrotic cardiomyocytes, MMP immunoreactivity starts to increase again through infiltration of MMP-containing inflammatory cells into the infarcted myocardium. Immunoreactivity of MMPs in inflammatory cells has previously been described by the group of Libby et al ${ }^{187}$. They found increased MMP-1 and -3 immunoreactivity in macrophages and leukocytes of aortic aneurysms. In another study of the same group, increased MMP-2 and -9 immunoreactivity was demonstrated in macrophages, lymphocytes, foam cells, smooth muscle cells and endothelial cells of human atherosclerotic plaques ${ }^{188}$. Interestingly, inactivation of the plasminogen gene in mice, which leads to reduction of the activation of latent MMPs, results in impaired leukocyte infiltration, reduced removal of necrotic debris and decreased smooth muscle cell migration in a model of electric injury of the vessel wall, indicating the particular importance of activated MMPs in the early wound healing response ${ }^{159}$. The assumption that inflammatory cells are involved in collagen degradation during the cardiac wound healing response after infarction was suggested by findings of Cannon et al ${ }^{199}$. They found that whole-body irradiation which inlhibited invasion of inflammatory cells in the rat heart after infarction, resulted in preservation of the collagenous network $24 \mathrm{hrs}$ after the induction of myocardial infarction.

Using zymography, we previously described an increase in MMP-1, -2 and -9 activity in the infarcted rat heart. The increase in MMP activity started at day 2 and peaked 7 days after infarction ${ }^{96}$. This period of increased MMP activity correlates with the significant influx of MMP containing inflammatory cells into the infarcted myocardium, as seen in the present study.

\section{Figure 1 - MMP immunoreactivity in normal and infarcted myocardium}

a: MMP-1 localization in normal myocardium. All cardiomyocytes contain MMP 1. ba MMP-1 in cardiac tassue, less than 6 hours after infarction. Note the diminished MMP immunoreactivity in ischemic cardiomyocytes. c: MMP'-1 Jocalization 2 days after myocardial infarction. Only vital cardiomyocytes contain MMP-1. Note the PMNs (red spots), between the necrotic cardiomyocytes. d: Phoromicrograph of human myocardium, 3 days after infarction, immunohistochernically stained with anti $\$$ MP- 9 . Almost all inflammatory cells, that invade the infarcted ventricle contain MMMP-9. e: Localization of MMP-9 in the infarct zone of human ruptured cardiac tissue of a patient who died 4 days after the onset of infarction. A granular staining, possibly remnants of PMNs, is localized in the interstitium between necrotic myocytes. $f$ MMP-9 in myocardium 4-5 days after infarction. In a relatively normal area of the myocardium, MMP-9 containing inflammatory cells are detected inside vessels. g: Immunohistochemical localization of MMP-1 in granulation tissue, 7 days after myocardial infarction. Note MMP-1 contaning endothelial cells, smooth muscle cells, macrophages and fibroblast-like cells. h: In scar tissue, that has been formed after a previous infarction, fibroblast-like cells contain MMP-1. i: MMP-9 in PMNs, 4 day after infarction. Immunoreactivity of MMP-1, -2 and -3 was also found in PMNs (data not shown). j: Double staining of anti MMP-3 and anti CD 68 to detect MMPP-3 containing macrophages in the infarct zone of ruptured myocardium 4 days after infarcion. MMP' 3 is stained red and macrophages bluc. Almost all macrophages in this area contain MMP-3. The red staining in the necrotic cardiomyocytes is considered to be background staining since vital cardiomyocytes are stainecl more intensely with the MMP-3 antibody. (Scale bar represents $100 \mu \mathrm{m}$ in A-D, and $20 \mu \mathrm{m}$ in E-J) 
However, other studies demonstrated collagen degradation as early as a few hours after iscliemia in rat and porcine myocardium, which is prior to any significant influx of inflanmatory cells ${ }^{104,6^{3}}$. A possible explanation for this apparent discrepancy might be that the MMPs that leak out of the ischemic cardiomyocytes play a role in collagen degradation eatly after infarction. Another possibility is that other enzymes than MMP-1, $-2,-3$ and -9 are responsible for the early collagen degradation after infarction. In this regard, MMP-13 might be one of the candidates, since this enzyme is also capable of degrading fibrillar collagens. MMP-13 expression was recently demonstrated in mactophages, during vascular aneurysm formation ${ }^{190}$. MMP-8, which can also degrade interstitial collagen and which is predominantly present in PMNs is another possible candidate for this very early collagen degtadation. However, if MMP-8 or MMP-13 are involved, they have to be synthesized by other cell types than PMNs and macrophages, since collagen is degraded before the invasion of inflammatory cells.

The results of the MMP-1, -2,-3 and -9 double stainings with both a PMN marker (CD-15) and a macrophage marker (CD-68) showed less MMP containing inflammatory cells at the centre of the infarcts compared to the infarct borderzones. This suggests that these cells release their MMPs during their migration from the border zone to the centre of the infarct. In this view it is surprising that we hardly found MMPs in the interstitium. Only MMP-9 was observed in the interstitium in infarcted areas, the other MMPs were observed inside the cells. Since only secreted MMPs are capable of degrading connective tissue, these observations might imply that, of the MMPs studied here, MMP-9 is the most active one.

\section{MMP immunoreactivity in granulation tissue}

After the initial inflammatory response, approximately 5-7 days after infarction, granulation tissue starts to develop. The data presented here demonstrate MMP-1, -2 and -3 in macrophages, fibroblast-like cells and endothellial cells, while MMP-9 was only seen in macrophages. The presence of MMP-containing fibroblast-like cells in granulation tissue implies a further role for $\mathrm{MMPS}_{\mathrm{s}}$ in the structural remodeling process of the infarcted myocardium. Detection of MMPs in endothelial cells might emphasize the importance of MMP activity for the migration of these cells into the infarctzone. This is consistent with the findings of others who showed that the invasive process of vascular endothelial cells during angiogenesis or wound healing is regulated by proteinases ${ }^{48}$.

\section{Cardiac rupture}

Approximately $70-80 \%$ of the cardiac ruptures occur during the first week after the onset of symptoms of myocardial infarction ${ }^{191-193}$. During this period the infarcted tissue is at its weakest because of severe myocyte necrosis and the proteolytic action of infiltrating inflammatory cells ${ }^{130}$. The second week post-infarction, the scat tissue becomes progressively stronger due to extensive collagen deposition. Therefore, rupture is less likely to occur. If one assumes that MMPs do indeed play a significant role in the onset of cardiac rupture, a different localization or quantity of MMPs in the ruptured and infarcted myocardium might be expected. In the present study however, we found no qualitatively different localization between the two groups. This could imply a restricted role for MMPs in the development of cardiac rupture. In other rupture prone tissues (like aortic aneurysms), it has also been suggested that MMPs play a limited role in rupture 
development, ${ }^{18 \%}$ since similar MMP activities werte found in stenotic aortas and aortic aneurysms. It has, however, been demonstrated that several MMPs do participate in the development of aneurysm formation by degrading elastin bonds in the media "

In addition, it seems unlikely that MMPs synthesized by inflammatory cells are responsible for the rupture to occur, since ruptures may occur within a few hours after infarction, during which period the inflammatory cells have not yet invaded the infarcted myocardium ${ }^{180}$. Also similar numbers of inflammatory cells were demonstrated in infarcted and ruptured myocardium ${ }^{191,195}$, implying a comparable inflammatory response in the two groups. On the other hand, an altered balance between MMPs and the activity of their inhibitors (TIMPs), rather than the presence of MMPs could be involved in the transition of myacardial infarction to cardiac nupture.

\section{Limitations of the study}

An important limitation of the present study is the fact that the used antibodies do not discriminate between the latent and active forms of the enzymes. It is therefore not known to which extent the detected enzymes were activated. It is, however, likely that the MMPs present inside cells are latent and that MMPs released into the interstitium are partly activated since MMPs are only activated after release. It is known from zymographic studies in infarcted rat myocardium ${ }^{96}$ as well as in porcine ${ }^{182}$ and human failing hearts ${ }^{181}$ that several MMPs indeed become activated during cardiac remodeling. Unfortunately, the archive of autopsy tissue we used, consisted of formalin fixed, paraffin embedded tissues, in which MMP activity or mRNA levels of MMPs cannot be determined.

\section{Conclusions}

After studying the time course of MMP immunoreactivity in human infarcted cardiac tissue, we conchude that 1) tissue MMP immunoreactivity decreases as early as a few hours after infarction, through loss of MMP-1, -2 and -3 inmunoreactivity of ischemic cardiomyocytes, 2) 12 hours after the infarction, MMP immunoreactivity begins to increase again as a result of infiltration of MMP-1, $-2,-3$ and -9 containing inflammatory cells into the infarcted myocardium, 3) in early granulation tissue MMP-1, $-2,-3$ and -9 are extensively present in fibroblast-like cells and endothelial cells implying a fut ther role for MMPs in the structural remodeling process and the angiogenic response of the infarcted myocardium during wound healing and 4) No differences in localization of MMPs were found between the infarct and rupture group. 



\section{Chapter 3}

Inhibition of matrix metalloproteinases attenuates left ventricular remodeling, delays infarct healing and depresses cardiac function after myocardial infarction in mice 


\section{SUMMARY}

The objectives of the present study were to assess the impact of matrix metalloproteinases (MMPs) on left ventricular (LW) remodeling, infarct healing and cardiac function in a murine model of myocardial infarction (MI). First we followed the mRNA expression (by RT-PCR) and/or activity (by zymography) of MMP-2, MMP-3, MMP-9 and MMP-13, in the first 5 weeks postMI. Subsequently, the effects of the broad range MMP inhibitor (GM6001) on LV remodeling, infarct healing and cardiac function were studied 1 and 2 weeks after MI. Within the first week, the activities of MMP-2, -3 and -9 were upregulated in the infarcted LV. Already the first day postMI, MMP-13 mRNA expression was significantly upregulated, whereas the mRNA levels of MMP-2, -3 and -9 remained fairly high, but constant over the first 5 weeks postMI. Infarcted mice allocated to GM6001 treatment had comparable infarct sizes, but less LV dilatation (LV circumference, GM6001 vs control: $11.9 \pm 0.9$ vs 14.8 $\pm 0.6 \mathrm{~mm}, p<0.05)$ and thicker infarcted LV walls $(0.68 \pm 0.02$ vs 0.52 $\pm 0.02 \mathrm{~mm}, p<0.05), 7$ days after MI. In these infarcts, necrotic areas were larget $\left(0.84 \pm 0.07\right.$ vs $\left.0.37 \pm 0.04 \mathrm{~mm}^{2}, \mathrm{p}<0.05\right)$, cell densities lower (447 \pm 26 vs $704 \pm 30$ cells $/ 0.1 \mathrm{~mm}^{2}, \mathrm{p}<0.05$ ) and collagen contents reduced $(8.3 \pm 1.1 \%$ vs $25.9 \pm 4.2 \%$ Sirius Red positive area, $\mathrm{p}<0.05)$. These effects of MMP inhibition on $\mathrm{LV}$ remodeling and healing wete most prominent 7 days after $M I$ and showed a trend towards normalization after 14 days. Cardiac output, measured 14 days after surgery, yielded a lower cardiac index after maximal stimulation of the hearts in GM6001 treated infarcted mice $(0.31 \pm$ $0.03 \mathrm{vs} 0.43 \pm 0.03 \mathrm{ml} / \mathrm{min} / \mathrm{g}, \mathrm{p}<0.05)$. In conclusion, in the mouse heart, MMP activity is elevated in the first weeks after MI and administration of a MMP inhibitor attenuates $L V$ remodeling, reduces the rate of infarct healing and depresses cardiac function after MI. 


\section{INTRODUCTION}

The matrix metalloproteinases (MMPs) constitute an important enzyme system, which has been held responsible for the degtadation of many extracellular matrix (ECM) components. MMPs, which have high selectivity and affinity for many components of the $\mathrm{ECM}$, are secreted in a proenzyrne form and require proteolytic cleavage for activation. MMPs can be activated through cleavage by other MMPs or serine proteases, of which plasmin is an important example ${ }^{70}$. In the normal myocardium, MMPs largely reside in their latent form, while after myocardial infarction (MI), the pool of latent MMPs becomes activated, as has been demonstrated for human, rat and porcine myocardium ${ }^{96,102,105,106}$. The precise function of MMPs in left ventricular (LV) remodeling after $\mathrm{MI}$ is not dear. It is thought that loss of myocardial collagen fibers by the activity of MMPs can result in slippage of cardiomyocytes and cellular elongation, which can, together with the death of the cardiomyocytes, lead to loss of structural support, distortion of tissue architecture, wall thinning, LV dilatation and even rupture of the infarcted myocardium ${ }^{96,197}$.

Two recent studies have described the effects of MMP inhibition on cardiac remodeling. The first study by Spinale et al. demonstrates that MMP inhibition limits LV remodeling and reduces wall stress during the development of heart failure after 3 weeks of rapid pacing in pigs ${ }^{198}$. The second study, by Rhode et al. demonstrates that administration of a broad range MMP inhibitor attenuates left ventricular dilatation, 4 days after MI in mice ${ }^{106}$. The impact of chronic MMP inhibition on infarct healing, LV remodeling and cardiac function after $M I$ is currently unknown.

The objectives of the present study were 1) to investigate the mRNA expression and activity of MMP-2, MMP-3, and MMP-9 and the mRNA expression of MMP-13 in the mouse heart, the first 5 weeks after $\mathrm{MI}$ and 2) to assess the impact of chronic MMP inhibition (GM6001) on LV remodeling, infarct healing and cardiac function, 1 and 2 weeks after $M I$.

The present study shows that MMP irhibition attenuates LV dilatation and infarct thinning, and reduces cellular infiltration and collagen deposition in the infarct, thus delaying the rate of infarct healing. These prominent effects of MMP inhibition on infarct healing were associated with negative effects on cardiac function.

\section{MATERIALS AND METHODS}

\section{Coronary artery ligation}

Male mice (Swiss, Iffa Credo), 10-12 weeks old at the time of surgery were used. MI or sham surgery was induced by coronary artery ligation according to recently described methods ${ }^{199}$. All experiments were performed according to institutional guidelines.

\section{Myocardial MMP activity by zymography}

To study the time course of the expression of activated forms of several MMPs in the infarcted mouse heart, mice were sacrificed $1,2,4,7,14,35$ days after $M$ and 1 and 7 days after sham surgery ( $n=5-6$ per group). After sacrifice, the hearts were subdivided into left ventricular free wall and non-infarcted septum and rapidly frozen. The presence of 
actrvated forms of MMPs was visualized using gelatin (for MMP-2 and MMP-9) or casein (for MMP-3) zymography. MMP activities were quantified by measuring integrated optical densities (IOD) of the lytic bands (Gel-Pro Analyzer v2.0).

\section{mRNA expression of MMP-2, $-3,-9$ and -13 by RT-PCR}

The mRNA expression of MMP-2, $-3,-9$ and -13 were determined semi-quantitively using RT-PCR, 1, 2, 4, 7, 14 days after $M I$ and 4 and 7 days after sham operation ( $\mathrm{n}=4-6$ per group). Total RNA was isolated from the LV free wall and the non-infarcted septum, using the Ultraspec ${ }^{\text {TM }}$ RNA Isolation System (Biotecx Laboratories, Inc, Houston, TX). PCR primers used for:

MMP-2

(sense): 5'-ACAGCCCTGCAAGTTTCCGTTCCGC3' (antisense) 5'-TGGGGCCTCATACACAGCGTCAATC-3';

MMP-3 (sense): $5^{\prime}$-AAGGGTCTTCCGGTCCTGCT-3' (antisense): 5'-CTCCAACCCGAGGAACTTCT-3';

$\underline{M M P}-2$ (sense):5'-TGGCACCCCTCACCTTCACC-3' (antisense):5'-GGAAAGTGACATGGGGCACC-3";

$\underline{M M P-13}$ (sense): 5'-CCCTTGATGCCA-TTACTAGTCTCCG-3' (antisense): 5'-AGGAATTCGTTGGCATGACTCTCAC-3';

RNA polymerase Ifif (sense): 5'-GAGAT'GCI'GAGAGAGCCAACGA-3'

(antisense): 5'-CACCACCTCTTCCTCCTCTT-3'.

PCR products were quantified by measuring the IOD of the appropriate bands. Each sample was corrected for the expression of RNA polymerase II.

\section{MMP inhibitor treatment}

The peptide hydroxamic acid, $N-[2(R)-2$ (hydroxamido-carbonylmethyl)-4methylpentanoyI]-L-tryptophane methylamide (GM6001; Glycomed Inc., Alameda, CA) inhibits MMP activity by binding of the hydroxamine group to the zinc atom present in all MMPs. GM6001 was dissolved in 1\% (wt/vol) carboxymethylcellulose and injected daily $(100 \mathrm{mg} / \mathrm{kg} / \text { day, IP) })^{\text {kg:90. }}$. The dose of GM6001 was adapted from previously described in wivo studies with rabbits and rats ${ }^{89,90,200}$. For control treatment, the same volume of $1 \%$ carboxymethylcellulose was used. To ensure maximal inhibition of MMP activity at the initial phase of infarct healing, GM6001 or control treatment was started 2 days before infarct or sham operation. The effects of GM6001 and vehicle on infarct healing were studied at 1 and 2 weeks, and the effect on sham operation was studied 2 weeks after surgery. The presence of GM6001 in the infarcted LV was confirmed using a colorimetric assay, previously described by Hanemaajer et $\mathrm{al}^{201}$. In short, a modified prourokinase was used in which the activation sequence, normally recognized by plasmin, was replaced by a sequence that is specifically recognized by MMPs. Activation of this artificial urokinase $(5 \mu \mathrm{g} / \mathrm{ml}$ ) by various concentrations of MMP-9 was measured in the presence of cardiac tissue extracts of mice treated for 2 weeks with either GM6001 or the vehicle, using a chromogenic substrate for urokinase (S-2444,0.4 mM; Chromogenix, Mölndal, Sweden). Colour development of S-2444 was assessed by measuring the absorbance at $405 \mathrm{~nm}$, using a Titertek Multiskan 8-channell photometer ${ }^{201}$. 
$a$

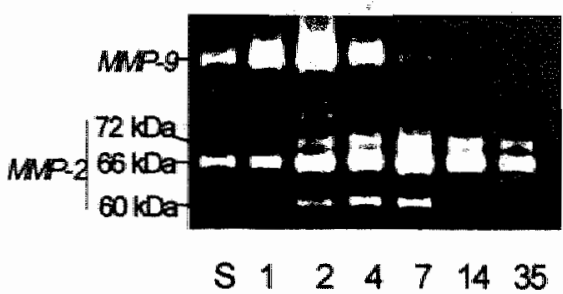

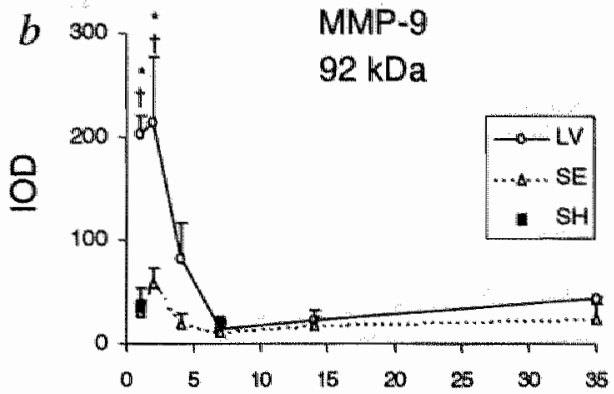

days after surgery
C

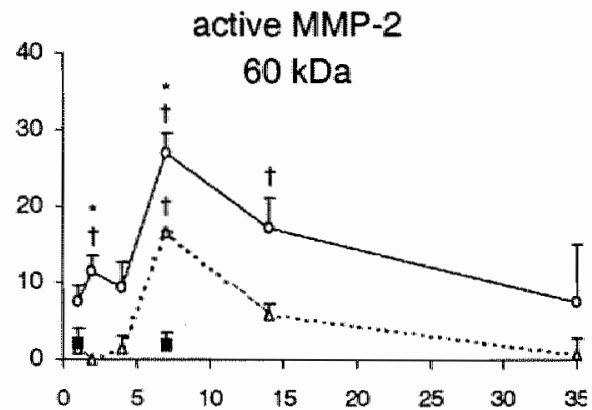

$e$

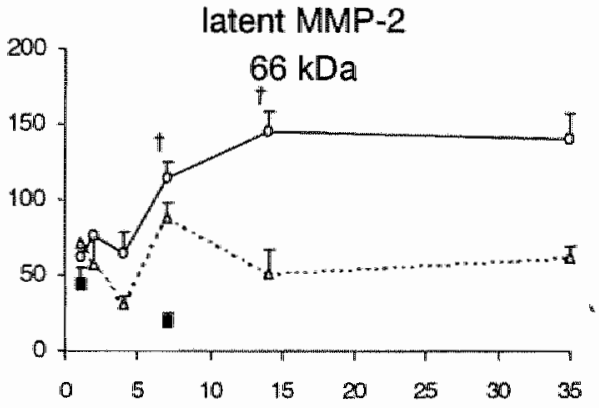

latent MMP-2
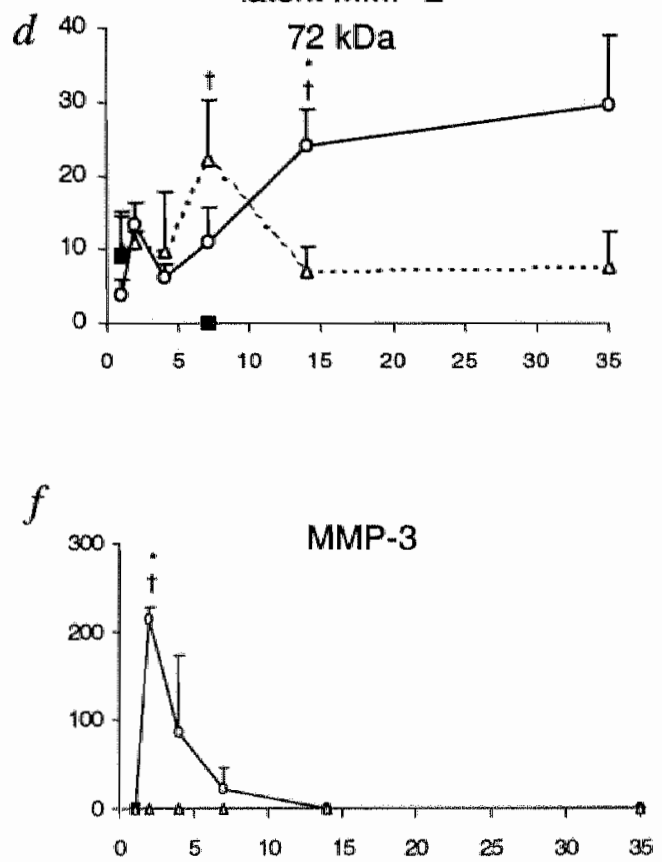

Figure 1 - MMP activity in the infarcted mouse heart

a. A representative gelatin zymogram demonstrating the time course of MMP activity in the infarcted LV after MI. The top band represents MMP-9 and three bands with molecular weights of $\sim 72 \mathrm{kDa}, \sim 66 \mathrm{kDa}$ and $\sim 60 \mathrm{kDa}$ represent respectively two proenzyme forms and one activated form of $M M P-2^{160}$. Note that MMP-9 peaks early, while the 3 forms of MMP-2 increase more slowly and reach maximal levels 7 days after MI. "S' represents MMP activity in LV tissue of a sham operated control. b-f. Time course of resp. MMP-9, rwo forms of latent MMP-2, active MMP-2 and MMP-3 in the mouse heart after MI and sham surgery. Each point is based on measurements in $4-6$ mice. " $: p<0.05$ compared to non-infarcted septum, ${ }^{t}: p<0.05$ compared to shams. 

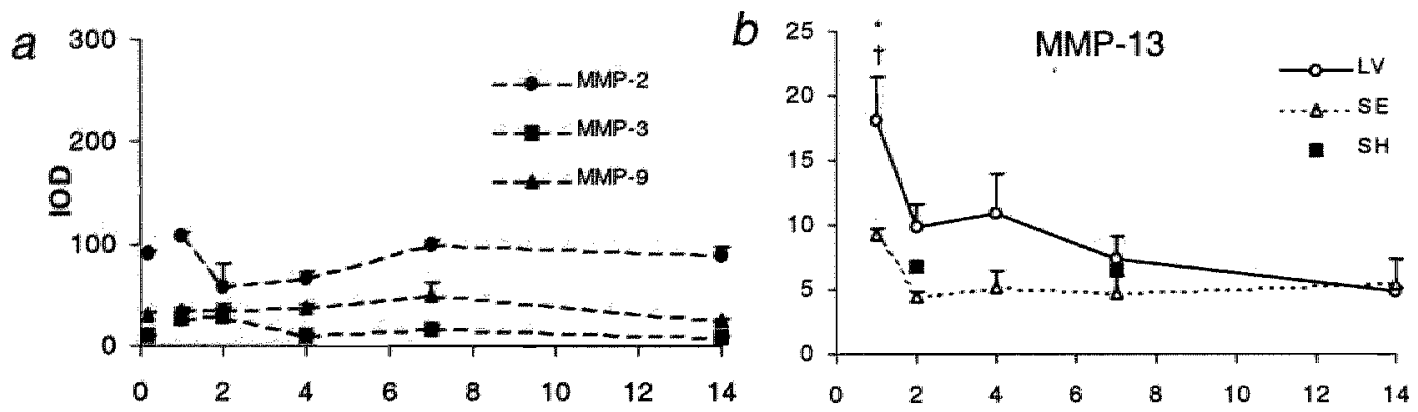

days after surgery

Figure 2 - mRNA expression of MMPs in the infarcted mouse heart

a. mRNA expression of MMP-2,-3 and -9 is not significantly upregulated in the infarcted LV after MI. $b$. MMP-13 mRNA expression is significantly upregulated in the infarcted LV, 1 day after MI. ": $p<0.05$ compated to non-infarcted septum, ${ }^{t}: \mathrm{p}<0.05$ compared to shams.

\section{$L V$ remodeling and infatct healing}

Infarct size, LV circumference, infarct thickness, septum thickness and collagen. deposition were studied 1 and 2 weeks after surgery in the GM6001 and control groups, using a computerized morphometry system (Quantimet 570, Leica, Cambridge, UK) on AZAN stained or sirius red stained sections ${ }^{199}$. It has previously been demonstrated that the sirius red positive area closely correlates with tissue hydroxyproline concentration ${ }^{106}$. Immunohistochemistry was performed to quantify macrophages (moma-2 monoclonal antibody, $1: 50$ on cryostat sections $\mathrm{s}^{202}$ ) and smooth muscle cells and myofibroblasts (mouse anti-human $\alpha$-smooth muscle actin (asma), 1:500 on paraffin sections, DAKO).

\section{Cardiac function}

Cardiac output (CO) was evaluated 2 weeks after surgery. In short, animals were anesthesized (100 $\mathrm{mg} / \mathrm{kg}$ pentobarbital, IP) and an electromagnetic flow-probe (1.2 mm; Skalar, Delft, The Netherlands) was placed on the ascending aorta, and connected to a Skalar MDL400 sine-wave flowmeter. An abdominal aorta catheter was connected to a pressure transducer (micro-switch, model 156PC 156 WL, Honeywell Inc, Amsterdam, The Netherlands) and fed into a personal computer. Flow-probes were factory-calibrated; late diastolic flow was assumed to be $0 \mathrm{ml} / \mathrm{min}$. After collecting base-line values of cardiac output $\left(\mathrm{CO}_{\text {ress }}\right)$, stroke volume (SV), mean arterial pressure (MAP) and heart reate, a rapid infusion ( $2.5 \mathrm{ml}$ in one minute) of a warm Ringer's solution was started through a 


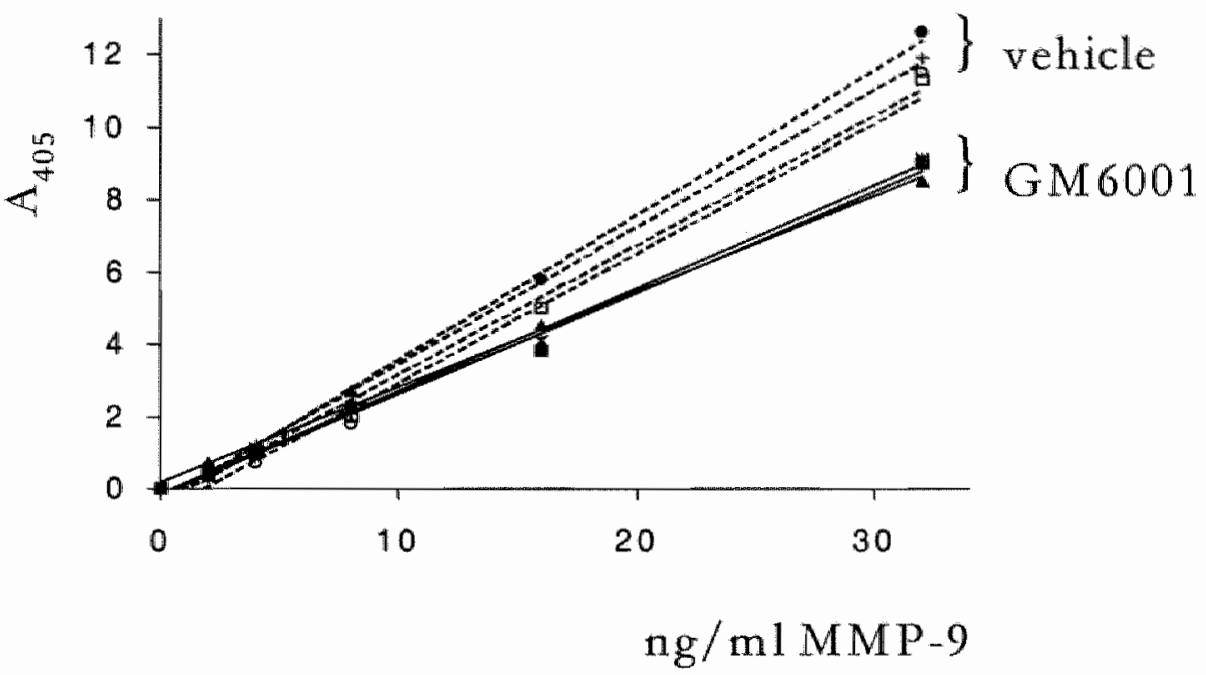

Figure 3 - Inhibition of MMP-9 activity by GM6001 in LV tissue

Modified pro-uPA was mixed with infarcted $L V$ tissue extracts, MMP-9 at various concentrations and a chromogenic substrate for urokinase. Absorbance was measured at $405 \mathrm{~nm}$. LV tissue extracts of 3 GM6001 treated mice (broken lines) blunted MMP-9 activity compared to LV tissue of 4 whicle treated mice (solid lines).

catheter introduced into the femoral vein. It was previously shown in rats that volume overload elevates cardiac output (CO) to maximal values during the last 10-15 seconds of a 1 minute fluid load and that infarction blunts the increase in $\mathrm{CO}$, proportional to the degree of heart failure ${ }^{203}$.

\section{Statistics}

All above described parameters were measured without knowledge of the treatment group. Data are expressed as mean \pm SEM. Means between groups were compared by use of the Mann-Witmey $U$ test. $A$ value of $P<0.05$ was considered statistically significant.

\section{RESULTS}

\section{Time course of myocardial MMP activity after infarction}

One day after MI, a five-fold increase in the activated form of MMP-9 was observed in the infarcted LV (figures $1 \mathrm{a}$ and $1 \mathrm{~b}$ ). MMP-9 activity peaked at day 2 and returned to control levels after 7 days. In zones remote of the infarct (septum), no significant MMP-9 increase was observed. Active MMP-2 (60 kDa band) increased at day 2, peaked at day 7 
Table 1. Heart weights and cardiac dimensions in control and GM6001 treated mice, 1 and 2 weelks after surgery

\begin{tabular}{|c|c|c|c|c|c|c|}
\hline \multirow{3}{*}{$\begin{array}{l}\text { Drugg treatment: } \\
\text { Surgery: }\end{array}$} & \multicolumn{2}{|c|}{1 week } & \multicolumn{4}{|c|}{2 wreeks } \\
\hline & control & GM6001 & \multicolumn{2}{|c|}{ control } & \multicolumn{2}{|c|}{ GM6001 } \\
\hline & MI & MI & sham & MI & sham & MI \\
\hline Heart weight (mg) & $187 \pm 11$ & $179 \pm 9$ & $177 \pm 4$ & $1.97 \pm 7$ & $189 \pm 6$ & $211 \pm \pi$ \\
\hline Infarct size $(\%)$ & $41 \pm 1$ & $45 \pm 4$ & 0 & $47 \pm 1$ & 0 & $42 \pm 2$ \\
\hline LV circumference $(\mathrm{mm})$ & $14.8 \pm 0.6$ & $11.9 \pm 0.9^{\circ}$ & $10.5 \pm 0.7$ & $15.4 \pm 0.5^{\dagger}$ & $10.2 \pm 0.2$ & $14.1 \pm 0.5^{7}$ \\
\hline LV thickness (mm) & $0.52 \pm 0.02$ & $0.68 \pm 0.05^{*}$ & $1.28 \pm 0.06$ & $0.40 \pm 0.02^{\dagger}$ & $1.30 \pm 0.04$ & $0.59 \pm 0.02^{t^{*}}$ \\
\hline Sept. thickness (mm) & $1.5 \pm 0.2$ & $1.4 \pm 01$ & $1.7 \pm 0.1$ & $1.6 \pm 0.1$ & $1.5 \pm 0.1$ & $1.4 \pm 0.1$ \\
\hline number of animals & 5 & 4 & 4 & 9 & 6 & 9 \\
\hline
\end{tabular}

*: $\mathrm{p}<0.05$ compared to control Ml group; $f \mathrm{p}<0.05$ compared to corresponding sham

and returned to control levels 5 weeks after $M I$ (figures $1 \mathrm{a}$ and 1c). Even in the noninfarcted septum, active MMP-2 significantly increased at day 7 . Two latent forms of MMP-2 (66 kDa and $72 \mathrm{kDa}$ bands) showed a slow, but persistent increase in the infarcted LV from day 4 (figures $1 \mathrm{a}, 1 \mathrm{~d}$ and $1 \mathrm{e}$ ).

Casein zymography on cardiac tissue revealed two caseinolytic bands of respectively 51 $\mathrm{kDa}$ and $88 \mathrm{kDa}$ (not shown). The $51 \mathrm{kDa}$ band, which corresponds to MMP-3 activity, was only detected in LV tissue early after MI. Its activity peaked 2 days after $M I$ and disappeared again at day 14 (figure $1 \mathrm{f}$ ).

\section{mRNA expression of MMP-2, $-3,-9$ and -13 by RT-PCR}

A constant high level of $\mathrm{MMP}_{-2},-3$ and -9 mRNA expression was observed in the infarcted LV and septum at all studied time points after sham or infarct surgery (figure 2a). MMP-13 was significantly upregulated in the infarcted LV, 1 day after MI and slowly returmed to control levels 7 days after MI. No increase in MMP-13 expression was observed in the non-infarcted septum (figure $2 \mathrm{~b}$ ).

\section{MMP inhibition attenuates $L V$ remodeling}

The biological activity of GM6001 in the infarcted LV was succesfully demonstrated using a colorimetric assay. Figure 3 shows that LV tissue of GM6001 treated mice inhibit MMP-9 activity in vitro, when compared to LV tissue of control treated mice. In both the control and GM6001 treatment groups, $M I$ resulted in $L V$ dilatation and thinning of the infarcted LV wall. However, MMP inhibitor treatment significantly attenuated LV dilatation and infarct thinning (table 1 and figures $4 a$ and $4 b$ ). The effect of GM6001 on LV dilatation was more pronounced in the 1 week group (GM vs control: $11.9 \pm 0.9 \mathrm{~mm}$ vs $14.8 \pm 0.6 \mathrm{~mm}, \mathrm{p}<0.05$ ), compared to the 2 weeks group (GM vs control: $14.1 \pm 0.5$ vs $15.4 \pm 0.5 \mathrm{~mm}, \mathrm{p}=0.06)$. The effect of $\mathrm{GM6001}$ on infarct thinning was comparable in the 
1 and 2 weeks GM6001 groups (table 1). GM6001 treatment had no significant effects on heart weight, infarct percentage, septum thickness, or on cardiac dimensions of sham animals.

\section{Infarct healing}

Because of the striking effects of GM6001 on LV dilatation and infarct thinning, parameters of infarct healing were studied in more detail. Extensive collagen deposition was found in the center of the infarcts of control treated mice, both 7 and 14 days after infarction (figures $4 \mathrm{e}, 4 \mathrm{f}$ and $5 \mathrm{a}$ ). Interestingly, GM6001 treatment reduced this collagen deposition, especially 7 days after $\mathrm{MI}$ (GM vs control: $8.3 \pm 1.1 \%$ vs $25.9 \pm 4.2 \%, \mathrm{n}=4$ per group, $\mathrm{p}<0.05$ ) and to a lesser extent in the 14 days MI group (GM vs control: $36.5 \pm$ $2.5 \%$ vs $46.7 \pm 1.6 \%, \mathrm{n}=8$ per group, $\mathrm{p}<0.05$ ). No increase in collagen content was found in the septum of both infarct groups, when compared to shams.

The total area of necrosis in the center of the infarcts was used as an indicator of the rate of infarct healing (figures $4 c, 4 d$ and $5 b$ ). One week after $\mathrm{MI}$, this nectotic area was larger in GM6001 treated animals compared to the controls (GM vs control: $0.84 \pm 0.07$ vs $\left.0.37 \pm 0.04 \mathrm{~mm}^{2}, \mathrm{n}=4-5, \mathrm{p}<0.05\right)$. Two weeks after MI, when the gross amount of necrotic cardiomyocytes had been removed, the necrotic areas were no longer significantly different (GM vs control: $0.13 \pm 0.05$ vs $0.08 \pm 0.03 \mathrm{~mm}^{2}, \mathrm{n}=8$ per group, $\mathrm{p}=0.2)$. GM6001 also reduced total cell number, the number of myofibroblasts and macrophages in 7 days old infarcts (table 2 and figures $4 \mathrm{~g}-1$ ). After 14 days, the cellular composition of the GM6001 treated infarcts was no longer different compared to the control infarcts.

\section{Cardiac function}

Cardiac function was evaluated 2 weeks after surgery by measuring cardiac index (figure 6) and SV index (table 3) at rest and after volume loading. In both treatment groups, MI blunted the increase in cardiac index after volume overload. Interestingly, in the GM6001 infarct group, cardiac index was significantly lower, both in rest and after volume overload when compared to the corresponding infarct group. This was mainly due to a decrease in stroke volume, since GM6001 had no effect on heart rate. In addition, no difference in MAP was observed between the GM6001 and control groups.

\section{DISCUSSION}

\section{MMP activities in the infarcted mouse heart}

The upregulation of the activated forms of MMPs in the infarcted mouse heart in the present study corresponds with data published in other species ${ }^{96,102,105}$. The early activation of MMP-9 and MMP-3 after MI corresponds with the period of ECM degtadation and the invasion of inflammatory cells into the infarct ${ }^{43}$. Heymans et al. recently demonstrated that MMP-9 is synthesized by macrophages and leukocytes ${ }^{204}$. In addition, MMP-9, but not MMP-3 deficiency in mice resulted in slightly reduced $(18 \%)$ infiltration of 


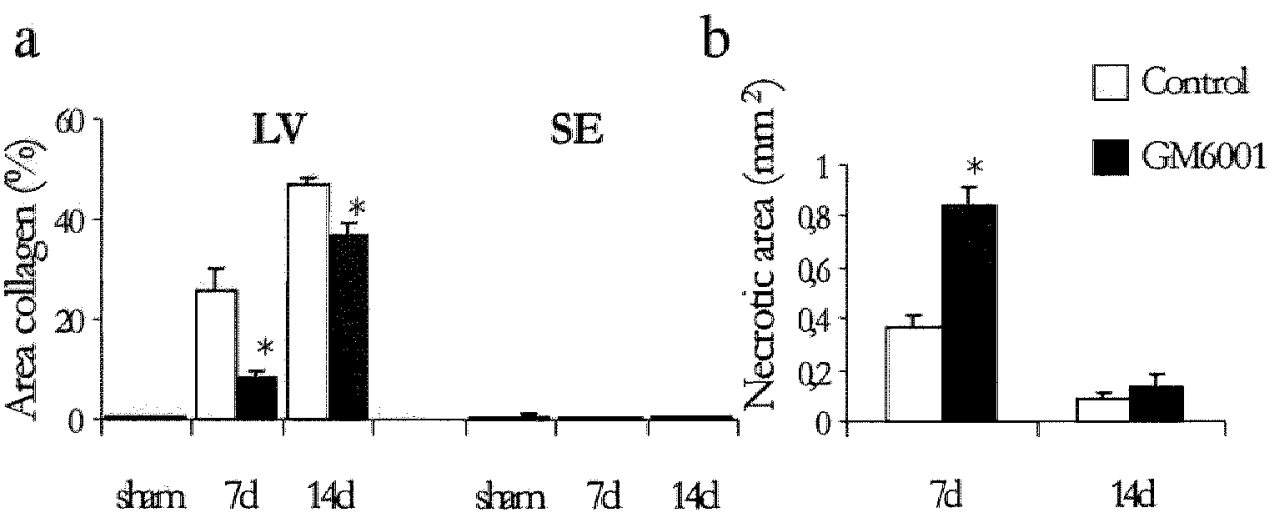

\section{Figure 5 - Collagen deposition and areas of necrosis}

a. Quantification of sirius red stainings show depressed collagen deposition in the center of the infarcts of GM6001 treated mice. This reduction was most prominent 7 days after MI. b. Larger areas of necrotic cardiomyocytes were observed in the infarcts of GM6001 treated mice, when compared to control treated mice. $\mathrm{p}<0.05$ compared to control MI.

inflammatory cells into the infarct, indicating that MMP-9 facilitates migration of inflammatory cells through the ECM ${ }^{204}$. Constant levels of MMP-3 and MMP-9 mRNA expression after MI in the present study indicate that the increase in MMP-3 and MMP-9 activity is not due to increased mRNA trancription, but rather due to increased activation of the latent pool of MMPs, which is assumed to be present in the heart ${ }^{5 / 6}$. The mRNA expression of MMP-13, the only collagenase present in rodents, was already increased 1

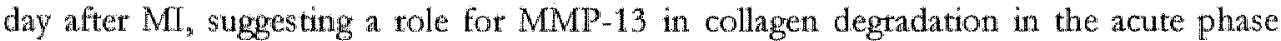
postinfarction. Further studies are needed to determine whether the increase in MMP-13 transcription also results in increased presence of the MMP-13 protein.

The activity of MMP-2 peaked at day 7, which is much later than the other MMPs in the present study, and which suggests a function for this gelatinase during the period of the formation of granulation tissue.

\section{MMP inhibitor study}

Proteolytic degradation of ECM components is an essential feature during wound healing in various tissues. MMPs may be involved in various aspects of wound healing: 1) degradation of ECM components in the acute inflammatory phase, 2) promotion of cell migration ${ }^{86,89}$, 3) regulation of the activity of certain growth factors, like TNF- $\alpha$, TGF $-\beta$ and $I L-1 \beta,{ }^{81}$ 4) initiation and promotion of angiogenesis ${ }^{15}$, 5) remodeling of newly synthesized connective tissue $e^{9 / 2}$.

We investigated the hypothesis that chronic MMP inhibition influences long-term LV 
Table 2. Cellular composition of 1 and 2 week old infarcts

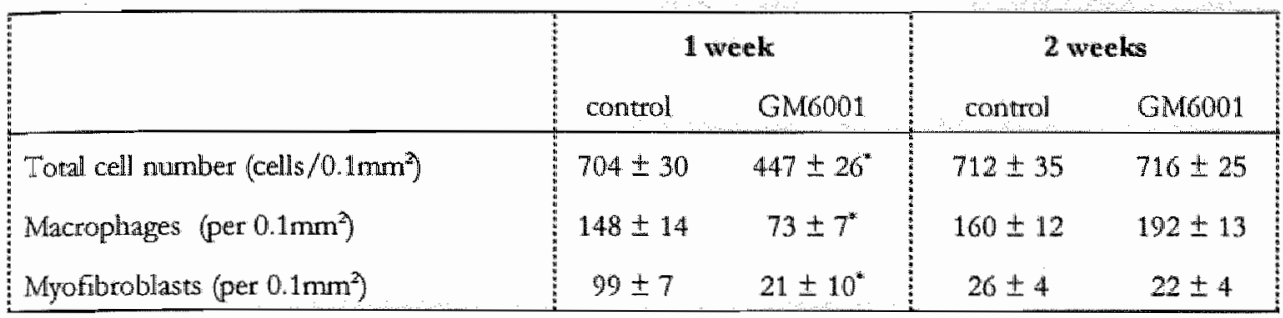

*: $p<0.05$ compared to control MI group

remodeling and demonstrated that chronic MMP inhibition attenuates both LV dilatation and thinning of the infarcted wall. Attenuated LV dilatation after MMP inhibitor treatment might be explained by preservation of the ECM in the infarctzone, early after MI. This might prevent cardiomyocyte slippage, which is an important determinant of $\mathrm{LV}$ dilatation ${ }^{197}$. The larger necrotic areas in the GM6001 group probably account for the thicker infarcts and suggest an altered infarct healing. Larger necrotic areas, decreased cell numbers, the reduction in collagen deposition 7 days after MI and normalization of these parameters at day 14 , indicate that cardiac wound healing is delayed, but not inhibited after MMP inhibitor treatment.

The negative effects of MMP inhibition on collagen deposition in the present study may seem paradoxical, since it may be expected that MMP inhibition should inhibit collagen degradation and thus promote collagen accumulation. An inhibitory effect of MMP inhibition on collagen deposition is however not new, since GM6001 treatment has comparable effects during neointima formation ${ }^{90}$. There are several possible explanations for these effects of MMP inhibition. First, the delay in healing in the present study reduced the number of myofibroblast-like cells in the infarct. Since myofilbroblasts are the main cell type responsible for collagen synthesis ${ }^{179}$, lower numbers result in a reduction in collagen deposition. Alternatively, MMPS may interfere with other pathways than ECM degradation, that are active during the repair process of the heart. In this view, MMPs regulate the activity of certain gtowth factots, like TNF- $\alpha$, TGF- $\beta$ and IL-1 $\beta^{\text {Bt, } 82}$. Decreased activity of TGF- $\beta$ might reduce the synthesis of new collagen fibers ${ }^{2015}$.

Delayed wound healing by MMP inhibition has also been demonstrated in vascular and dermal wound healing studies, where MMP activity facilitated the migration of intlammatory cells and smooth muscle cells ${ }^{86,89,96}$. It recently became evident that proteolytic enzymes play an essential role in infarct healing. Infarct induction in plasminogen deficient mice and urokinase plasminogen activator (uPA) deficient mice resulted in complete inhibition of infarct healing ${ }^{204,206}$. In addition, adenoviral gene transfer of TIMP-1 delayed infarct healing. The fact that plasmin is an important activator for most MMPs, and the observation that MMP-9 activity was reduced in the infarcts of uPA deficient mice ${ }^{204}$, indicate that the absent infarct healing in plasminogen or uPA deficient mice is, at least partly, mediated through reduced MMP activity. Thus, pharmacological intervention using an broad range MMP inhibitor has similar, although 
Table 3. The effects of GM6001 on stroke volume index (i.e. SV/BW), heart rate and mean arterial pressure (MAP) in rest and after maximal stimulation, 2 weeks after surgery.

\begin{tabular}{|c|c|c|c|c|c|c|c|}
\hline & \multicolumn{2}{|c|}{$\begin{array}{c}\text { SV indlex } \\
(\mu / \text { beat/gram bodyweight) }\end{array}$} & \multicolumn{2}{|c|}{$\begin{array}{c}\mathrm{MAP} \\
(\mathrm{mmHg})\end{array}$} & \multicolumn{2}{|c|}{$\begin{array}{l}\text { Heart rate } \\
\text { (beats/min) }\end{array}$} \\
\hline & & rest & $\max$ & rest & $\max$ & rest & $\max$ \\
\hline \multirow[t]{2}{*}{ control } & sham & $0.43 \pm 0.02$ & $1.13 \pm 0.05$ & $46 \pm 4$ & $70 \pm 9$ & $514 \pm 25$ & $482 \pm 18$ \\
\hline & MI & $0.39 \pm 0.03$ & $0.87 \pm 0.06^{*}$ & $37 \pm 3$ & $52 \pm 4 *$ & $518 \pm 14$ & $497 \pm 11$ \\
\hline \multirow[t]{2}{*}{ GM6001 } & sham & $0.42 \pm 0.06$ & $0.95 \pm 0.08$ & $47 \pm 4$ & $60 \pm 5$ & $523 \pm 44$ & $512 \pm 32$ \\
\hline & $\mathrm{MI}$ & $0.26 \pm 0.03^{*}$ & $0.66 \pm 0.06 * t$ & $42 \pm 4$ & $54 \pm 5$ & $518 \pm 25$ & $477 \pm 26^{*}$ \\
\hline
\end{tabular}

$* \mathrm{p}<0.05$ compared to corresponding sham; $; \mathrm{p}<0.05$ compared to corresponding control group

transient effects on infarct healing as adenoviral TIMP gene transfer and uPA/plasminogen gene deficiency.

\section{Cardiac function}

The extent of LV dilatation of the heart in response to $M I$ is an accurate predictor of the development of heart failure ${ }^{168}$. In this regard, on the basis of the favorable effects of MMP inhibition on LV remodeling in the present study and in two previous studies ${ }^{106,198}$, MMP inhibitors might emerge as a potential therapy for parients at risk for the development of heart failure. However, the present study demonstrates that MMP inhibition after MI deteriorates cardiac function, both at test and after maximal stimulation of the heart. Reduced collagen deposition in the infarcts of MMP inhibitor treated mice might offer a possible explanation for the lowered cardiac index. Decreased collagen content in the infarctzone increases the compliance of the infarct zone, which results in mechanical disadvantages compared to the control mice, where extensive collagen deposition produces a stiffer infarct ${ }^{207,208}$. Thus, the present study indicates that the use of MMP' inhibitors as potential therapeutic agents for heart failure should be applied with caution, since they may depress cardiac function.

Figure 4 - Structural analysis of control and GM6001 treated hearts, 7 days postMI

and $b$. AZAN stained cardiac tissue sections reveal reduced wall thinning and $L V$ dilatation after GM6001 treatment. $\mathrm{c}$ and d. HE staining demonstrates less cellular infiltration and larger necrotic areas in the center of the infarcts of GM6001 treated mice. Bar represent $100 \mu \mathrm{m}$. e and $\mathrm{f}$. Sirius red staining shows extensive collagen deposition in the center of control infarcts and only little in GM6001 infarcts. $g$ and $\mathbf{h}$. The number of asma positive fibroblast-like cells in the infarcts of GM6001 treated mice is extremely reduced compared to the control treated infarcts. $i$ and $\mathbf{j}$. MOMA-2 immunohistochemistry reveals less infiltrating macrophages into the GM6001 infarcts. Bar represents $100 \mathrm{~mm}$. 


\section{Control}

a
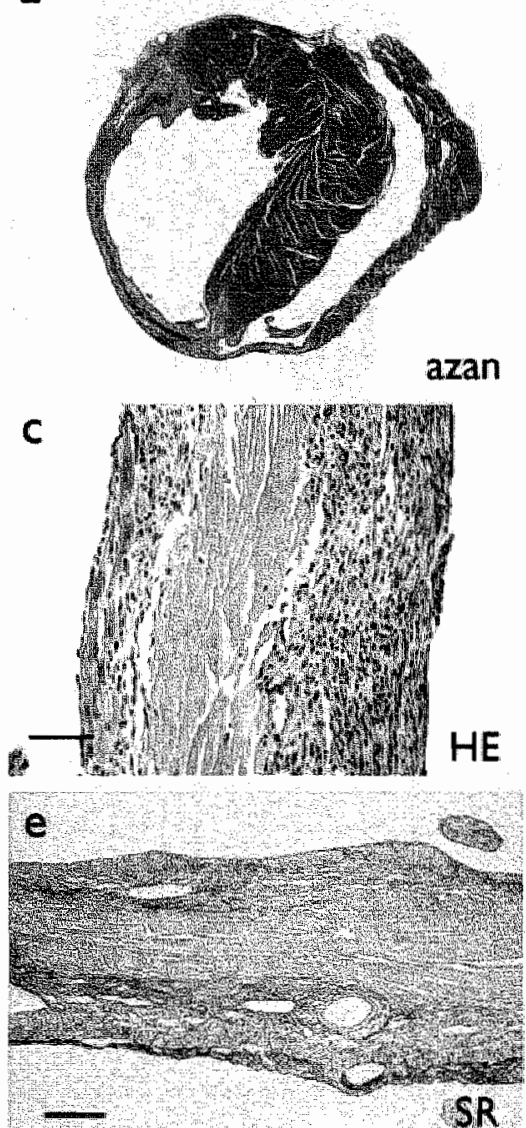

b

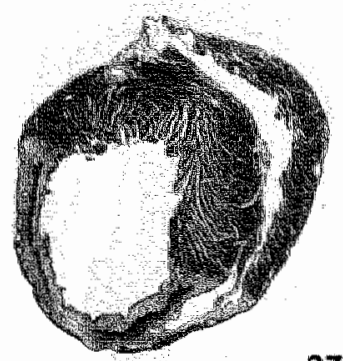

azan

\section{GM6001}

$b$
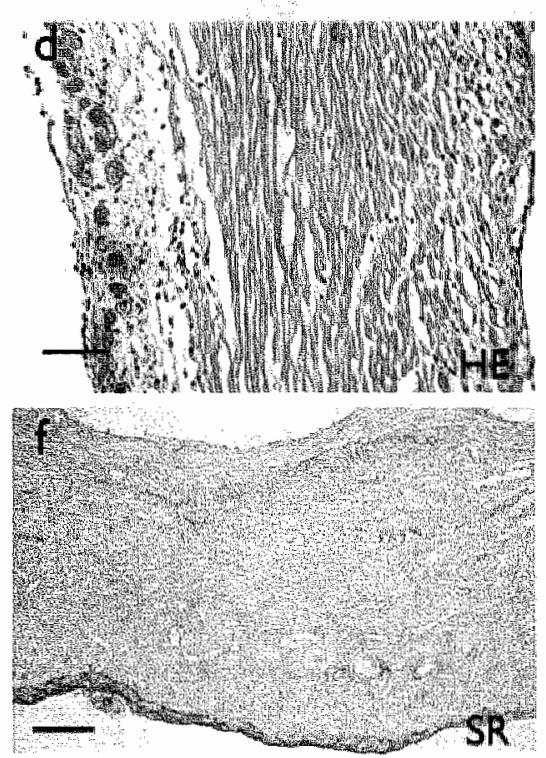

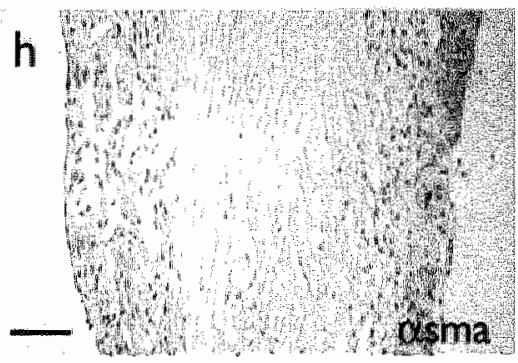

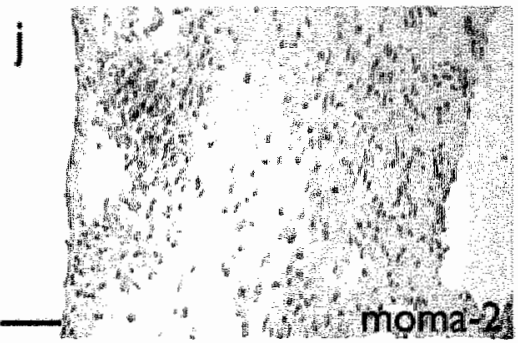




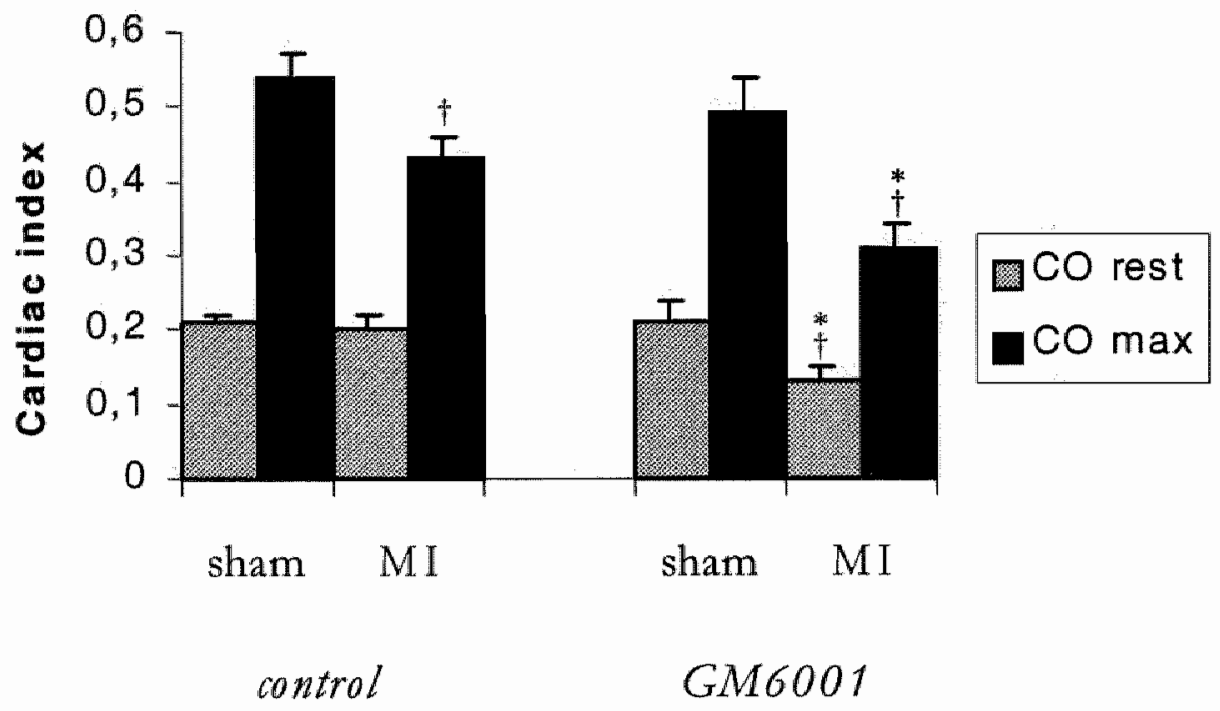

Figure 6 - Cardiac index

GM6001 tratment depressed cardrac index (in $\mu / \mathrm{min} / \mathrm{gr}$ BW), 2 weeks after $\mathrm{MI}_{n}$ both in rest and after maximal stimulation (2.5 mL, fluid load in 1 minute). * $p<0.05$ compared to control M, t: $p<0.05$ compared to matching shams.

\section{Conchusions}

In the mouse heart, MMP activity is elevated in the first weeks after MI and administration of a MMP inhibitor attenuates LV remodeling, reduces the rate of infarct healing and depresses cardiac function after MI. 


\section{Chapter 4}

Preliminary observations on the effects of adenoviral gene transfer of a plasmin-inhibitor after myocardial infarction in the mouse 


\section{SUMMARY}

This study was set-up to investigate the role of the plasminogen system in the wound healing response of the mouse heart after myocardial infarction. For this purpose a recombinant adenovirus encoding a hybrid protein (adATF.BPTD) consisting of the receptor binding domain of $\mathrm{UPA}$ linked to a potent plasmin inhibitor, or a control adenovirus were injected 7 days before coronary artery ligation. Both control and adATF.BPTI injection resulted in high mortality, mainly during the first few hours after coronary artery ligation. Nevertheless, analysis of the hearts of mice that survived the complete experiment demonstrated that infarct healing was not affected at 7 days after infarction, by adATF.BPTI infection. In conclusion, our pteliminary observations on the effects of systemic adenoviral gene transfer of a plasmin inhibitor during the healing phase of the heart after myocardial infarction, indicate high mortality, but no effect on infarct healing. 


\section{INTRODUCTION}

The generation of plasmin is primarily controlled by the balance between the plasminogen activators ( $\mathrm{PPA}$ and $\mathrm{uPA}$ ) and their physiological inhibitors, the plasminogen activator inhibitors (PAIs). The two distinct plasminogen activators have different biological functions. Whereas $\mathrm{PA}$ is primarily involved in clot dissolution, uPA binds to a specific cell-surface receptor (UPAR) and is predominant in tissue remodeling ${ }^{209}$. Since uPAR does not have a transmembrane domain and is therefore not directly coupled to an intracellular adaptor, the major function of UPAR is assumed to be to focus the proteolytic activity to the cell surface. In addition, recent studies have demonstrated that UPAR has other functions, like the regulation of cellular adhesion and migration by associating with the extracellular domains of integrins and by binding directly to vitronectin, an abundant ECM glycoprotein ${ }^{126,210}$.

The functional role of the plasminogen/plasmin system has been studied in several models associated with wound healing and inflammation. For example, in plasminogen deficient mice, vascular wound healing was significantly impaired as a consequence of delayed removal of necrotic debris, reduced leukocyte infiltration and smooth muscle cell migration ${ }^{159}$. This effect was mediated by $u P A$, since reduced neointima formation was also observed in uPA deficient mice but not in TPA deficient mice.

To a large extent, the wound healing response of the heart after myocardial infarction resembles the normal response of parenchymatous tissue to injury including the invasion of inflammatory cells into the affected myocardium, fibroblast proliferation and angiogenesis ${ }^{211}$. Based on the fact that plasmin plays a pivotal role in cell migration in other wound healing models, we considered that plasmin-mediated proteolysis could also be important in cardiac tissue temodeling ${ }^{159,161,187,188,212}$. In the previous chapter we have demonstrated that inhibition of MMP activity resulted in a delay in infarct healing due to a decrease in cell migration. Since plasmin is an important activator for MMPs, we hypothesized that plasmin inhibition would also delay infarct healing.

In the present study, we investigated the role of the plasminogen system in the wound healing response of the mouse heart after coronary artery ligation. For this purpose we used a recombinant adenovinus encoding a hybrid protein consisting of the receptorbinding domain of UPA linked to a potent plasmin inhibitor. This hybrid protein can not only inhibit the activity of plasmin directly at the cell surface but also can compete with UPA for binding to its receptor.

\section{MATERIALS AND METHODS}

\section{Animals}

Male mice (C57-BL/6), 10-12 weeks old at the start of the experiments were used. Housing and procedures involving experimental animals were performed in accordance with local institutional guidelines and approved by the Committee for Animal Experiments of the University of Maastricht. 


\section{Experimental protocol}

A recombinant adenovirus (adATF.BPTI) encoding a hybrid protein consisting of the receptor binding aminoterminal fragment of urokinase (ATF) linked to the mature protein of bovine pancreas trypsin inhibitor (BPTI) and a control adenovinus lacking a transgene were a kind gift of P.H.A. Quax (TNO Leiden, the Netherlands) ${ }^{213}$. BPTI, also known as Trasylol, is a potent plasmin inhibitor. Cells transduced with this adenovirus produce a plasmin inhibitor that can also bind the urokinase receptor.

Seven days before coronary artery ligation either adATF.BPTI $\left(1 \times 10^{10} \mathrm{pfu} / \mathrm{ml}, 200 \mu \mathrm{l}\right)$ or the control adenovirus (ad.control: $1 \times 10^{10} \mathrm{pfu} / \mathrm{ml}, 200 \mu \mathrm{l}$ ) were injected into the tail vein. Blood was drawn from the retro-orbital plexus of each mouse, 3,7 and 14 days after adenovirus injection. For the quantification of ATF.BPTI protein levels in plasma, an ELISA was set-up using a monoclonal antibody against the aminoterminal fragment of UPA as a catching antibody and a rabbit polyclonal against aprotinin as a detecting antibody ${ }^{252}$. For quantification a standard of ATF.BPTI was prepared by infection of CHO cells, of which the ATF concentration was determined using an uPA-ELISA.

\section{Cotonary artery ligation.}

To induce a myocardial infarction, we used a recently developed methodology ${ }^{199}$. In short, the animals were anaesthetized with Ketamine $(0.1 \mu \mathrm{g} / \mathrm{gt}$ bodyweight) and Xylazine (50 $\mu \mathrm{g} / \mathrm{g}$ bodyweight) and ventilated by positive pressure $(1.5 \mathrm{ml} / \mathrm{stroke} ; 70$ strokes $/ \mathrm{min}$ ) through an endotracheal tube. Via a thoracotomy and opening of the pericardium, a myocardial infarction (MI) was induced by permanent ligation of the main left coronary artery. After ligation, the thorax was closed and the skin sutured. The sham operated animals underwent an identical surgical procedure, except placement of the ligature. Animals were killed 1 week after surgery ( $\mathrm{n}=12$ per group).

\section{Tissue processing.}

Seven days after MI (i.e. 14 days after adenovirus injection), animals were sacrified, under pentobarbital aneasthesia, by arresting their hearts in diastole after injecting $0.5 \mathrm{ml} 0.1 \mathrm{M}$ cadmium chloride directly into the heart. Subsequently, the heart was perfused with Phosphate Buffered Saline, pH 7.4 (PBS), followed by 5\% phosphate buffered formalin (5 min each) at a pressure of $100 \mathrm{mmHg}$. To ensure maximal vasodilatation, sodium nittoprusside ( $0.1 \mathrm{mg} / \mathrm{ml}$, Sigma, St Louis, MO, USA) was added to both perfusion solutions. Heart and lungs were excised and weighed. Hearts were fixed by immersion into $10 \%$ phosphate buffered formalin during 24 hours, processed and embedded in paraffin according to routine histological procedures.

\section{RESULTS}

\section{Survival}

A total of 24 mice underwent coronary artery ligation, of which 12 received control virus and 12 were subjected to adATF.BPTI treatment. 13 mice died within a few hours after surgery ( 6 had received adATF.BPTI and 7 control virus). An additional 5 animals died between 3-5 days after surgery due to cardiac rupture ( 3 received adATF.BPTI and 2 
Table 1. Mortality of adenovirus treated mice (days after MI)

\begin{tabular}{|l|ccc|c|}
\hline & \multicolumn{3}{|c|}{ numbers of deaths } & survival \\
& first few hours & $2-3$ days & rupture $(3-5$ days $)$ & 7 days \\
\hline adATFBPT $(\mathrm{n}=12)$ & 6 & 1 & 3 & 2 \\
adControl $(\mathrm{n}=12)$ & 7 & 1 & 2 & 2 \\
\hline
\end{tabular}

control virus). 2 animals died 2-3 days after MI, from unknown causes $(1$ received adATF.BPTI and 1 control virus). Finally, 4 animals survived the complete experiment (2 received adATF.BPTI and 2 control virus), and were sacrificed 7 days after MI (table 1).

\section{Plasma levels of ATF.BPTI}

Plasma levels of ATF.BPTI were determined by ELISA, 7 and 14 days after adenovirus injection in both treatment groups (table 2). High plasma levels of ATF.BPTI persisted. for at least 14 days after ad.ATF.BPTI injection. Unfortunately, 1 of the 2 animals of the adATF.BPTI group, that survived the myocardial infarction for 7 days (i.e. 14 days after virus injection), died spontaneously, a few hours before it was to be sacrificed and blood should be drawn. For this reason, we could not determine plasma ATF.BPTI levels, at the 14 days time point from this animal. However, we did use its heart for histochemical analysis.

\section{Histological analysis of the heart and liver}

We performed histological analysis on the 4 infarcted hearts that had survived the complete experiment. On Heamatoxilin \& Eosin (H\&E) stained sections, adATF.BPTI had not induced differences in cellular infiltration into the infarct zone. In addition, the residual necrotic area was not obviously different between the two treatment gtoups (Figure 1). Administration of the adenovirus vector was associated with substantial liver pathology. Microscopic analysis of H\&E stained sections of the liver tevealed infiltrates of inflammatory cells at the time of MI surgery, 7 days after virus injection (not shown).

\section{DISCUSSION}

The plasminogen system has been implicated in several models associated with wound healing and inflammation (dermal wound healing and neointima formation) ${ }^{159,161}$. The adenovirus used in the present study, adATF.BPTI, was previously succesfully tested ex vivo, in an organ culture of human saphenous vein, the vessel commonly used as by-pass vein graft. In these organ cultures, adATF.BPTI at $10^{10} \mathrm{pfu} / \mathrm{ml}$, resulted in a strong reduction $(>85 \%)$ of neointima formation, when compared to control virus treatment ${ }^{213}$. Since infarct healing after $M I$ can also be regarded as a response of wound healing and inflammation, we hypothesized that plasmin inhibition by adATF.BPTI would attenuate 
Table 2. Plasma ATFBPTI levels determined by ELISA, 7 and 14 days after vinus injection

\begin{tabular}{|l|cc|}
\hline & \multicolumn{2}{|c|}{ ATF.BPTI levels $(\mathrm{ng} / \mathrm{ml})$} \\
& 7 days after injection & 14 days after injection \\
\hline adATEE.BPT & $46.2 \pm 12.3(\mathrm{n}=9)$ & $44.5(\mathrm{n}=1)$ \\
adControl & $0.9 \pm 1.9(\mathrm{n}=8)$ & $0.4 \pm 0.5(\mathrm{n}=2)$ \\
\hline
\end{tabular}

infarct healing. Out preliminary observations suggest that this hypothesis should be rejected.

Several explanations can be given for the fact that adenoviral gene transfer of the plasmin inhibitot ATF.BPTI did not result in delayed infarct healing. First, we cannot prove that the plasmin inhibitor had reached the ischemic area in high enough

concentrations. Since approximately $95 \%$ of the injected adenovirus goes to the liver, hepatocytes are the main cells transfected ${ }^{214}$, resulting in the synthesis of ATF.BPTI by the liver. Since the coronary artery is ligated, the protein might not have acces to the infarct zone in high enough concentrations, thereby preventing an effect on infarct healing. Although the adenovirus was injected 7 days before infarct surgery, providing sufficient time for $\mathrm{A}^{\prime} \mathrm{TF} . \mathrm{BP} \mathrm{P}^{\mathrm{T}} \mathrm{I}$ to reach the future infarct zone, cotonary artery ligation may have ended the continuous delivery of newly synthesized ATF.BPTI into this part of the myocardium. For local action of ATF.BPTI as a plasmin inhibitor it needs to bind to the uPAR. This uPAR is usually upregulated in areas of tissue remodeling. However, if UPAR upregulation occurs after ligation of the coronary artery, this would also prevent the circulating ATF.BPTI to reach the uPAR in the infarct zone. However, regarding the inhibitory effects of adenovinus mediated TTMP-1 and PAI-1 transfection on infarct healing in chapter 6 , acces of the protein to the infarct zone will probably not be a major issue in this study. Nevertheless, in follow up experiments, we will visualize the plasmin inhibitor in the myocardium, using a fluorescent label attached to the BPTI. Another possibility to overcome the problem of possible underperfusion is to choose another experimental model of myocardial healing, where the coronary artery is open. An example of such a model is the ischemia/reperfusion model.

A second explanation for the lack of effects of ATF.BPTI on infarct healing relates to the fact that this plasmin inhibitor might bind to the uPAR in other tissue than the heart. Until now, it is unknown, if and where uPAR is expressed in the heart after infarction. However, in UPAR-deficient mice, it was recently demonstrated that this receptor was not essentially involved in infarct healing ${ }^{204}$. Binding of ATF.BPTI to uPAR might therefore result in scavenging of ATF.BPTI to sites, other then where the plasmin activity is located and prevent the inhibition of plasmin activity.

The high mortality in this study could be caused by toxicity of the adenovectors used. Indeed, other studies have demonstrated that the window between an effective and a toxic dose of adenovirus is extremely narrow ${ }^{214}$. During the first few hours of infection, 

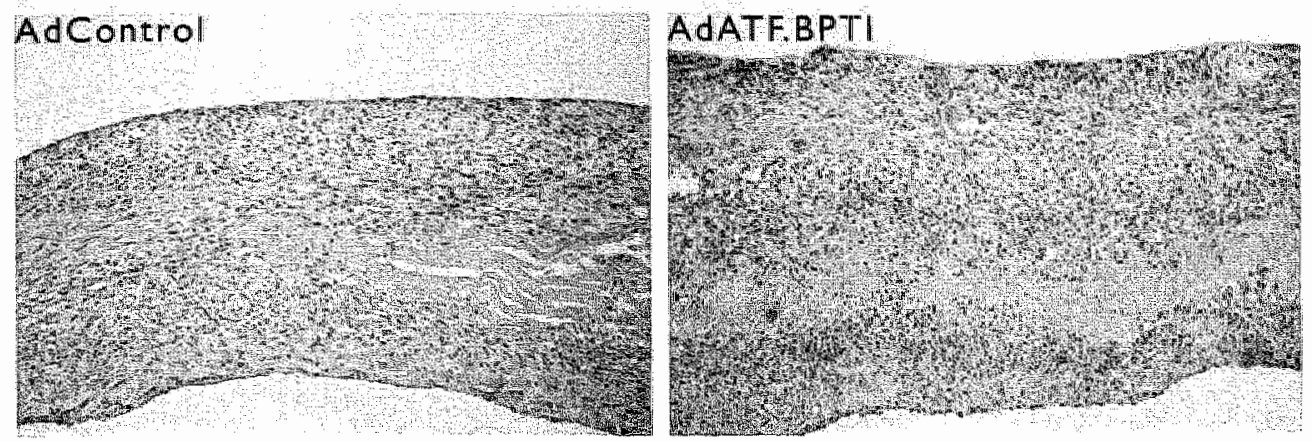

Figure 1 - H\&E stained sections of 7 days old infarcts after adControl and adATF.BPTI infection. Note that the infiltration of inflammatory cells is not reduced after adATF.BPTT infection, indicating that the rate of infarct healing is not atrenuated.

the adenovector proteins act directly on the hosts defence system, provoking an acutephase immune reponse marked by rapid release of inflammatory cytokines, including II 6 and IL-8. Over the next 1 to 4 days, most of the vector associated toxicity can be attributed to cellulat production of adenoviral late proteins involved in the assembly of the viral coat. Subsequenty, the immune system recognizes and destroys adenoviral peptides on the surface of the infected cell. This late phase toxicity may be associated with hepatocyte hypertrophy and hepatic fibrosis ${ }^{215}, 216$. Inflammatory infiltrates in the liver in the present study, 7 days after adATT.BPTI injection, indicates toxicity of the adenovector as a prominent side effect. Whether this toxicity in combination with infarct surgery has resulted in the high mortality remains speculative. In addition, hepatic abnormalities may have resulted in reduced clearance of anesthetics and/ot metabolites.

Cardiac rupture, which appears to occur in $\mathrm{C} 57 / \mathrm{B1}-6$ mice, is probably related to the genetic background of the animals, since cardiac rupture does not occur in Swiss mice (of chapter 3) used in the previous chapter. It probably does not relate to the expression of the plasmin inhibitor, since rupture occurred in comparable numbers in both adenovirus groups.

In conclusion, our preliminary experiments on the effects of adenoviral gene transfer of a plasmin inhibitor during the healing phase of the heart after myocardial infarction, showed high mortality, but no effect on infarct healing. However, several kinetic issues related to gene delivery remain to be addressed. 



\section{Chapter 5}

Disruption of the plasminogen gene in mice abolishes wound healing following myocardial infarction

(American Journal of Patbology, in press) 


\section{SUMMARY}

Background The plasminogen system plays an important role in the proteolytic degradation of extracellular matrices during wound healing. In the present study we investigated the impact of the plasminogen system on cardiac wound healing and function after myocardial infarction.

Methods and Results Myocardial infarction was induced in plasminogen deficient mice (Plg-/-) and in wild-type controls $(\mathrm{Plg}+/+)$. Structural analyis 1,2 and 5 weeks after infarction, revealed that infarct healing was virtually abolished in $\mathrm{Plg}-/$ - mice, indicating that the plasminogen system is required for the repair process of the heart after infarction. In the absence of plasminogen, intlammatory cells did not migrate into the infarcted myocardium. Necrotic cardiomyocytes were not removed and the formation of granulation tissue and fibrous tissue did not occur. In these non-healling infarcted hearts, LV dilatation was not altered. In addition, gelatinolytic activity of MMP-2 and MMP-9 was depressed in the Plg-/ infarcted hearts, suggesting that the plasmin effect on infarct healing may be mediated by MMPs. Surprisingly, cardiac function was only attenuated to a rather small extent in the $\mathrm{Plg} / \mathrm{-}$ - infarcted mice when compared to the wild-types.

Conchusions This study provides direct prove that plasmin mediated proteolysis plays a central role in cardiac wound healing after myocardial infarction in mice. 


\section{INTRODUCTION}

Myocardial infarction (MI) leads to necrosis of cardiomyocytes in the ischemic ventricle and is followed by a wound healing response. This response generally resembles that of parenchymatous tissue to ischemic injury, including migration of inflammatory cells into the affected myocardium, extacellular matrix degradation, fibroblast proliferation and angiogenesis. On the other hand, cardiac wound healing has several unique characteristics such as the sustained presence of myofibroblasts in the infarcted myocardium ${ }^{166}$ and the fact that cardiomyocytes are terminally differentiated cells, which have lost the ability to divide. Myocardial healing is therefore independent of cardiomyocyte regeneration, but depends on the formation of granulation tissue. The mechanisms responsible for inflammatory and reparative phases of healing following myocardial infarction are not fully understood. However, recent evidence indicates an involvement of proteinases, including the plasminogen activators and metalloproteinase systems, in the process of extracellular matrix degradation and cell migtation during cardiac wound healing ${ }^{204}$. Plasmin, generated from plasminogen, is the active enzyme of the plasminogen/plasmin. system and degrades a variety of extracellular matrix (ECM) components ${ }^{4}$. A relevant feature of plastmin is the proteolytic amplification which can be achieved by activating several matrix metalloproteinases (MMPs), which are also involved in the degradation of extracellular matrix components ${ }^{190}$. The generation of plasmin is primarily controlled by the balance between the plasminogen activators (t-PA and $u-P . A$ ) and their physiological inhibitors, the plasminogen activator inhibitors (PAIs) ${ }^{205}$. In a tecent study, Heymans et al demonstrated that mice deficient in $u-P A$ showed impaired infarct healing and were completely protected against cardiac rupture after induction of a myocardial infarction ${ }^{204}$. It is unknown whether this prominent effect of $\mathrm{u}-\mathrm{PA}$ in infarct healing is mediated through the activation of plasminogen. In the present study we further investigated the tole of the plasminogen system in infarct healing and function, in a model of chronic myocardial infarction in plasminogen deficient mice.

\section{METHODS}

Plasminogen deficient (Plg- $/-$ ) mice were developed and characterized as described previously ${ }^{158}$. Plasmin activity was unmeasurable in $\mathrm{Plg}-/$ - mice $(<5 \%$ of $\mathrm{Plg}+/+$ mice $)$ and neither plasminogen mRNA nor translation products could be identified by Northern of Westem blot of liver extracts from Plg- $/$ - mice ${ }^{158}$. The sane strain of mice has been used in the present study in which we did not measure plasminogen levels. Plg/- mice survive embryonic development but develop spontaneous fibrin deposition due to impaired thrombolysis and suffer retarded growth and reduced fertility and survival ${ }^{15 s}$ " In Plg-/ and in wild-type controls cardiac wound healing was studied, 1 week $(n=2$ per group), 2 weeks ( $n=8-10$ per group) and 5 weeks $(n=5-7$ per group) after induction of the infarct. Survival was not different between the two infarct groups, respectively $70 \%$ and $77 \%$ in $\mathrm{Pg}-/$ - and $\mathrm{Plg}+/+$ infarcted mice. Mortality was highest within the first hours after surgery. Only one wild-type animal died after this period, on day 5 , due to cardiac rupture. Equal numbers of sham operated $\mathrm{Pg} /-$ and $\mathrm{Plg}+/+$ animals served as controls. 
All experiments were performed according to the guidelines of the institutional animal care committec. MI was induced surgically, by permanent ligation of the main left coronary artery as recently described ${ }^{159}$. Tissue processing and architectural measurements were adapted from the same study.

\section{Infusion of $5^{\prime}$-bromo-2'-deoxyuridine (BrdU)}

To label DNA-synthesizing cells, all animals in the 2 weeks post-MI and sham group received 5'-bromo-2'-deoxyuridine (BrdU, Serva, Heidelberg, Germany; infusion rate 13 $\mathrm{mg} / \mathrm{kg} / \mathrm{day}$ ) from an osmotic minipump (Alzet 2001, Alza Corporation, Palo Alto, CA, USA), seven days before sacrifice.

\section{Immunohistochemistry}

Immunohistochemistry was performed on both the 1,2 and 5 weeks group, using conventional methods to identify macrophages (moma-2 monoclonal antibody) ${ }^{202}$, endothelial cells (biotin labeled lectin from Bandeiraea Simplicifolia, Sigma Chemicals, St Louis, MO, USA) ) $^{217}$, smooth muscle cells and myofibroblasts (monoclonal anti- $x$-smooth muscle cell actin (asma), DAKO, Danmark), laminin (polyclonal anti-mouse laminin) ${ }^{218}$ and DNA synthesis (monoclonal anti-BrdU, Harlan Sera-Lab, Loughborough, England). For quantification of DNA synthesis, the total labeling fraction ( $L F=$ number of BrdUpositive/ total numbers of counted nuclei $x 100 \%$ ) of $\mathrm{BrdU}$ positive cells was calculated per $0.1 \mathrm{~mm}^{2}$ in the center and borderzones of the infarcts and in the non-infarcted septum. Apoptosis was studied in the 2 weeks post-surgery groups, by means of the Terminal Transferase dUTP Nick End Labeling (TUNEL) assay as described by Kockx et al $^{219}$. For quantification of apoptotic cells, total numbers of nuclei and percentage of Tunel positive nuclei were counted in the whole infarcted area. DNA synthesis and apoptosis were studied in the 2 week post-surgety groups.

\section{Myocardial MMP extraction and zymography}

A separate group of animals ( $6 \mathrm{Plg}-/-, 4 \mathrm{Plg}+/+$ ) was sacrificed, 2 weeks after surgery for myocardial MMP activity analysis. The hearts were perfused with saline and the LV free walls were rapidly frozen in liquid nitrogen and stored at $-80^{\circ} \mathrm{C}$. The frozen tissue was cut into small pieces, washed with cold saline and incubated in $100 \mu$ lextraction buffer $\left(10 \mathrm{mM}\right.$ cacodylic acid $(\mathrm{pH} .5 .0), 0.15 \mathrm{mM} \mathrm{NaCl}, 1 \mu \mathrm{M} \mathrm{ZnCl}_{2}, 20 \mathrm{mM} \mathrm{CaCl}_{2}, 1.5 \mathrm{mM} \mathrm{NaN}{ }_{3}$

\section{Figure 1 - Structural composition of the infarcts}

a and b) Hematoxilin and eosin stained sections of $\mathrm{Plg}+/+$ and $\mathrm{Plg}-/$ - infarcts, 2 weeks after $\mathrm{MI}$. In $\mathrm{Plg}+/+$ infarcts, the necrotic cardiomyocytes are replaced by granulation tissue, whereas in $\mathrm{Plg}-/$ - infarcts wound healing is absent. $\mathbf{c}$ and d) laminin, a basement membrane component encages normal cardiomyocytes $(\mathrm{Plg}+/+)$. In the center of 2 week old $\mathrm{Plg}-/$ - infarcts, these basement membranes are still present. The intensity of the staining however decreases in time. e and f) Sirus red staining, 2 weeks after MI shows extensive collagen deposition in the Plg $+/+$ infarcts and only little in the $\mathrm{Plg}-/$ - infarcts. $\mathrm{g}$ and h) In situ hybridization shows that type I collagen mRNA expression is more pronounced in 2 week old wild-type infarcts, than in 2 week old Plg- $/$ - infarcts. Bars represent $50 \mu \mathrm{m}$. $i$ and $i$ ) Infarcted hearts from $\mathrm{Plg}+/+$ and Plg- $/$ - mice, 5 weeks after surgery. Note the extensive infarct thinning in the wild-types, where the infarcted wall has almost become transparent. 


\section{PLG +/+}

\section{a}
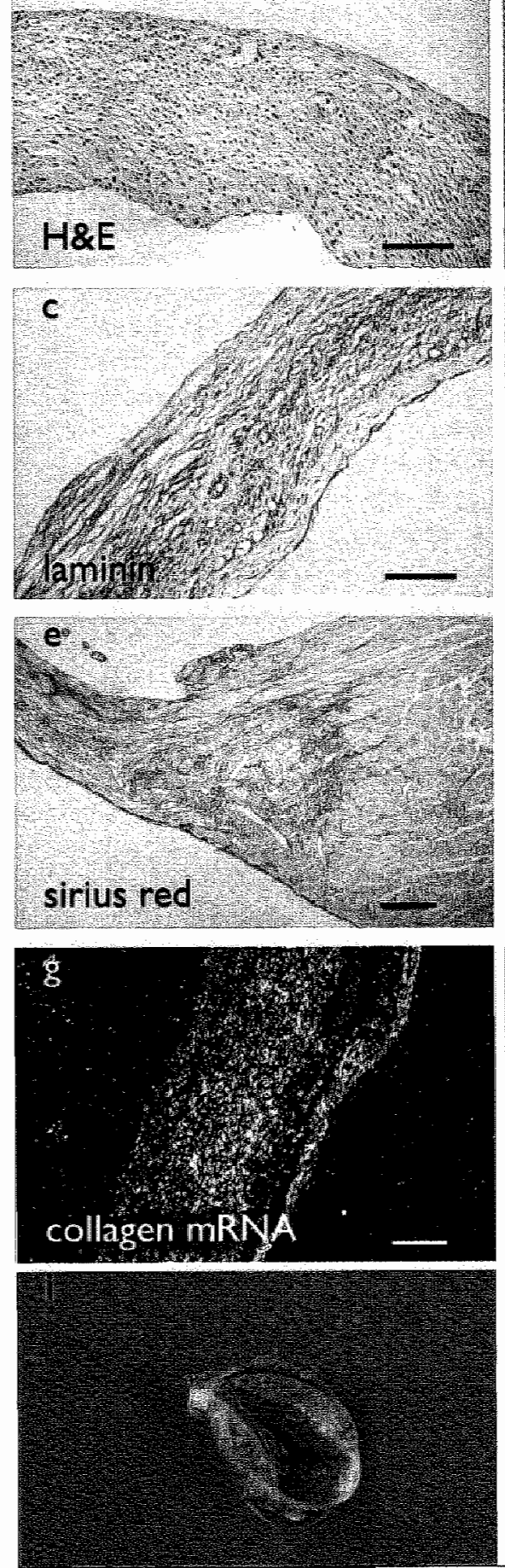

PLG -/-
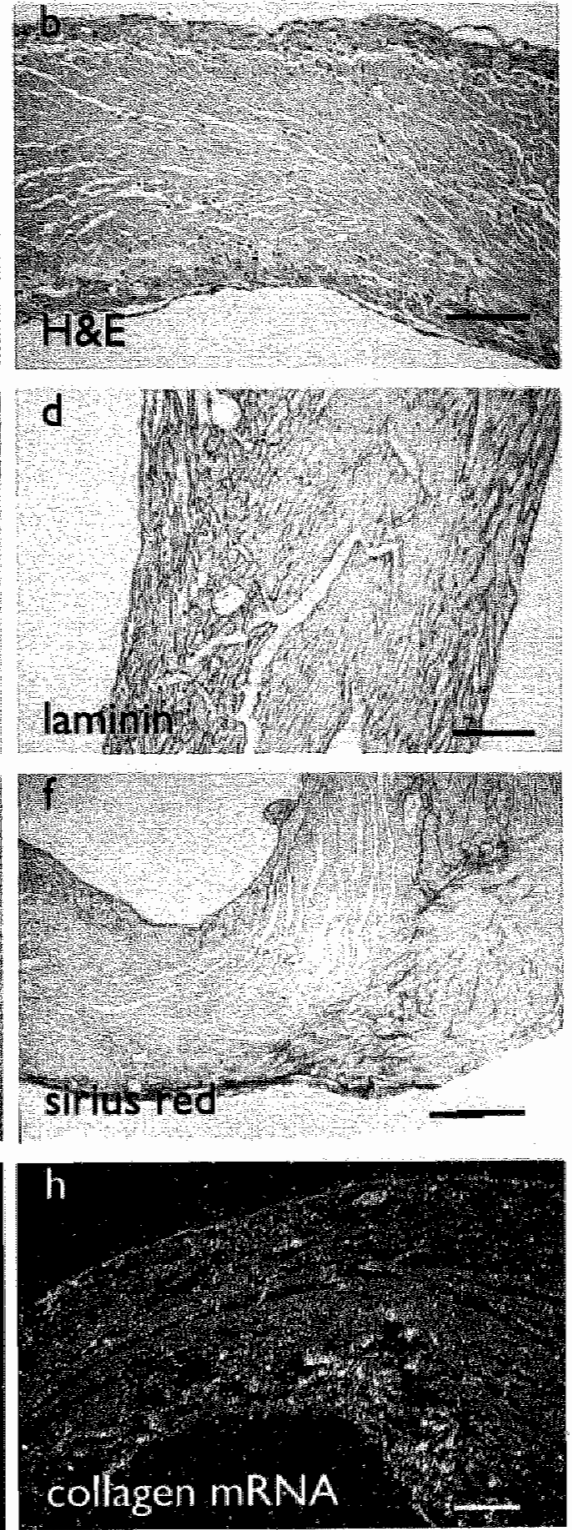
and $0.01 \%$ Triton $\mathrm{X}-100)$ per $10 \mathrm{mg}$ wet weight at $4{ }^{\circ} \mathrm{C}$ with continuous agitation for 24 $\mathrm{h}$. This step was repeated with fresh buffer. The extraction buffer was collected and $\mathrm{pH}$ raised to 7.5 by addition of $1 \mathrm{M}$ Tris, ( $\mathrm{pH} 8.0$ ). MMP activity was visualized using the zymography technique ${ }^{96}$. In short, $10 \mathrm{~kg}$ of myocardial protein extracts were loaded per lane onto electrophoretic gels (SDS-PAGE) containing gelatin $(0.66 \mathrm{mg} / \mathrm{ml})$. Following electrophoresis, gels were washed twice for $15 \mathrm{~min}$. with $2.5 \%$ Triton X-100 and inculbated overnight at $37^{\circ} \mathrm{C}$ in substrate buffer $(50 \mathrm{mM}$ Tris-HCl, $\mathrm{pH} 8.0,5 \mathrm{mM} \mathrm{CaCl}$, $0.02 \%$ sodiumnitrate). After incubation, gels were stained for $30 \mathrm{~min}$ in $0.05 \%$ Coomassie blue $\mathrm{R} 250$ in acetic acid:methanol water (1:4:5) and destained in the same solvent. In each gel a reference sample was used to normalize scanned lytic activities between gels.

\section{Hemodynamic measurements}

Cardiac output (CO) was evaluated in sham operated and infarcted mice, 2 weeks after surgery. In short, an electromagnetic flow-probe (1,2 mm; Skalar, Delft, The Netherlands) was placed on the ascending aorta, adjacent to its exit from the heart and connected to a Skalar MDL400 sine-wave flowmeter (Skalar). An abdominal aorta catheter was connected to a pressure transducer (micro-switch, model 156PC $156 \mathrm{WL}$, Honeywell Inc, Amsterdam, The Netherlands). Signals were sampled at a rate of $2 \mathrm{kHz}$ and fed into a personal computer for off-line analysis. After collecting base-line values of cardiac output $\left(\mathrm{CO}_{\text {rest }}\right)$ for 15 minutes, a rapid intravenous infusion ( $2.5 \mathrm{ml}$ in one minute) of a warm $\left(37^{\circ} \mathrm{C}\right)$ Ringer's solution was started. "This procedure increased $\mathrm{CO}$ to a plateau-value. In a pilot study, in Swiss mice, we observed an increase in CO from $7.9 \pm 0.4$ to $21.1 \pm 0.7$ $\mathrm{ml} / \mathrm{min}$ in sham operated mice and from $5.7 \pm 0.4$ to $15 \pm 1.4 \mathrm{ml} / \mathrm{min}$ in MI mice.

For pressure measurements, a separate group of animals ( $n=5-6$ per group) were anesthesized with urethane ( $2.1 \mathrm{mg} / \mathrm{g}$ bodyweight, subcutaneously, Sigma). A 1.4 French high-fidelity catheter tip micromanometer (SPR-671; Millar instruments, Houston, TX) was inserted through the right caroticl artery in the left ventricular cavity. Following hemodynamic stabilization, left ventricular pressure was sampled with a computer at a rate of $2 \mathrm{kHz}$, and stored for analysis of left ventricular systolic pressure (LVSP), enddiastolic pressure (LVEDP), and maximal positive ( $\mathrm{dP} / \mathrm{dt}_{\text {max }}$ ) rate of pressure development. Increasing amounts of dobutamine $(0.5,1.0,1.5,2,3 \mathrm{ng} / \mathrm{g} / \mathrm{min} ;$ Dobutrix, Lilly, Brussels, Belgium) were administered for 2 minutes each by continuous infusion in the left external jugular vein, via a catheter, which was connected to a Harvard microinjection purnp (Harvard Apparatus Inc, Hollyston, MA). Pressure measurements were performed after 90 seconds dobutamine infusion.

\section{Statistics}

All above described parameters were measured without knowledge of the treatment group. Data are expressed as mean \pm SEM. Means between groups were compared by the use of the Mann-Whitmey $U$ test. $A$ value of $\mathrm{P}<0.05$ was considered statistically significant. 


\section{RESULTS}

\section{Infarct healing is absent in Plg-/- mice}

Histological examination of the $\mathrm{Plg}-/$ - infarcts demonstrated a complete absence of cardiac wound healing and the persistence of necrotic cardiomyocytes in the center of the Plg-/ - infarcts, which remained present as "ghost cells" until at least 5 weeks after MI (figures $1 \mathrm{a}$ and $\mathrm{b}$ ). Both in $\mathrm{Plg} / /$ - and $\mathrm{Plg}+/+$ infarcts, $1-2$ cell layers of cardiomyocytes in endocardium and epicardium survived the MI. Also the basement membranes that surrounded the cardiomyocytes were still visual in the $\mathrm{Plg}-\mathrm{A}$ infarcts, as demonstrated by laminin immunohistochemistry 1,2 and 5 weeks after MI (figures $1 \mathrm{c}$ and d). The intensity of the laminin staining around the necrotic cardiomyocytes in Plg-/-infarcts was slightly decreased in time when compared to normal cardionyocytes. The absent wound healing in the Plg-/- mice was associated with a lack of influx of macrophages into the infarct. Also myofibroblasts and endothelial cells were scarcely present in the center of 2 and 5 weeks old Plg- $/$ - infarcts.

In Plg $+/+$ infarcts, the necrotic cardiomyocytes had been replaced by granulation tissue, containing abundant macrophages (figures $2 a$ and $b$ ), endothelial cells (lectin staining, data not shown), and $\alpha$-smooth muscle actin positive cells (e.g. myofibroblastlike cells and smooth muscle cells, figures $2 c$ and d).

\section{Fibrous tissue formation is abolished in PIg- $/$ - infarcts}

Sirius red staining demonstrated extensive collagen deposition in $\mathrm{Plg}+1+$ infarcts, but not in Plg- / infarcts, 2 weeks after surgery (figures $1 \mathrm{e}$ and $\mathrm{f}$ ). Quantification revealed relative collagen positive areas of $48.0 \pm 12.1 \%$ in the center of $\mathrm{Plg}+/+$ infarcts and greatly reduced collagen deposition in $\mathrm{Plg}-/$ - infarcts $(0.7 \pm 0.3 \%, \mathrm{p}=0.002$, figure 3$)$, which was comparable to that in the sham operated animals. The bordexzones of $\mathrm{Plg} / \mathrm{-}$ - infarcts revealed some collagen deposition, although much less than in the Plg+/+ infarcts. RNA In situ lyybridization using a type I collagen probe $^{179}$ demonstrated diffuse collagen expression throughout the entire Plg $+/+$ infarct. Type $I$ collagen mRNA expression was restricted to the borderzones and the endo- and epicardial layers in Pl $\mathrm{g}-/$ - infarcts (figures $1 \mathrm{~g}$ and $\mathrm{h}$ ).

\section{Cell turnover is not altered in Plg- $/-$ infarcts}

Total cell numbers were lower in the center of 2 weeks Plg- $/$ infarcts $(180 \pm 130$ cells per $\left.0.1 \mathrm{~mm}^{2}\right)$ than of $\mathrm{Plg}+1+$ infarcts $(910 \pm 160$ cells, $\mathrm{p}=0.004$, figure 4$)$. Measurement of DNA synthesis by BrdU labeling (figures $2 e$ and $f$ ), yielded similar percentages of BrdU positive nuclei in the $\mathrm{Plg} /-(23 \pm 7 \%)$ and $\mathrm{Plg}^{+} /+(26 \pm 5 \%, \mathrm{p}=0.33)$ infarcts, indicating that the proliferative capacity of the $\mathrm{Plg} /$ - cells is not reduced. Also, the percentage of apoptotic cells, measured by the Tunel-staining technique, was not significantly different in the Plg $+/+(0.4 \pm 0.2 \%)$ and $\mathrm{Plg}-/-(0.4 \pm 0.3 \%, \mathrm{p}=0.64)$ infarcts, 2 weeks following MI (figure 4). Thus, the absent wound healing in $\mathrm{Plg}-/$ - mice is the consequence of abolished cell migration and not of cell turnover. 


\section{PLG +/+}
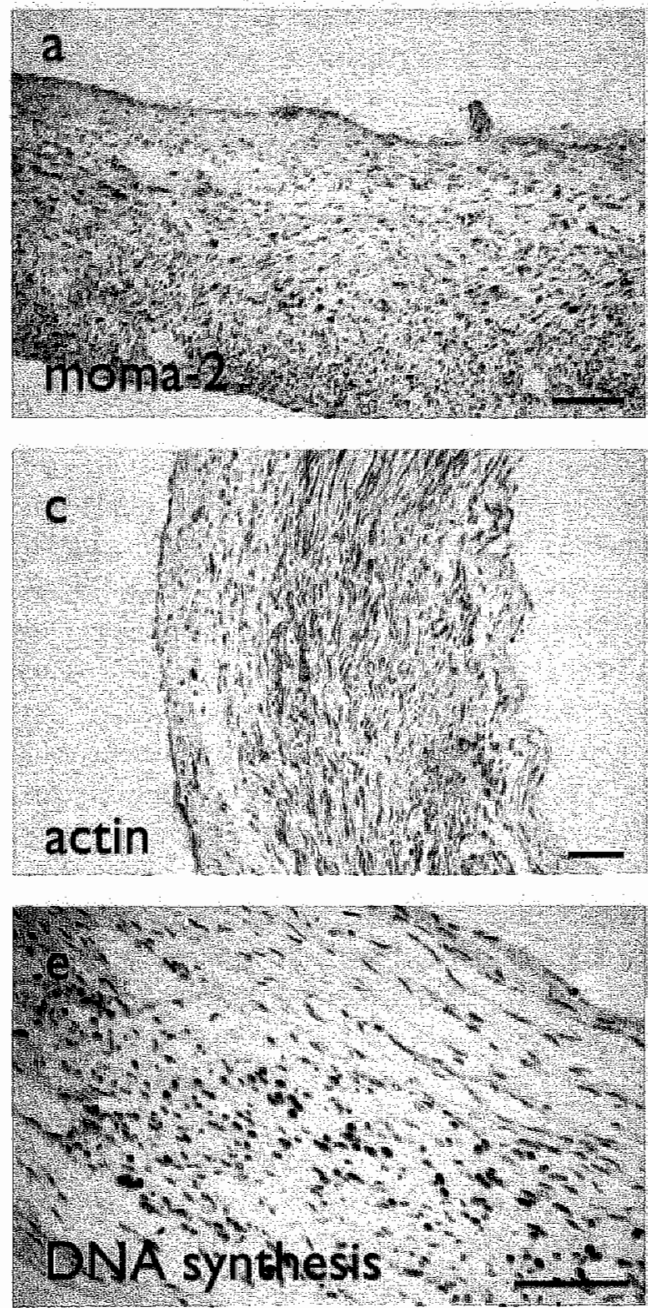

PLG -/-
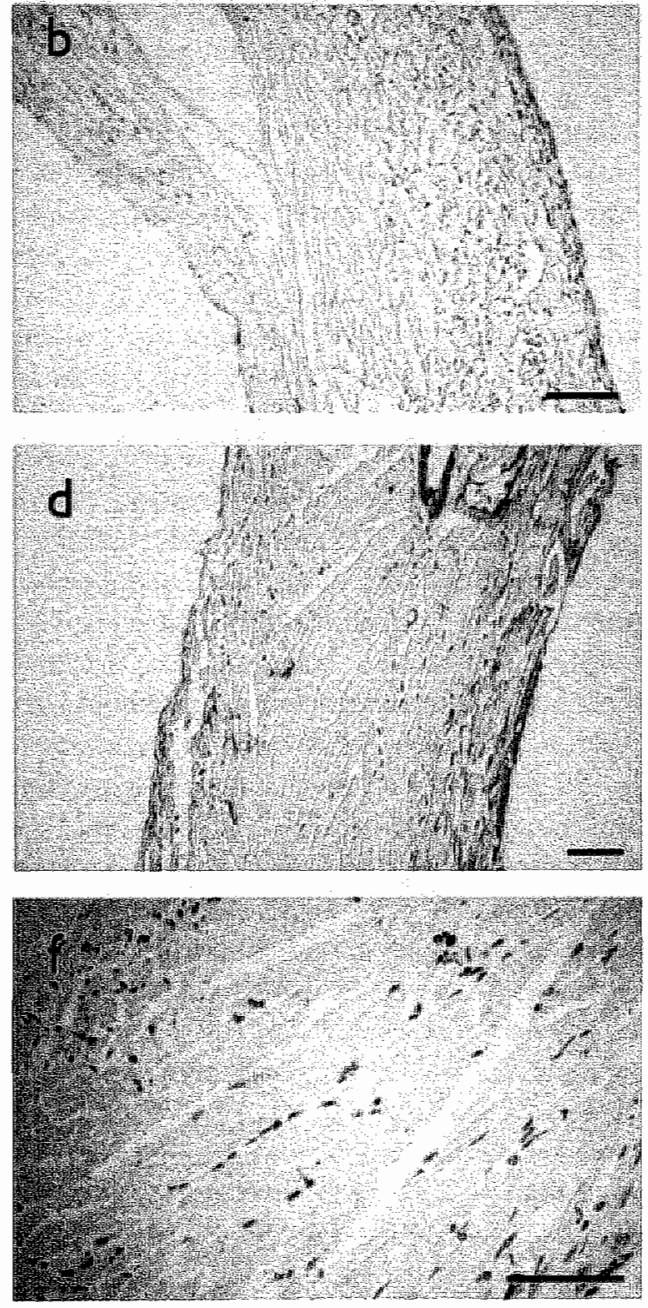


\section{Architectural changes of the left ventricle of infarcted hearts}

The occurrence of architectural changes shortly following the onset of MI is well established: the infarcted left ventricle dilates, the infarcted wall becomes thinner and the non-infarcted septum undergoes hypertrophy. These cardiac adaptations are normal compensatory mechanisms after infarction to maintain stroke volume at an adequate leve $\mathrm{l}^{203}$. In the present study, all these architectural changes were observed 2 and 5 weeks after MI, in both the $\mathrm{Plg}-/$ and $\mathrm{Plg}+/+$ infarcted hearts (table 1 ). Infarct sizes, left ventricular lumen areas (measure for dilatation) and septum thicknesses were not significantly different between the two infarct groups. However, the infarcted wall of the Plg-/- hearts remained thicker than that of $\mathrm{Plg}+/+$ hearts $(0.45 \pm 0.06$ vs $0.23 \pm 0.03$ $\mathrm{mm}, \mathrm{p}=0.004$ ), as clearly shown in figures $1 \mathrm{i}$ and $\mathrm{j}$. These thicker infarcted walls of the $\mathrm{Plg}-\mathrm{P}$ - mice probably contribute to the increased heart weights, observed in the $\mathrm{Plg} / \%$ infarcts (table 1).

\section{Gelatinase activity is decreased in PIg- $/$ - infarcts}

Gelatin zymography on murine left ventricular tissue revealed four distinct proteins with gelatinase activity (figure 5). The identity of these gelatinolytic bands in mouse tissue extracts has been described by others ${ }^{160}$. The top band $(\sim 97 \mathrm{kDa})$, represents MMP-9. Three bands with molecular weights of $\sim 72 \mathrm{kDa}, \sim 66 \mathrm{kDa}$ and $\sim 60 \mathrm{kDa}$ represent respectively the pro-, intermediate- and active forms of MMP-2. Quantification of the intensities of the bands demonstrated a downregulation in the activity of MMP-9 (77\%) and active MMP-2 (49\%) in 2 weeks old $\mathrm{Plg}-/$ - infarcted hearts (figure 5). We observed no differences in the intensity of the $66 \mathrm{kDa}$ band between the two strains and a $40 \%$ decrease in the activity of the $72 \mathrm{kDa}$ band in the Plg-/-mice. No differences in MMP activity was seen between sham operated $\mathrm{Plg}-/-$ and $\mathrm{Plg}+/+$ mice.

\section{The impact of impaired healing on cardiac function}

Cardiac function was evaluated 2 weeks after surgery by measuring the rate of pressure development in the hearts $\left(\mathrm{dP} / \mathrm{d} t_{\max }\right)$ and cardiac output levels (CO). Under basal conditions, contractility $\left(\mathrm{dP} / \mathrm{dt}_{\max }\right.$ ) was similat in the infarcted $\mathrm{Plg}+/+$ and $\mathrm{Plg} /$ - hearts. However, after inotropic stimulation by dobutamine, $\mathrm{dP} / \mathrm{dt}_{\text {raxi }}$ was blunted in the $\mathrm{Plg}-/$ infarcted hearts as compared to the wild-types (figure 6). Heart rate responses to dobutamine were similar in all groups (data not shown). Also CO levels at rest were comparable in the sham and infarct groups (Table 2). We therefore maximally challenged the hearts, by a rapid intravenous fluid load. In rats, it has previously been shown that volume overload elevates cardiac output (CO) to maximal values during the last $10-15$

\section{Figure 2 - Cellular composition of the infarcts}

a and b) Large numbers of macrophages infiltrate into 1 week old Plg $+1+$ infarcts in contrast to the Plg1 - infarcts. $\mathbf{c}$ and d) $\alpha$-smooth muscle actin immunohistochemistry reveals myofibroblasts and smooth muscle cells in the center of the $\mathrm{Plg}+/$ t infarcts. In the center of the Plg-/ infarcts, the only $\alpha$-sma positive cells were vascular smooth muscle cells e and f) BrdU immunohistochemistry in the infarcted myocardium. The absolute number of $\mathrm{BrdU}$ positive cells is higher in the $\mathrm{Plg}+/ \mathrm{t}$, but the percentage of cells that is BrdU positive is very similar in the $\mathrm{Plg}+1+$ and $\mathrm{Plg}-/-$. Bars represent 50 urm. 


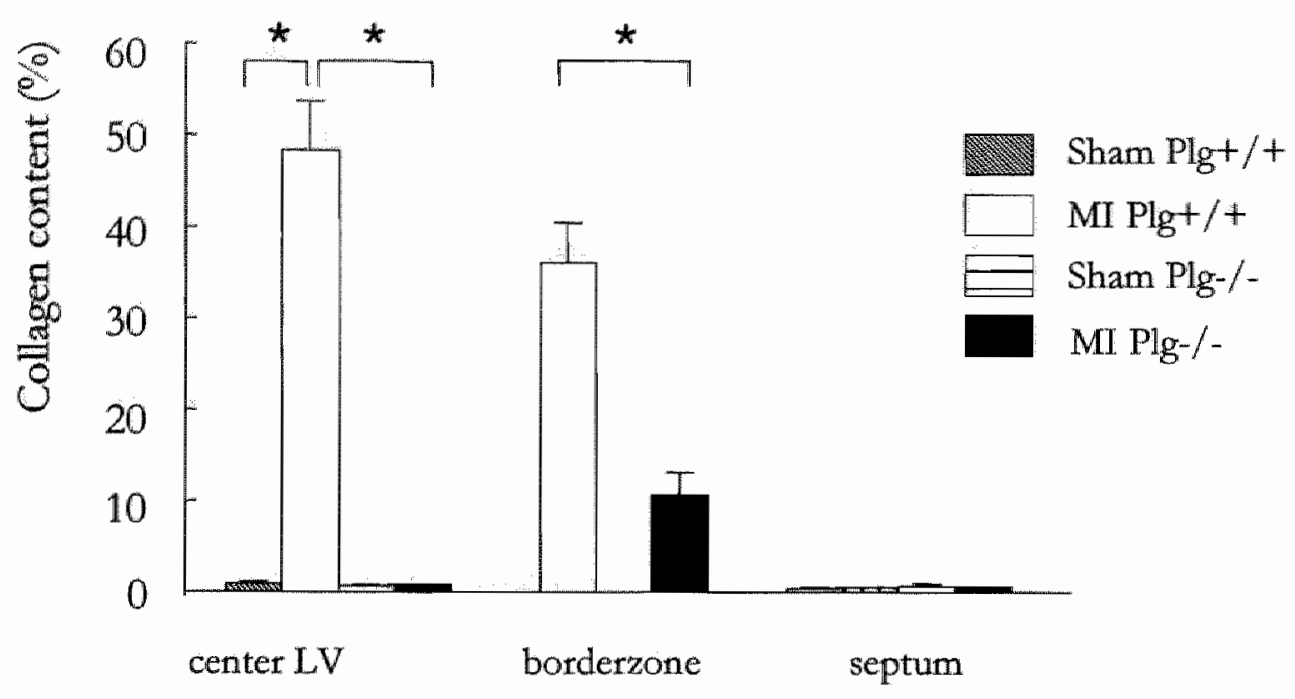

Figure 3 - Quantification of the Sirus Red staining demonstrates completely abolished collagen deposition in the center of the $\mathrm{P} / \mathrm{g} /,-$ infarcts $(\mathrm{MI}=$ myocardial infarction, $\mathrm{SH}=$ sham operation)

seconds of a 1 minute fluid load and that infarction blunts the increase in $\mathrm{CO}$, proportional to the degree of heart failur ${ }^{203,220}$. After volume overload in $\mathrm{Plg}-/$ - and $\mathrm{Plg}+/+$ mice, $\mathrm{CO}$ levels were comparably blunted in both infarct groups when compared to the shams ( $\mathrm{n}=3-5$ per group, table 2). Taken together, these measurements demonstrate impaired function in the Plg-/-infarcted hearts during mild stimulation, and equalization of cardiac output in the two strains at extreme loads.

\section{DISCUSSION}

\section{Role of the plasminogen system in infarct healing}

Early events of tissue repair following $M I$ include migration of inflammatory cells into the wound and degradation of the extracellular matrix and necrotic cardiomyocytes ${ }^{96}$. Inflammatory cells migrate into the wound by degrading the extracellular matrix surrounding the cardiomyocytes, using proteinases such as plasmin, MMPs, cathepsins etc $^{41}$. In the present study, the infiltration of macrophages, (myo)fibroblasts and endothelial cells was found to be abolished in the absence of plasminogen, for at least 5 weeks after MI. This indicates that plasmin is required for cellular infiltration into the infarct, either directly by extracellular matrix proteolysis, or indirectly, through activation of MMPs. In fact, decreased activity of MMP-9 and active MMP-2 was found in the Plg$/$ - infarcts compared to the wild-types. The intensity of the latent MMP-2 band was suppressed to a smaller extent in Plg $/$ - infarcts. This indicates that de novo synthesis of 


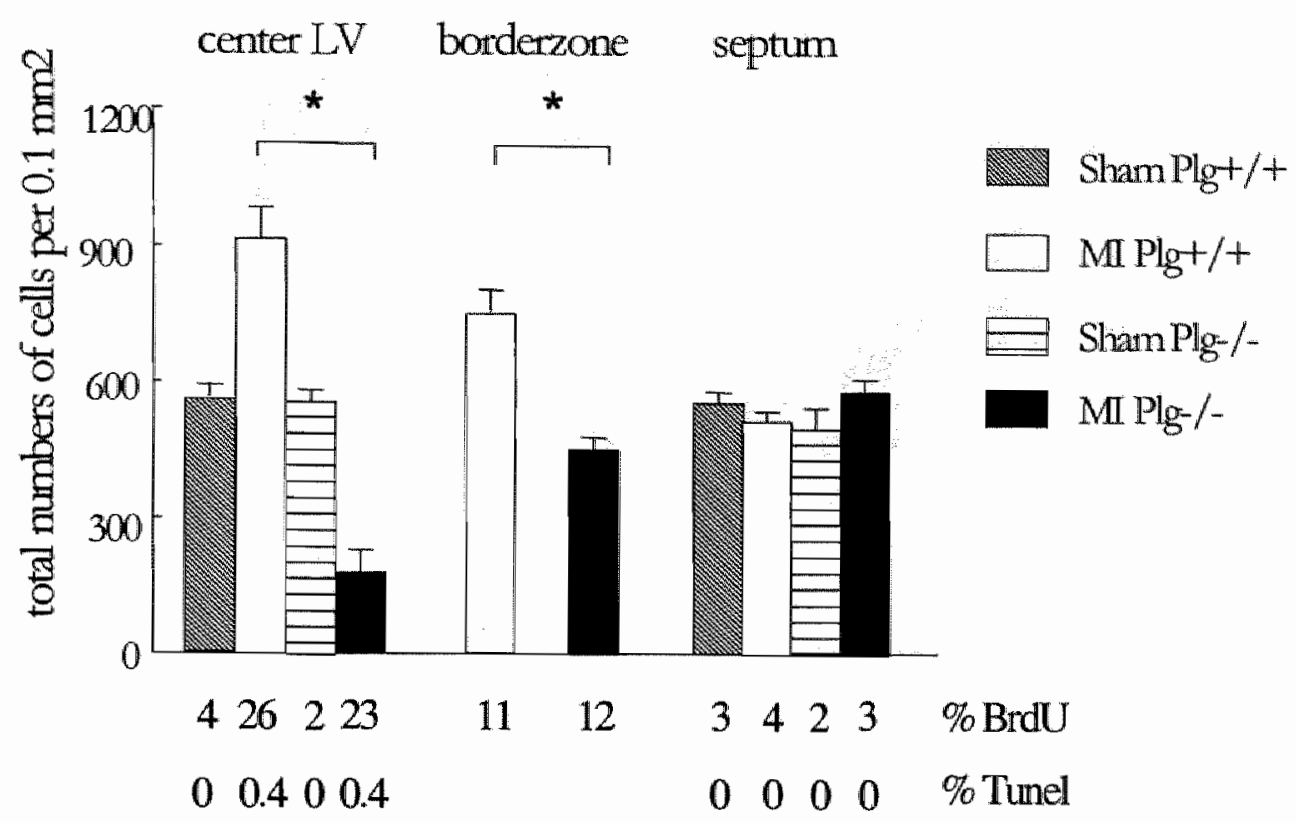

Figure 4 - Cell turnover in Plg $+/+$ and Plg $/$ - hearts, 2 weeks after MI

Despite reduced absolute cell numbers (bars) in the $\mathrm{Plg}-/$ - infarcted hearts, the percentage of $\mathrm{BrdU}$ positive cells is not significantly different from the $\mathrm{Plg}+/+$ infarcts (resp. $23 \%$ and $26 \%, \mathrm{p}=0.33$, by Mann-Whitney test). This was also seen for levels of apoptosis, as measured by the Tunel staining technique (MI=myocardial infarction, $\mathrm{SH}=$ sham operation).

MMP-2 is barely affected. The small effect of Plg deficiency on the amount of latent MMP-2 suggests that MMP-2 activity is decreased due to inhibited activation of proMMP-2, rather than a reduced synthesis. It also indicates that the effect of plasmin on infarct healing is at least partly mediated by activation of MMP-9 and MMP-2. This is supported by the funding that mice deficient in MMP-9 showed a reduction in the infiltration of leukocytes into the infarct and were protected against cardiac rupture ${ }^{204}$. In the present study we were unable to investigate the role of plasminogen in the development of left ventricular rupture since cardiac rupture did not take place in $1 \mathrm{gg} /$ and only in one $\mathrm{Plg}+/+$ infarcts. The role of plasminogen in cardiac wound healing as shown here is consistent with its role in dermal and vascular wound healing $\mathrm{g}^{159,161}$. However, the effects on cardiac healing are more pronounced, since vascular wound healing was delayed, but not completely abolished in plasminogen deficient mice ${ }^{3,9}$, and dermal wound healing was associated with impaired keratinocyte migration, but an intact inflammatory response ${ }^{161}$. In conclusion, impaired cardiac wound healing in both $\mathrm{Plg}-/$ - 


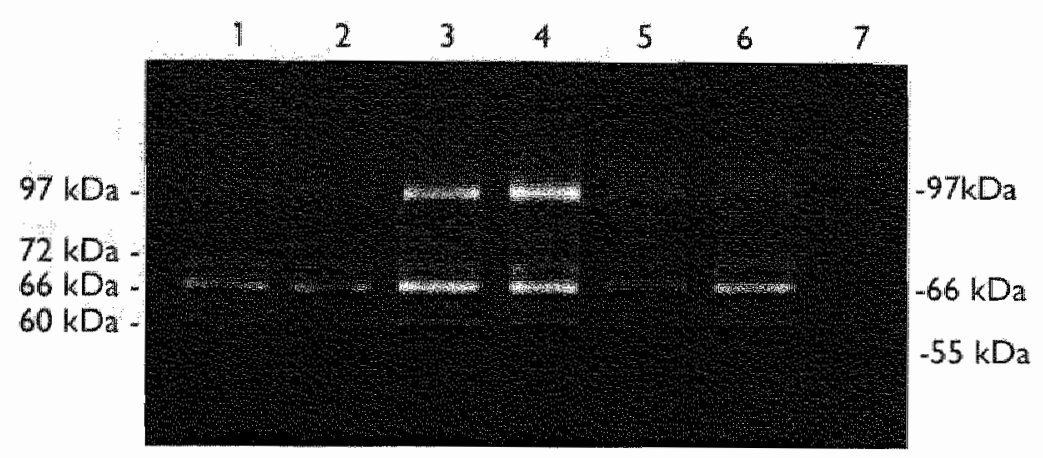

b)

\section{$54 \mathrm{kD}$}
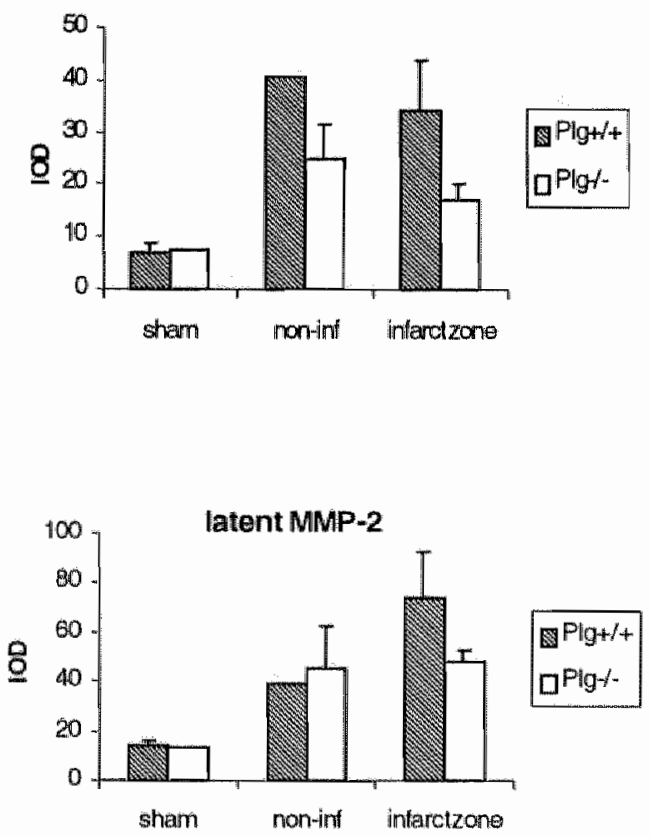

MMP-9

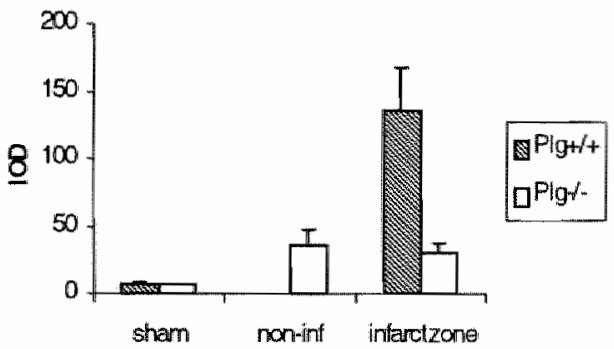

active MMP-2

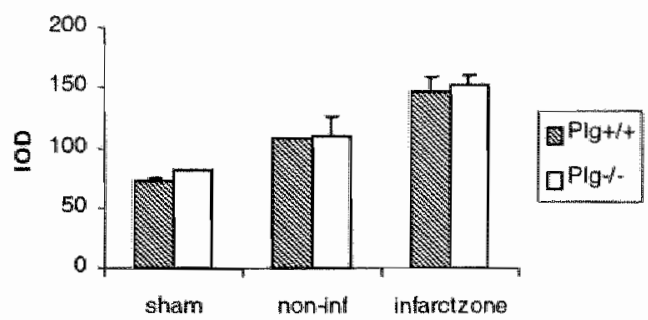

Figure 5 - MMP-2 and MMP-9 activity in Plg-/- and Plg+/+ hearts.

a) Gelatin zymography, demonstrating $M^{2} M^{2}-2$ and $M M P-9$ activity in cardiac extracts, two weeks after surgery. Lane 1-2: Plg-/-infarcts, lane 3 4: Plg+/+ infarcts, lane 5: Plg+/+ sham, lane 6: Plg $/$ - sham; lane 7: marker. The $97 \mathrm{kDa}$ band corresponds to MMP-9. Three bands with molecular weights of $\sim 72 \mathrm{kDa}, \sim 66 \mathrm{kDa}$ and $\sim 60 \mathrm{kDa}$ represent tespectively two proenzymes and one activated form of MMP.

2. b) Quantification of the scanned gelatinolytic bands. 


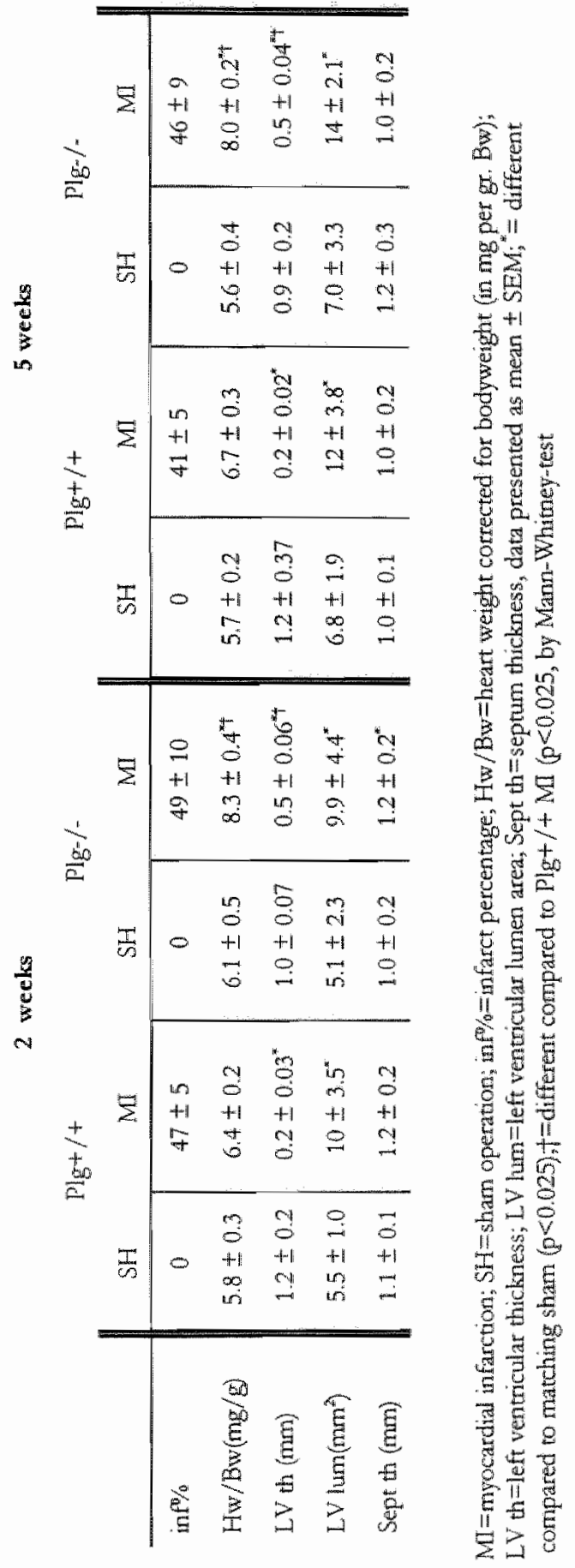


Table 2. Cardiac output elevation after $2.5 \mathrm{ml}$ volume overload

\begin{tabular}{c|c|c||c|c|}
\multicolumn{2}{c}{} & \multicolumn{2}{c}{ Plg } & \multicolumn{2}{c}{ PH } & MI & SH & MI \\
\hline $\mathrm{CO}_{\text {rest }}(\mathrm{ml} / \mathrm{min})$ & $4.8 \pm 1.0$ & $4.8 \pm 0.8$ & $4.9 \pm 0.7$ & $3.2 \pm 0.4$ \\
$\Delta \mathrm{CO}(\mathrm{ml} / \mathrm{min})$ & $9.7 \pm 2.9$ & $6.8 \pm 1.3$ & $9.1 \pm 1.2$ & $6.8 \pm 0.4$
\end{tabular}

$M I=$ myocardial infarction; $S H=$ sham operation, $n=3-5$ per group. Data are presented as mean $\pm S E M$. No statistical differences were observed between groups.

and $\mathrm{u}-\mathrm{PA}-/-$ mice $^{204}$ indicate that plasmin proteolysis is needed for the normal repair process of the heart after infarction. The plasmin-mediated ECM degradation is initiated by enhanced activity of uPA. Although plasmin cannot directly degrade interstitial collagens, it can initiate collagenolysis by activation of latent MMPs.

\section{LV architecture and performance in the absence of infarct healing}

Despite the absence of cardiac wound healing, architectural changes of the LV were comparable in $\mathrm{Plg}$ - - infarcts and wild-type infarcts, except the less pronounced thinning of the infarcted wall in $\mathrm{Plg} /$ - mice. The latter might be explained by the persistent presence of necrotic cardiomyocytes in the $\mathrm{Plg} / \mathrm{m}$ infarcts, which have larger volumes than the collagen fibers in the Plg+/ + infarcts. Larger heart weights in the Plg- $/$ - infarcts can not be explained by a hypertrophic response of the non-infarcted myocardium, since septum thicknesses are not different between the Plg- $/-$ and Plgt $/ t$ infarcts. The increased heart weights are more likely explained by the reduction in infarct thinning in the $\mathrm{Plg} /$ - mice. Another temarkable observation was that left ventriculat dilatation was not increased in the absence of healing, suggesting that the infarcted wall of the Plg-/hearts with its large number of necrotic cells, has a similar tensile strength as the infarcted wall of Plgt $/+$ hearts, where fibrous tissue is deposited to restore the structural integrity. This suggests that maintenance of tensile strength in the infarcted Plg-/ - wall may be due to preservation of the extracellular matrix and/or to the $1-2$ cell layers of surviving cardiomyocytes in both endo and epicardium.

The impact of impaired healing on left ventricular function was evaluated by measuring cardiac output and left ventricular pressure devellopment. Both parameters provide information on global cardiac function. An impaired function was observed in the $\mathrm{Plg} / \mathrm{-}$ infarct group after submaximal stimulation (dobutamine). However, extreme challenge (wolume overload) resulted in equalization of cardiac output between the two groups. The reduced response to dobutamine does not depend upon differences in betaadrenoceptor signaling, since heart rates were similar in all groups. There is no à priori reason to assume a difference in contractility of cardiomyocytes in the non-infarcted myocardium between $\mathrm{Plg}-/$ and $\mathrm{Plg}+/ \mathrm{t}$ animals. The observed reduction of the response to dobutamine in the knock-outs is however compatible with the observed 


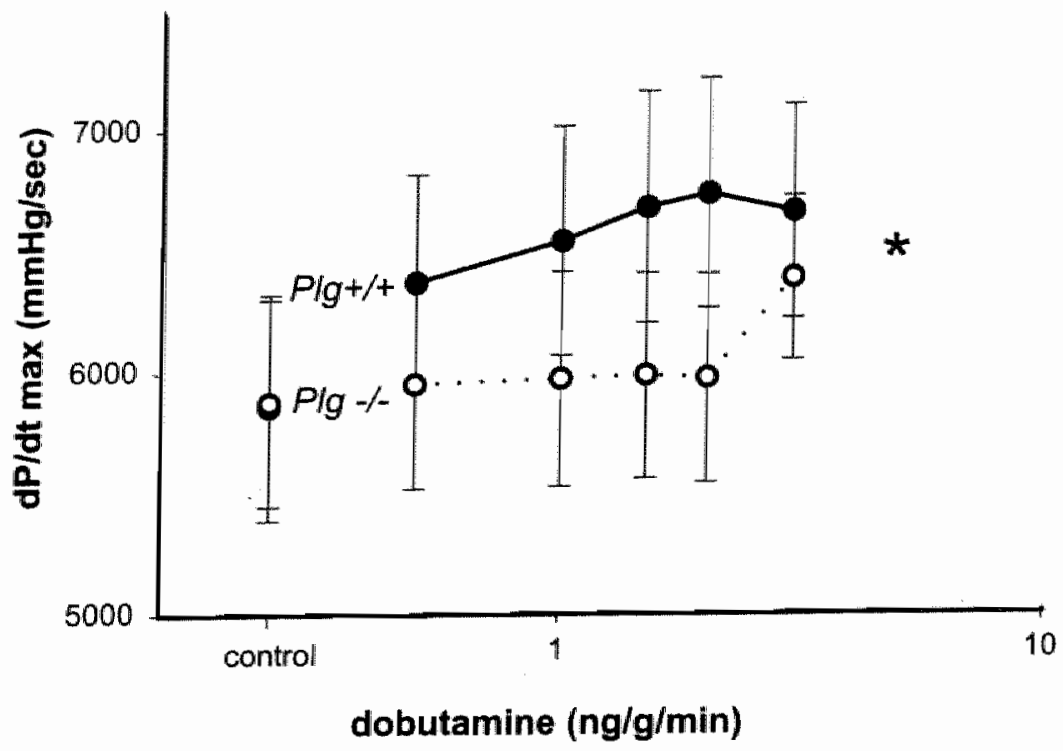

Figure 6 - The cardiac contractile response to dobutamine infusion is blunted in the 2 week Plg- $/$ - infarcts ( $n=5-6$ per group, $p=0.014$, by two way analysis of variance)

structural changes in the infarcted area. In Plg-/ infarcts, reduced collagen deposition when compared to the wild-type infarcts, and the presence of necrotic cardiomyocytes increase the compliance of the infarct zone. This may result in mechanical disadvantages compared to the wild-types, where collagen deposition produces a virtually inextensible infarct ${ }^{208}$. However, at extreme volume loads, both infarcts are stretched to a maximum and stiffness of the two infaret types is no longer different. Under these conditions, pump function will exclusively be determined by the healthy part of the myocardium, which apparently is comparable between the two infarct types. 



\section{Chapter 6}

\section{Inhibition of plasminogen activators or matrix metalloproteinases prevents cardiac rupture but impairs infarct healing and causes cardiac failure}

(Publisbed in modified format in: Nature Medicine, 1999; (5): 1135-1142) 


\section{SUMMARY}

Cardiac rupture is a fatal complication of acute myocardial infarction lacking treatment. Here, acute myocardial infarction resulted in rupture in wild-type mice and in mice lacking tissue-type plasminogen activator ( $\mathrm{tPA}$ ), urokinase receptor (UPAR), matrix metalloproteinase stromelysin-1 (MMP-3) or metalloelastase (MMP-12). Instead, deficiency of urokinase-type plasminogen activator (uPA-/-) completely protected against rupture, whereas lack of gelatinase-B (MMP-9) partially protected against rupture. However, uPA-/- mice showed impaired scar formation and infarct revascularization. Temporary administration of PA inhibitor-1 or the matrix metalloproteinase-inhibitor TIMP-1 completely protected wild-type mice against rupture but did not abort infarct healing, thus constituting a new approach to prevent cardiac rupture after acute myocardial infarction. 


\section{INTRODUCTION}

More than 1.5 million people suffer acute myocardial infarction (MI) annually in the United States. About 30\% of those patients die within the first 24 hours, due to arrhythmias or pump failure. With improved treatments, cardiac rupture has become a serious complication, accounting for 5 to $31 \%$ of in-hospital mortality after $M{ }^{221,222}$. Rupture mainly affects middle-aged patients with a transmural MI but no previous history of angina and is usually fatal due to absence of treatment. Surgical repair suffers a $27 \%$ operative mortality and offers only a $31 \%$ long-term survival ${ }^{223}$. Hypertension, undue physical activity, diabetes, cardiac hypertrophy, fatty infiltration, infarct expansion and delayed thrombolysis with streptokinase have been related to rupture but the relevance of these risk factors remains controversial ${ }^{224,225}$. Genetic predisposition factors or criteria for identifying patients at risk for cardiac rupture after MI remain undetermined. A better understanding of the mechanisms of cardiac rupture might lead to prevention, but this has been precluded by lack of reproducible animal models. The plasminogen system comprises two plasminogen activators (PAs) [tissue-type PA (tPA) and urokinase-type PA (uPA), and their PA inhibitor-1 (PAI-1)], and the matrix metalloproteinases (MMPs), including among others stromelysin-1 (MMP-3), gelatinase-B (MMP-9) and tissue inhibitor of metalloproteinase-1 (TIMP-1). Evidence suggest that these systems are involved in matrix remodeling after $\mathrm{MI}^{106,226}$. Impaired $\mathrm{PA} / \mathrm{MMP}$ proteolysis may be involved in cardiac fibrosis ${ }^{227}$ and in coronary or myocardial remodeling after $\mathrm{Mn}^{228}$, whereas proteinase inhibitors may improve cardiac function by protecting against wall thinning or dillatation ${ }^{106}$. The role of PA/MMP proteinases in healing and revascularization of the infarct and in cardiac rupture, however, remains unknown.

Here, we used a combination of gene-inactivation and gene-transfer techniques in mice to address these issues. Deficiency of uPA and, to a somewhat lesser extent, of MMP-9 prevented cardiac rupture after MI. Long-term inhibition of UPA gene function, however, impaired infarct healing and predisposed to cardiac failure under adrenergic stress. Instead, temporary PA/MMP inhibition by adenoviral gene transfer prevented rupture without aborting infarct healing and therefore may constitute a new treatment paradigm for fatal cardiac rupture.

\section{METHODS}

Mouse model of myocardial infarction and experimental procedures.

Wild-type mice and mice lacking tPA, uPA, UPAR, MMP-3 (a gift from J. Mudgett), MMP-9 or MMP-12 mice, all of a C57/bl-6 background, 8-12 weeks old at the time of experiments, were used ${ }^{229}$. Myocardial infarction was done as described ${ }^{199}$. Shamoperation included all procedures except ligation of the left anterior decending coronary artery. 


\section{Histology, immunostaining and motphometry}

Infarcted mice were anesthetized, injected with $100 \mu$ saline containing $0.1 \mathrm{mM}$ cadmium chloride and perfusion-fixed with 1\% paraformaldehyde at physiological pressure. Fixed hearts were cryoembedded or embedded in paraffin. Sections $6 \mu \mathrm{m}$ in thickness were used for histologic analysis or for immunostaining as described ${ }^{154,199}$. Double-staining for uPA or MMP-9 and Mac-3. (to detect macrophages) or myeloperoxidase (to detect neutrophils) were done as described ${ }^{190}$. Morphometric analysis and counting of immunoreactive cells (in at least three optical fields of about $0.1 \mathrm{~mm}^{2}$ ) were done using a Quantimet 600 image analysis system (Leica, Brussels, Belgium). Counting of capillaries and coronaries were done as described ${ }^{154}$. Antibody sources were: CD-3 (to detect T-cells) and CD-19 (to detect B-cells), PharMingen (San Diego, California); myeloperoxidase, Prosan (Merelbeke, Belgium).

\section{Blochemical and hematological analysis}

In situ zymography of $\mathrm{PA}$ or uPA activities, gelatin zymography of MMP-2 and MMP-9 activities in extracts, and immunoblotting for plasminogen/plasmin were determined as described ${ }^{154,190}$. Infarct levels of latent and active TGF- $\beta 1$ were measured with commercially available ELISAs (R\&D Systems, Minneapolis, Minnesota).

\section{Adenovirus mediated PAI-1 or TIMP-1 gene transfer}

Adenovirus expressing human PAI-1 (AdPAI-1 ${ }^{149}$ ), human TIMP-1 (AdTIMP-1 ${ }^{230}$ ) or control AdRR5 virus (an empty adenovirus containing the CMV promoter and a polyadenylation signal that lacks a functional transgene ${ }^{231}$ ) have been described. One day before ligation of the left anterior descending coronary artery, $100 \mu$ containing $1.3 \times 10^{\circ}$ plaque-forming units of AdPAI-1, AdTIMP-1 or AdRR5 virus were injected into the tail veins of male wild-type mice. At $5 \mathrm{~d}$ after virus injection, PAI-1 plasma levels were measured as described ${ }^{149}$. TIMP-1 plasma levels were measured using a commercially available ELISA (Amersham). Virus-injected mice were analyzed for histology or used for staining of PAI-1, CD-45, Mac-3 (all at 4 or $5 \mathrm{~d}$ after virus injection) or collagen (sirius red; at 14 and $35 \mathrm{~d}$ after $\mathrm{MI}$ ).

\section{Hemodynamic measurements}

Pressure measurements were made as described ${ }^{199}$. Increasing doses of dobutamine (Dobutrex; Lilly, Brussels, Belgium) were administered at $14 \mathrm{~d}$ by continuous infusion over $2 \mathrm{~min}$ for each dose through a 2 French catheter (Portex Green, Baxter, United Kingdom) in the left external jugular vein using a Harvard microinjection pump (Harvard Apparatus, Holliston, Massachusetts). Hemodynamic measurements were done after $90 \mathrm{~s}$ of dobutamine infusion. Stroke volume and cardiac output were measured as described in rats and were adapted for the mouse.

\section{RESULTS}

\section{uPA and MMP-9 predispose to cardiac rupture after $M I$}

Ligation of the left anterior descending coronary artery caused an infarct involving $45 \%$ of the left ventricular (LV) wall (figure 1a). A few subendocardial cardiomyocytes survived, probably because of oxygen supply from the LV cavity. Within 4 days, about 
$30 \%$ of infarcted male wild-type mice suffered fatal rupture of the LV wall (figure $1 \mathrm{~b}$ ). Only male mice died, characteristically at night, indicating that rupture might be induced by stress, activity or fluctuations in hormonal balance. Cardiac rupture also occurred in about $30 \%$ of infarcted male tPA-/-, uPA-receptor- $/$ - (uPAR-/-), MMP-3-/- or MMP-12/- mice, but all 32 infarcted male uPA-/- mice and most (24 of 26) MMP-9-/- mice were protected against ventricular wall rupture $(\mathrm{P}<0.05$; table 1$)$. Lack of cardiac rupture in uPA-/- mice was not due to reduced LV pressure $(85 \pm 5 \mathrm{~mm} \mathrm{Hg}$, wild-type, compared with $81 \pm 4 \mathrm{~mm} \mathrm{Hg}$, uPA $-/-; \mathrm{n}=5$; $\mathrm{p}$, not significant).

\section{Infarct infiltration of leukocytes and cardiac rupture}

Leukocytes infiltrated wild-type infarcts at the site and at the time of ventricular rupture (figure $1 \mathrm{c}$ and $\mathrm{f}$ ), first at the borders and then in the entire infarct. Leukocyte infiltration 4 days after MI was similar in wild-type, tPA-/-, uPAR-/-, MMP-3-/- and MMP-12-/mice, slightly reduced in MMP-9 /- mice (by 18\%) and most substantially decreased in uPA-/ - mice (by 46\%) (table 1). Most of these cells were myeloperoxidase-positive neutrophils $(77 \pm 4 \%$ in wild-type and $67 \pm 5 \%$ in uPA-/-mice; $p$, not significant; figure 1c) with a small contribution by macrophages $(19 \pm 2 \%$ in wild-type and $7 \pm 3 \%$ in uPA$/$ - mice; $\mathrm{p}<0.05$ ) and lymphacytes (CD3-positive T-cells: $5 \pm 1 \%$ in wild-type and $3 \pm 1 \%$ in uPA- $/$ - mice, $n=6, p<0.05 ;$ CD19-positive $B$-cells: $2 \pm 1 \%$ in wild-type and $0.5 \pm 0.2 \%$ in $u P A-/-$ mice, $n=6, p<0.05$ ). The role of $u P A$ in neutrophil migxation in vivo did not seem to depend on uPAR, as uPAR-/- neutrophils accumulated normally in infarcts (table 1).

\section{Infarct leukocytes produce $u P A$ and MMP-9}

uPA and MMP-9 activity were increased (by 70-fold and 17-fold, respectively) in the infarct at the site and at the time of rupture (figures $1 \mathrm{~g}$ and $\mathrm{h}$ ). $\mathrm{tPA}$ activity was not affected in wild-type infarcts and did not compensatorily increase in $\mathrm{uPA}-1$ - infarcts (lysis area expressed as $\%$ of infarct area: $63 \pm 14 \%$ in wild-type and $72 \pm 7 \%$ in uPA- $/ ;$, not significant). Plasmin levels were higher in wild-type than in uPA $/-$ infarcts (figure 1d). uPA cannot directly degrade interstitial collagens (types I and III) but can initiate collagenolysis through activation of zymogen MMPs ${ }^{190}$. Activation of pro-MMP-9 was reduced in uPA-/ infarcts (figure 1e); the arbitrary densitometry units were 220 (inactive $92-\mathrm{kDa}$ pro-MMP-9) compared with 190 (total amount of partially active $88 \mathrm{kDa}+$ active $82-\mathrm{kDa}$ MMP-9) in wild-type infarcts, and $130(92-\mathrm{kDa})$ compared with $60(88-\mathrm{kDa}+82$ $\mathrm{kDa}$ ) in uPA-/- infarcts. Double immunostaining showed minimal expression of uPA and MMP-9 in sham operated hearts but substantially upregulated expression in myeloperoxidase-positive or CD45-positive leukocytes (not shown) and in Mac-3-positive macrophages in infarcted hearts (not shown). In contrast, levels of MMP-2 a fibroblastderived MMP not activated by plasmin ${ }^{190}$, progressively increased after MI to a maximum by 14 days after $\mathrm{MI}$ (tigure $1 \mathrm{~h}$ ).

\section{PAI-1 or TIMP-1 gene transfer prevents cardiac rupture}

We administered adenovirus expressing human PAI-1 (AdPAI-149), human TIMP-1 (AdTIMP-1 ${ }^{230}$ ) or a control AdRR5 adenovirus ${ }^{149,231}$ to male wild-type mice 24 hours before coronary ligation. AdPAI-1 increased plasma PAI-1 levels to $54 \pm 3 \mu \mathrm{g} / \mathrm{ml}$ and AdTIMP-1 increased TIMP-1 levels to $51 \pm 5 \mu \mathrm{g} / \mathrm{ml}$ within 5 days. Human PAI-1 was 
deposited in infarcts, thereby inhibiting uPA activity in the infarct by $60 \%$ (area of uPAmediated lysis expressed as percent of infarct area: $90 \pm 10 \%$ with AdRR 5 compared with $30 \pm 10 \%$ with $A d P A I-1 ;=4 ; P<0.05)$. All malle wild-type mice treated with AdPAI-1 $(\mathrm{n}=19)$ or AdTMP-1 $(\mathrm{n}=18)$ were protected against cardiac rupture, whereas rupture occutred in 5 of 20 wild-type mice injected with control AdRR5 virus $(p<0.05)$. AdPAI suppressed leukocyte infitration as efficiently as loss of uPA gene function, whereas AdTTMP-1 was more effective than MMP-9 gene inactivation (table 1).

\section{Impained scar formation in infarcted $\mathrm{PPA}-/$ - mice}

Removal of nectotic cardiomyocytes was complete by 14 days after $M I$ in all genotypes (table 1), except in uPA-/-mice, in which necrotic cardiomyocytes persisted for up to 5 weeks as 'mummified ghosts' embedded in laminin-rich basement membrane. Macrophage accumulation in infarcts was maximal by 7 days after $M I$ and was significantly less in uPA-/ than in wild-type infarcts $\left(\mathrm{Mac}-3\right.$ positive cells $/ \mathrm{mm}^{2}$ at 7 and 14 days: $150 \pm 2$ and $63 \pm 2$ in wild-type compared with $90 \pm 8$ and $45 \pm 2$ in uPAmice; $\mathrm{p}<0.05)$. Smooth muscle actin (SMA) immunoreactive myofibroblasts and collagen (not shown) were minimal in sham-operated hearts and progressively increased in all getiotypes except in uPA-/ - infarcts (figures $2 b$ and $c$ and table 1). In fact, the necrotic center of uPA / - infarcts remained devoid of fibroblasts and contained amounts of collagen similat to those in sham-operated hearts $(8 \pm 2 \%$ compared with $7 \pm 1 \%$, respectrvely; $\mathrm{p}$, not significant). Four-day-old uPA-/ infarcts contained reduced levels of latent TGF- $\beta 1$, a mediator of collagen deposition ${ }^{232}$ (pg latent TGF $-\beta 1 / \mu g$ protein: $15 \pm 2$ in wild-type compared with $7 \pm 1$ in $u P A-/$ - mice; $n=5 ; p<0.05$ ).

\section{Figure 1 - Myocardial infarction and cardiac rupture}

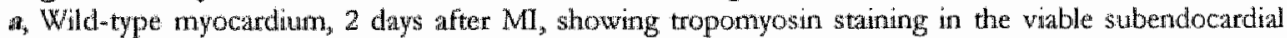
liyers and absent troponyosin expression in necrotic midmyocardium (inset). *, ventricular cavity; arrows, borders of infarct. b, Macroscopic view of ruptured LV wall (arrows) in the infarct border near viable right ventricle (RV; dark red colour) and necrotic LV (light redish colour). $c$, Myeloperoxiclase (MPO) staning, showing inflammatory infiltrate at the sire of wall rupture. $d$, Western blot of extracts from one sharn-operated heart (S) and two infarcted hearts (I), showing an increased ratio of active 68-kDa plasmin

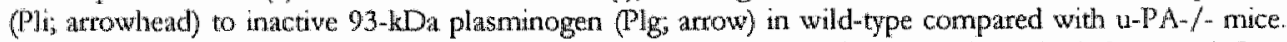
Lane 1, Plig standard; lane 2, Pli standard. $e$, Gelatin zymography of extracts from the infarct (D), infarct borders (BI) and non-infarcted left ventricle (LV) and right ventricle (RV), showing an increased ratio of the amounts of the partally active $88 \mathrm{kDa}$ and active $82 \mathrm{kD}$ a MMP-9 (arrowhead) to the amount of the inactive 92-kDa pro-MMP-99 (arrow) in the infarct and infarct borders in wild-type (WT) compared with u-PA- $/$ - mice. $f$, Accumulation of CD45-immunoreactive leukocytes in infarcts. Sham-operated hearts: $<10$ leukocytes $/ \mathrm{mm}^{2},{ }^{*}, \mathrm{P}<0.05, \mathrm{uPA}-/$ - compared with willd-type. $g$ and $h$, Acrivity of uPA $(g)$ and MMP.2 (b) and MMP-9 (b) in sham operated and infarcted wild-type hearts. $g$ For uPA activity, in situ zymographic lysis area is expressed as a percent of the total infarct area. (S) means septum and (LV) remote non-infarcted left ventricle. $b$, Gelatinographic MMP activity in infarct is expressed in arbitrary units (AU). ${ }^{*}, 1<0.05$ compared with $S, L V$ or sham-operated. Scale bars represent $625 \mu \mathrm{m}(\mathrm{a})$ and $25 \mu \mathrm{m}$ (c). 

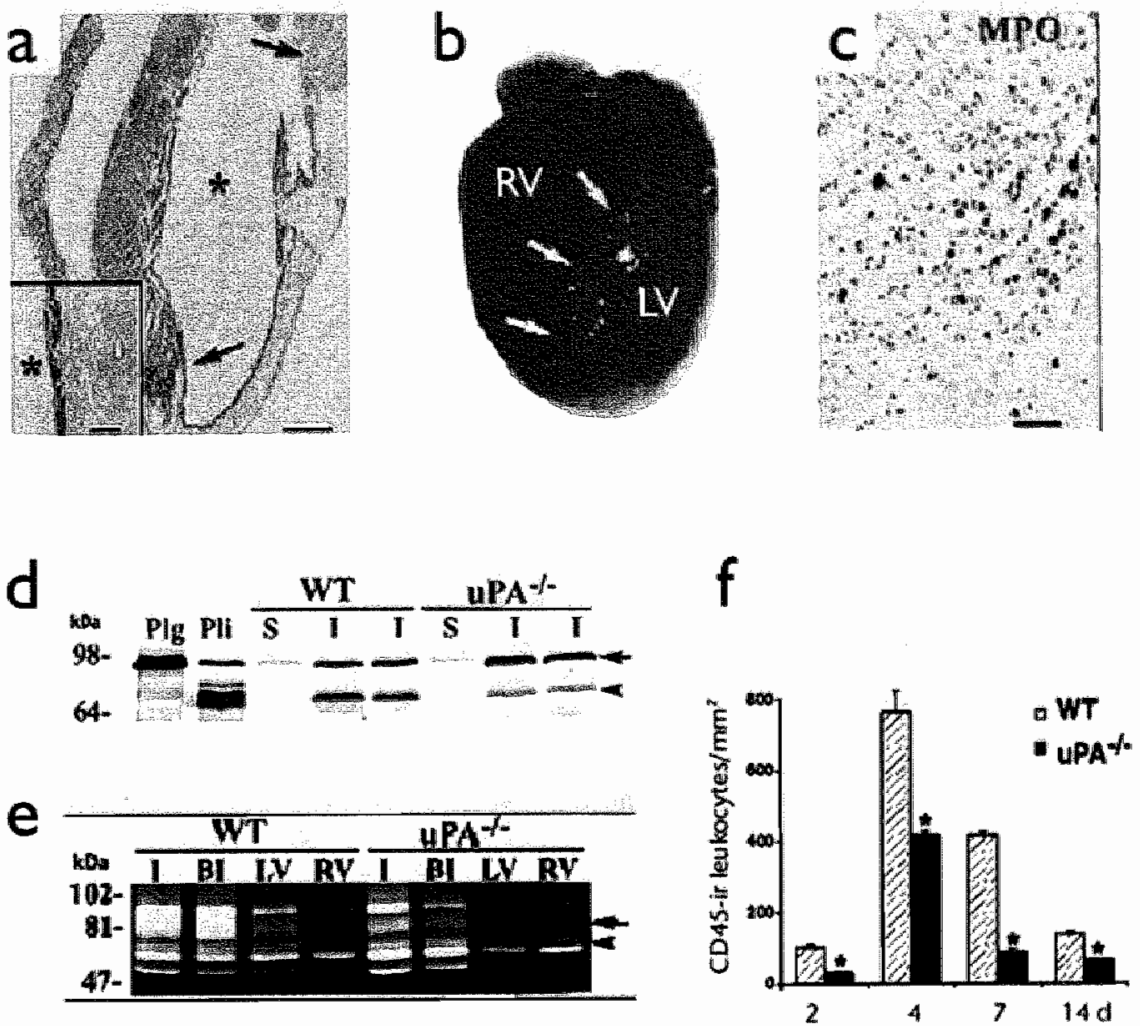

g

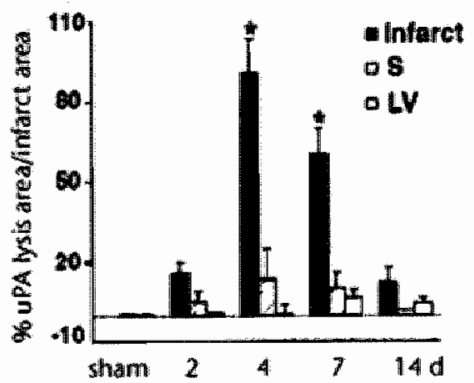

h

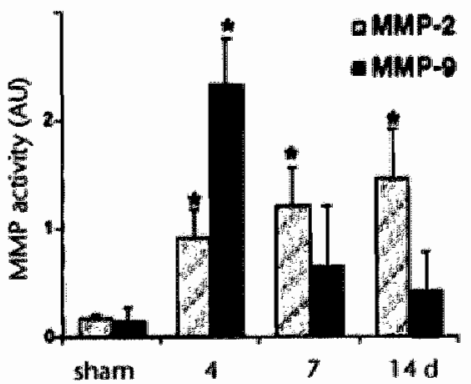


Furthermore, activation of latent TGF- $\beta 1$ was reduced in uPA-/-infarcts, consistent with previous suggestions ${ }^{232}$ (pg active TGF $\beta 1 / \mu g$ protein: $9 \pm 1$ in wild-type compared with $3 \pm 0.1$ in uPA-/ - mice; $\mathrm{n}=5 ; \mathrm{p}<0.05 ;$ ratio, $\mathrm{f}$ active/total TGF- $\beta 1: 0.6 \pm 0.1$ in wild-type compared with $0.4 \pm 0.1$ in uPA $-/-$ mice; $p=0.05$ ). In wild-types, macrophages and fibroblasts expressed uPA during myocardial healing (not shown). The number of thrombomodulin-stained capillairies in infarcts was only $5 \%$ (about 250 capillaries $/ \mathrm{mm}^{2}$ in all genotypes) of the number of capillaries in normal, non-infarcted myocardium. During subsequent healing, fewer capillairies revascularized infarcts in uPA-/- than in other genotypes, in particular in the subendocardium (table 1 and figure 2d). SMA. staining showed that about half of the coronaries survived infarction in all genotypes after 2 days (figure 2e). During subsequent healing, the number of coronary vessels in the infarct was restored in all genotypes except in uPA-/- mice (table 1 and figure $2 \mathrm{e}$ ). Both endothelial and smooth muscle cells expressed uPA during infarct revascularization (not shown).

\section{PAI-1 gene transfer does not abort myocardial healing}

Adlenoviral PAI-1 or "IIMP-1 gene transfer in wild-type mice impaired scar formation (table 1). However, in contrast to the persistent lack of healing in uPA-/- hearts, myocardial healing after PAI-1 gene transfer resumed beyond 14 days, resulting in normal scar formation by 5 weeks after infarction (figure $2 \mathrm{f}$ ). This probably resulted from the transient expression of PAI-1 after adenoviral gene transfer (plasma PAI-1 levels: $2 \pm 1$. $\mathrm{ng} / \mathrm{ml}$ by 14 days after transfer). Thus, transient PAI-1 gene overexpression only retarded but did not abort myocardial healing, whereas it prevented myocardial rupture.

\section{Impaired cardiac function in infarcted uPA- $/-$ mice}

Left ventricular pressure (LVP) and heart rate were similar in sham-operated and infarcted wild-type and uPA-/- mice in baseline conditions (not shown). Contractility $\left(\mathrm{dP} / \mathrm{dt}_{\mathrm{rax}}\right)$ was reduced in infarcted compared with sham-operated mice at 14 days, but to a similar extent in both genotypes (figure $2 \mathrm{~g}$ ). This might explain the comparable compensatory cardiomyocyte hypertrophy in non-infarcted septum. The adrenergic agent dobutamine increased contractility (figure $2 \mathrm{~g}$ ) and stroke volume (figure $2 \mathrm{~h}$ ) in wild-type but not in uPA-/- mice after MI. Cardiac output was increased in wild-type compared with $\mathrm{uPA} /-$ mice $(6.5 \pm 0.9 \mathrm{ml} / \mathrm{min}$ in wild-type mice compared with $4.2 \pm 0.8 \mathrm{ml} / \mathrm{min}$ in $\mathrm{uPA}-1-$ mice at a dobutamine dose of $6 \mathrm{ng} / \mathrm{g}$ per minute; $\mathrm{p}<0.05$ ).

Figure 2 - Impaired myocardial healing and cardiac function in uPA-/-mice.

a, Removal of necrotic infarct area (percent of total infarct area) is impaired in uPA-/- mice (black bars). $b$, Less accumulation of smooth muscle $\alpha$-actin immunoreactive myofibroblasts in uP $A-j-$ infarcts (black bats) than in wild-type infarcts (hashed bars). The lower number of $\alpha$-actin-positive myofibroblasts in infarcts at $14 \mathrm{~d}$ than at $7 \mathrm{~d}$ probably reflects loss of smooth muscle $\alpha$-actin expression. $c-c$, Less deposition of sirits-red stained collagen $(c)$, and fewer thrombomodulin-stained capillaries $(d)$ and SMAstained coronaries $(t)$ in uPA- $/$ - infarcts (black bars) than in wild-type infarcts (hashed bars). $f$, Collagen deposition is retarded but not aborted in AdPAl-1 treated infarcted mice. $g$ and $h, \mathrm{dP} / \mathrm{dt} t_{\max }(\mathrm{g})$ and stroke volume (SV) (b) in sham-operated (sh) and infarcted (MI) mice, showing that cardiac function was similar in baseline conditions, but impaired after dobutamine administration in infarcted uPA- $/$ - mice. *, $\mathrm{P}<0.05$, compared with wild-type; two-way ANOVA. 
a

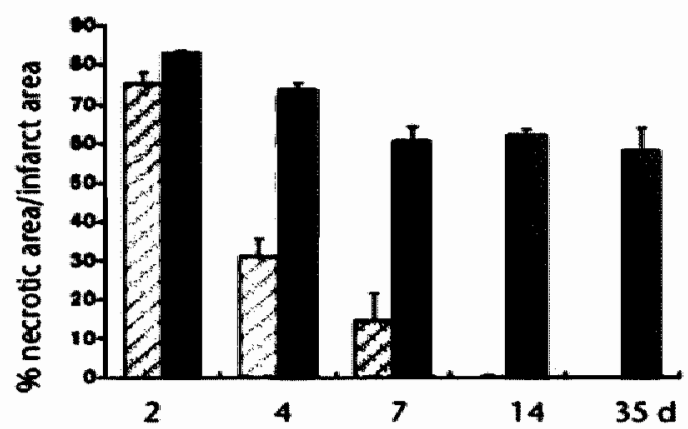

C

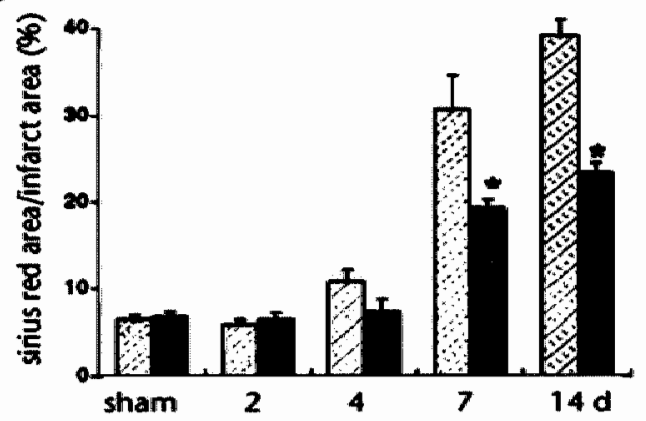

b

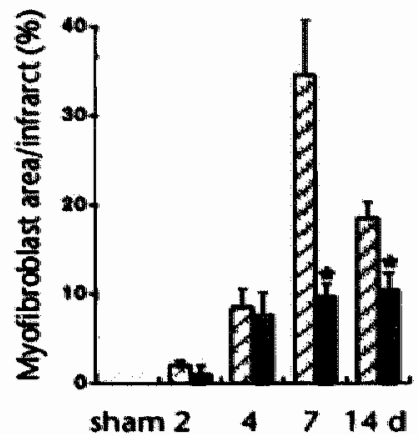

0

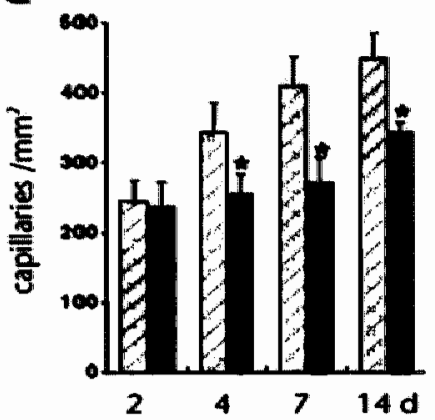

e

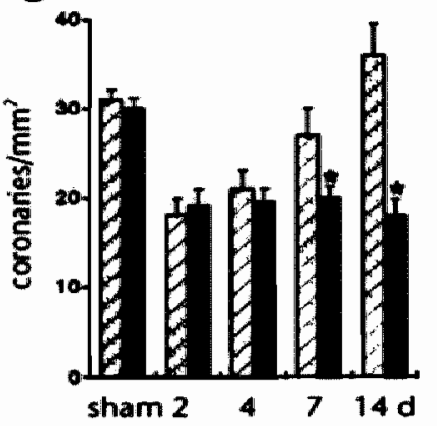

g

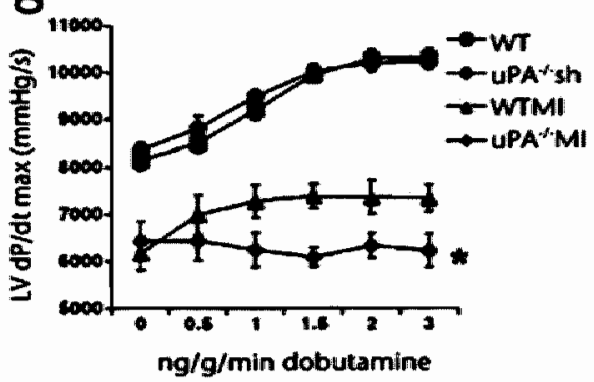

f

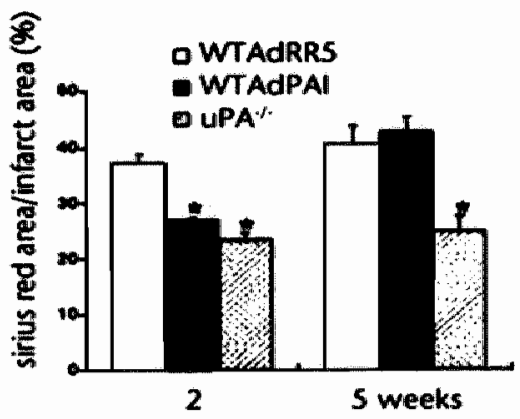

$\mathrm{h}$

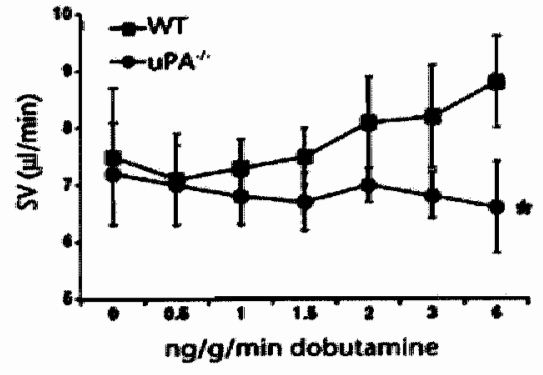


Ventricular relaxation ( $d P / d t_{\text {rani }}$ ) and end-diastolic pressures were similar in both genotypes (not shown).

\section{DISCUSSION}

This study demonstrates that UPA and, to a lesset extent, MMP-9 contribute to cardiac rupture, and shows that uPA is essential for cardiac functional recovery after MI. By degrading matrix mactomolecules, PA/MMPs allow inflammatory cells (in particular neutrophils) to infiltrate the infarct and to disnupt the collagen network, a pretequisite for cardiac rupture ${ }^{207}$. In a second phase, proteolysis allows infiltration of other wound cells that mediate infarct healing ${ }^{233}$. The need for plasmin proteolysis is emphasized by the comparably impaired infarct healing in mice lacking plasminogen (previous chapter). In addition, PA/MMPs may act through other mechanisms. PA/MMPs can produce matrix degradation fragments that affect growth and migration of inflammatory and other wound cell ${ }^{234}$, and PA/MMPs may influence the cytokine response and oxidative stress, thereby promoting cardiomyocyte injury ${ }^{235}$. In addition, PA/MMPs and their receptors may modulate adhesion, intracellular signaling and cell differentiation ${ }^{235-237}$. However, UPAR was not essential in vivo, indicating that the pericellular uPA activity is more important ${ }^{154}$; $\mathrm{PA} / \mathrm{MMP}$ s may activate and mobilize growth factors in the extracellular matrix ${ }^{236,238}$. Reduced activation of TGF- $\beta 1$ probably contributed to impaired collagen deposition in uPA / - infarcts; PA/MMPs may facilitate phagocytosis and lysosomal breakdown of matrix fragments by predigesting matrix macromolecules ${ }^{50}$. uPA and plasmin are unable to directly degrade interstitial collagen. However, uPA was coexpressed with MMP-9 in infiltrating leukocytes, and activation of zymogen MMP-9 was reduced in uPA-/- infarcts, indicating that $\mathrm{uPA}^{\mathrm{P}}$ /plasmin activate MMP-9. Activation of MMPs may, however, also result from other mechanisms including reactive oxygen metabolites, elastases or cathepsins released by neutrophils ${ }^{239}$. The finding that MMP-9-1mice were only partially protected against rupture may relate to the fact that MMP-9 only degrades basement membrane and denatured collagen, and that complete degradation of collagen fibers depends on a concerted action of interstitial collagenases and gelatinases. Such a cooperation between M.MPs is indeed indicated by the observation that complete prevention of rupture was only achieved after TIMP-1 gene transfer, but not after inactivation of a single MMP gene. In contrast to its involvement in rupture, MMP-9 seemed redundant in late infarct healing, possibly because expression of gelatinase-A (MMP-2), which is able to compensate for MMP-9, was increased. Our data do not exclude the possibility of involvement of other proteinases in cardiac destruction or healing ${ }^{240}$.

Cardiac function in infarcted uPA-/- mice was profoundly depressed. This may be related to the impaired revascularization of subendocardial uPA-/- infarct layers. In addition, the necrotic myocardial segment in infarcted $\mathrm{uPA} /$ - mice may be dyskinetic because of its reduced collagen content, and may impose a gteater workload on the residual viable cardiomyocytes in the remote myocardium.

Out findings may indicate that increased expression of uPA or MMP-9 could predispose to cardiac rupture, whereas increased levels of PAI-1 and TIMP-1 may be protective. So far, epidemiologic studies have only related increased expression of MMP- 


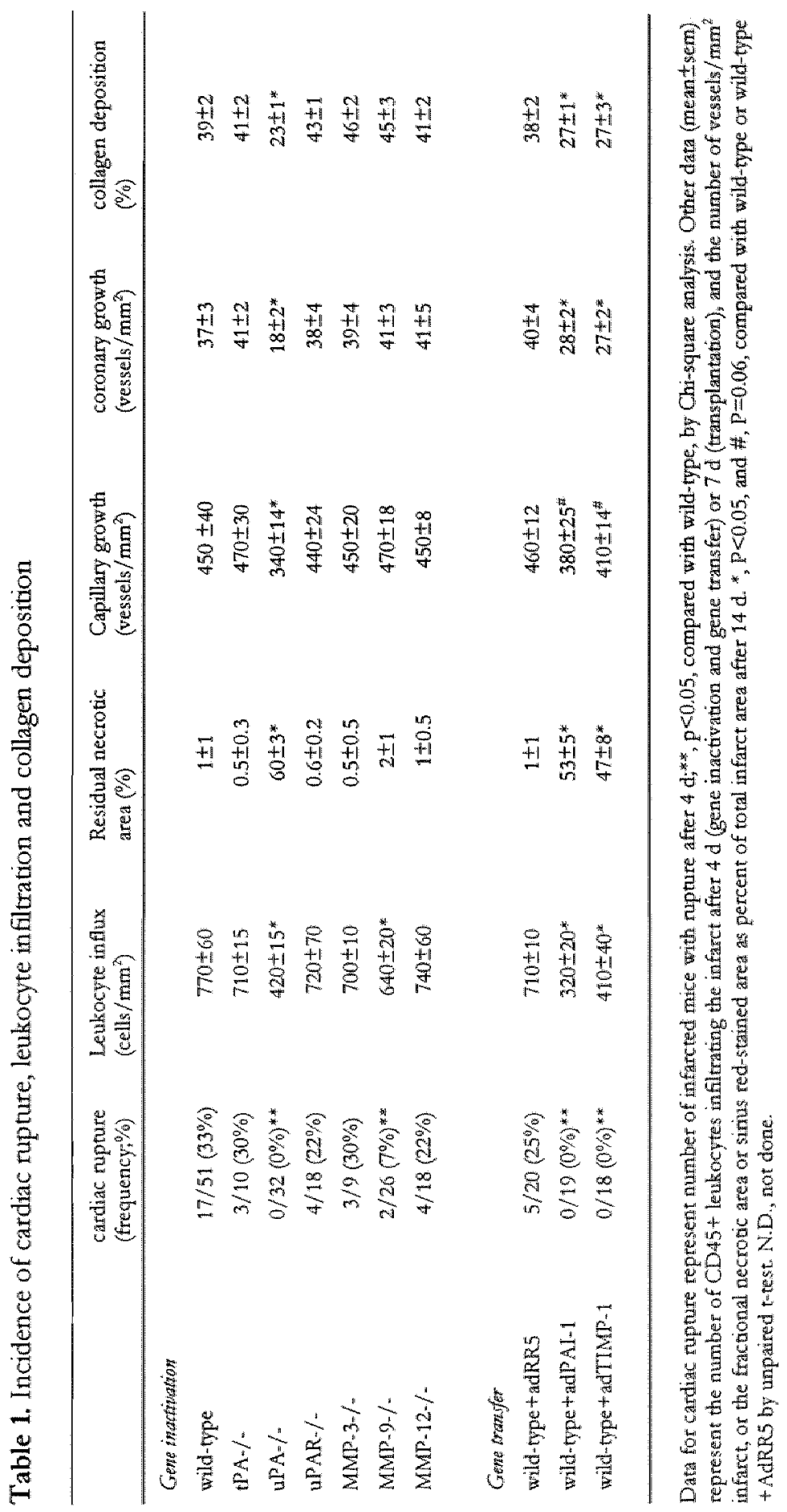


9 and PAI 1 or reduced levels of plasminogen (due to genetic or metabolic determmants) to coronary atherosclerosis ${ }^{241}$ and atherothrombosis ${ }^{242.244}$. However, genetic linkage studies relating uPA or MMP-9 to cardiac rupture are unavailable at present. Our findings also indicate that prevention of cardiac rupture by PAI-1 or TIMP-1 could develop into a new non-surgical treatment for fatal rupture. When used timely (immediately after hospital admission); temporarily (during the first week after MI when most ruptures occur) and cautiously (at non-toxic doses), $\mathbb{P} / \mathrm{MMP}$-inhibitors might prevent rupture, although care should be takken not to impair long-term cardiac recovery.

uPA was essential for capillary angiogenests and growth of collateral arteries during infarct revascularization. The greater requirement for $\mathrm{MPA}$ in revascularization of the myocardium than in other tissues may relate to its greater content of interstitial collagen. During revascularization, UPA is expressed by migrating endothelial and smooth muscle cells, but inflammatory cells, which produce angiogenic factors ${ }^{245}$, also express uPA. Defective revascularization of ischemic myocardium might provide an additional explanation for the increased incidence of reinfarction in patients suffering impaired fibrinolysis ${ }^{243}$. This indicates that therapeutic angiogenesis is determined by genetic predisposition factors, such as uPA, justifying genetic screening of patients, eligible for angiogenic treatment. It will be useful to determine whether decreased fibrinolysis in patients also impairs therapeutic myocardial angiogenesis as in uPA deficient mice. This study also watrants against prolonged or uncontrolled treatment of patients with proteinase inhibitors for post-infarct remodeling ${ }^{106}$, inflammation or cancer ${ }^{23.6}$. In. conclusion, transient administration of proteinase inhibitors may provide a new approach to prevent fatal cardiac rupture, but prolonged inhibition may lead to cardiac failute after MI. 


\section{Chapter 7}

General discussion 
In this thesis we investigated the role of MMPs and the plasminogen system in the repair and remodeling process of the heart after infarction. We hypothesized that MMPs and the plasminogen system are important for adequate healing of the infarcted myocardium. Our data show dual effects. By degrading ECM molecules, these proteolytic enzyme systems allow cells (inflammatory and fibroblast-like cells) to infiltrate in the infarct, a prerequisite for adequate infarct healing. At the same time, by disrupting the collagen rietwork, MMP activity weakens the infarcted wall and consequently contribute to infarct expansion, $L V$ dilatation and cardiac rupture.

\subsection{The role of matrix metalloproteinases in infarct healing}

It has recently been demonstrated that acute pharmacological broad range inhibition of MMPs attenuates LV dilatation 4 days after infarction of the mouse heart ${ }^{106}$. This led to the proposal that MMP inhibitors could be used as a potential therapy for patients at risk for the development of heart failure after MI. In the studies described in chapter 3, we administered a broad range MMP inhibitor to mice after infarction, and demonstrated that this treatment resulted in attenuation of $\mathrm{LV}$ dilatation and deteriorated cardiac function, 2 weeks after infarction. Impaired cardiac output after MMP inhibitor treatment implies that the benefits of MMP inhibitor administration to heart failure patients may be limited. The MMP inhibitor study demonstrates that MMPs also play an important role in several aspects of infarct healing, such as the migration of inflammatory cells to the infarct and the formation of scar tissue. In chapter 6 , the effects of MMP-3, MMP-9 and MMP-12 gene deficiency and TIMP-1 adenoviral overexpression on infarct healing were studied in the same murine model of myocardial infarction. In that study it became evident that both TIMP-1 overexpression and MMP-9 deficiency reduced the inflitration of inflammatory cells into the infarct, while MMP-3 or MMP-12 deficiency did not. In a later stage of infarct healing, proteolysis allows infiltration of other wound cells. Infiltration of fibroblast-like cells results in collagen deposition in the infarcted area. In this regard, MMP inhibitor treatment and adenovital TMMP-1 gene transfer, but not MMP-9 deficiency, reduced the infiltration of fibroblast-like cells and consequently, the deposition of collagen. In contrast to its involvement in early healing, MMP-9 seemed redundant in late infarct healing, probably because expression of MMP-2 (the other gelatinase), which is able to compensate for MMP-9, was increased during this stage of infarct healing (chapter 3). Thus, MMPs (but not MMP-9) are also involved in cell migtation duting this phase of healing. Since a dellay in scar tissue formation could only be achieved after TIMP-1 transfer or broad range MMP inhibition (chapter 3), but not after inactivation of a single MMP gene, we conclude that adequate infarct healing depends on the concerted action of several members of the MMP family.

\subsection{The role of matrix metalloproteinases in cardiac rupture}

The genetic backgtound of the mice used in chapter 6 (MMP-3, MMP-9, MMP-12 deficient mice and the C57/bl-6 mice used for adenoviall TIMP-1 gene transfer) was different from that of mice used for the MMP-inhibitor study (Swiss mice). About 30\% of the malle mice in chapter 6 suffered fatal cardiac rupture of the infarcted LV wall, 
within 4 days after MI. In contrast, cardiac rupture did not occur in the Swiss mice used in the MMP inhibitor study in chapter 3. Interestingly, cardiac rupture could be completely prevented by temporary adenovical TIMP-1 gene transfer and partly in MMP$9-/$ - mice ${ }^{204}$. These data indicate that the activity of several MMPs (among which MMP-9) contributes to the development of catdiac rupture, besides their role in infarct healing. By degrading matrix molecules, MMPs allow inflammatory cells to infiltrate the infarct and distupt the collagen network, a prerequisite for adequate infarct healing but also for cardiac rupture ${ }^{207}$.

The significance of MMP-9 in the processes of early infarct healing and rupture was emphasized by the observation that MMP-9 was predominantly found in leukocytes and macrophages and that its activity peaked around day 2 , the period in which most of the ruptures occur (chapters 2,3 and 6). The finding that MMP.9./- mice were only partly protected against cardiac rupture, whereas TIMP-1 overexpression resulted in complete protection, may relate to the fact that MMP-9 is unable to directly degrade interstitial collagen. However, MMP-9 does degrade basement membranes, whereas the complete degradation of collagen fibers depends on the concerted action of interstitial collagenases (MMP-1 and MMP-13) and gelatinases (MMP-2 and MMP-9). MMP-13, the main interstitial collagenase present in the mice, is another likely candidate for a role in infarct healing and cardiac rupture. This is emphasized by the fact that MMP-13 mRNA expression is significantly upregulated as early as 1 day post-infarction (chapter 3). "Taken together, these findings indicate that inhibition of MMP activity (using TIMPs or MMP inhibitors) could develop into a new approach to prevent cardiac rupture after acute myocardial infarction. To obtain maximal effects with potential future therapy, the MMP inhibitor should be used early after MI (during the first week after MI, when most ruptures occur) and the MMP inhibitors will have to block the activity of a number of MMPs (among them at least MMP-9 and MMP-13). Although broad range MMP inhibitor treatment also has positive effects on $\mathrm{LV}$ dilatation after $\mathrm{MI}$, care should be taken not to impair long-term cardiac function (paragraph 7.5).

\subsection{The role of the plasminogen system infarct healing and cardiac rupture}

The proteolytic enzyme plasmin is the active enzyme of the plasminogen system and degrades a variety of ECM components directly or via the activation of MMPs. We therefore investigated the role of the plasminogen system in infarct healing (chapters 5 and 6). In plasminogen or uPA deficient mice infarct healing was even further depressed. than after MMP inhibitor treatment (see table 1). In the Plg-/- hearts, inflammatory cells failed to migrate to the center of the infarcts and consequently, necrotic cardiomyocytes were not removed but remained present as ghost cells untill at least 5 weeks after infarction. In addition, no scar tissue was formed in the Plg- $/$ infarcted hearts. In the same collaborative study, we investigated other components of the plasminogen system in. relation to infarct healing and cardiac nupture (chapter 6). It turned out that also UPA. deficiency, but not $\mathrm{PPA}$ or uPAR deficiency, resulted in impaired healing, allthough the phenotype 
Table 1. Comparison between plasmin deficiency (either uPA-/ or Plg-/-) and MMP inhibitor treatment on several aspects of infarct healing and cardiac function

\begin{tabular}{|c|c|c|}
\hline & $\begin{array}{l}\text { MMP inhibitot treatment } \\
\text { (GM6001) }\end{array}$ & plasmin deficiency \\
\hline \multicolumn{3}{|l|}{ infarct healing } \\
\hline cellular infiltration & transient inllibition* & completely abolished \\
\hline collagen deposition (14d postMT) & $21 \%$ reduction vs. control $\mathrm{MI}$ & $99 \%$ reduction vs. WT MI \\
\hline \multicolumn{3}{|l|}{ LV remodeling } \\
\hline dilatation & transient inhibition* & no effect \\
\hline thickness of infarcted wall. & $32 \%$ increase comp. to control MT & $60 \%$ increase comp. to WT MI \\
\hline septum thickness & no effect & no effect \\
\hline cardiac functiont & major deterioration & minor deterioration \\
\hline
\end{tabular}

* nomalization at day 1.4 post MI

was less pronounced than in Plg-/-mice. In addition, uPA deficiency or adenovital PAI-1 overexpression protected against cardiac rupture.

Three distinct observations confirm that the effects of uPA/plasminogen deficiency are (party) mediated by reduced activation of MMPs. First, uPA was coexpressed with MMP-9 in infiltrating leukocytes (chapter 6). Second, MMP activity was reduced in both UPA-/- and Plg-/ - infarcts (chapters 5 and 6) and third, both interventions (MMP inhibition and $\mathrm{uPA}^{\mathrm{A}} / \mathrm{plasminogen} \mathrm{deficiency)} \mathrm{have} \mathrm{comparable}$ effects on infarct healing and cardiac rupture (chapter 5 and 6 ).

\section{Possible mechanisms of the plasminogen system to mediate infarct healing}

Together, these experiments identified the plasminogen system as a new and important regulatory system in the onset of cardiac wound healing. The mechanism through which components of the plasminogen system mediate infarct healing are based on the proteolytic activity of plasmin. Besides degtading ECM components and activating MMPs, which are essential conditions for cell migration, the plasminogen system may also act through other mechanisms. First, plasmin can activate or liberate growth factors from the ECM. For example, TGF-B1, a potent inhibitor of cell proliferation and a mediator of collagen deposition is activated by plasmin ${ }^{245}$. Reduced activation of latent TGF- $B 1$ was indeed found in 4 days old uPA-/-infarcts, indicating that the down-stream pathway of the plasminogen system in infarct healing also includes the activation of TGFB1. Second, several lines of exidence indicate molecular cross-talk between the plasminogen system and a series of other molecules ${ }^{247}$. In this regard, uPAR may regulate 


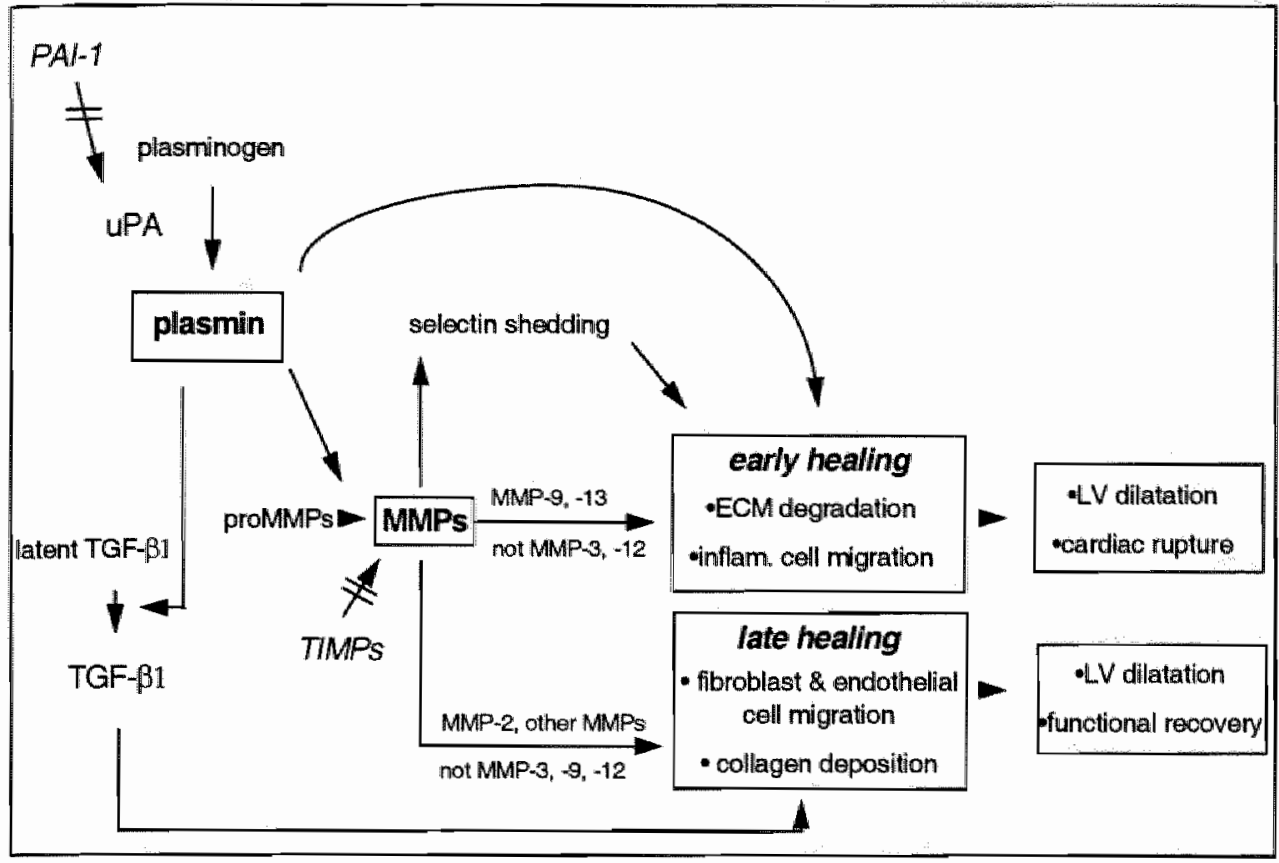

Figure 1 - The proposed mechanism of the plasminogen system and MMPs in infarct healing, $L V$ dilatation and cardiac rupture

cell migration by modulation of cell adhesion and intracellular signaling through complex formation with other integrins and vitronectin (paragraph 1.3.3). However, the findings in chapter 6 demonstrate that UPAR deficiency did not abort infarct healing, indicating that UPAR is not essential for cell migration during infarct healing. Third, selectin shedding by MMPs may be a prerequisite for neutrophil and possible monocyte migration through the endothelium. E and P-selectin are endothelial adhesion molecules which mediate the adhesion between neutrophils, monocytes and the endothelial cell surface. In order for these cells to migrate through the vessel wall, the selectins have to be cleaved off by MMPs. Fourth, plasmin and MMP activity tesults in matrix degradation fragments, which are chemotactic for inflammatory cells and other wound cells. The proposed concerted action of the plasminogen system and MMPs in infarct healing, LV dilatation and cardiac rupture are shown in figure 1.

\subsection{Impaired healing and LV dilatation}

LV dilatation and infarct thinning are prominent structural changes in the infarct region ${ }^{167}$. Patients exhibiting extensive $L V$ dilatation and infarct thinning after myocardial infarction are more likely to experience complications such as the development of congestive heart failure, aneurysm formation and myocardial rupture ${ }^{\mathrm{i} 68}$. Infarct expansion, 
defined as acute dilatation and thinning of the area of infarction, occurs within hours after infarction, before extensive collagen deposition has taken place. During this early period, the infarcted region is particularly vulnerable to distorting forces. Once healed, the scar itself is relatively nondistensible and much more resistant to further deformation. Infarct expansion is caused by myocyte slippage and stretching of the necrotic myocardium and is associated with damage to and loss of the myocardial extracellular matrix in the infarct ${ }^{43,167}$. A calssal relationship between the degradation of myocardial collagen fibers and the progression of LV dilatation has been demonstrated. Experimentally induced collagen degradation in normal myocardium has been reported to cause LV dilatation and increased chamber compliance ${ }^{170,171}$. On the other hand, inhibition of MMP activity has been demonstrated to blunt $\mathrm{LV}$ dilatation after infarction and during the development of congestive heart failure ${ }^{106,198}$.

The effects of impaired healing on LV dilatation seem complex. One might expect that impaired healing, as seen after MMP inhibitor treatment or in the Plg-/ - hearts results in salvation of the ECM in the infarct, caused by the reduction in the migration of MMP-containing inflammatory cells into the infarct. As a consequence, the collagen network is preserved, and cell slippage and LV dilatation prevented. In our studies, impaired healing after MMP inhibitor treatment indeed correlated with the prevention of extensive LV dilatation. In contrast, in $\mathrm{Plg} /$ - hearts, where the wound healing response was even further abolished, extensive LV dilatation was not prevented (see table 1). Thus, despite salvation of the collagen network in the early healing phase in the $\mathrm{Plg}-/$ - infarct, LV dilatation was comparable to that in the wild-types. This may relate to the persistent presence of necrotic cardiomyocytes and the absence of scar tissue in a later stage of healing, which increases the compliance of the infarct zone and make the Plg- $/$-infarcts more vulnerable to mechanical deformation.

\subsection{Impaired healing and cardiac function}

MMP inhibitor treatment, Plg and uPA deficiency had no effect on cardiac function in sham operated mice. However, two weeks after infarction, these interventions all resulted in depressed cardiac function. The deterioration in cardiac function was most extensive after MMP inhibitor treatment. In this group of mice, we measured depressed cardiac output levels both under basal conditions and after maximal stimulation (volume overload) of the hearts (chapter 3). Since mean arterial pressure and heart rates were not different compared to the control group, the depression in cardiac output was the result of a reduction in stroke volume. LV dilatation was not significantly affected at the time point at which cardiac output was measured ( 2 weeks post MI, see table 1 ). This suggests that the reduction in stroke volume was not the result of enlarged chamber volumes, but resulted from a different structural composition of the infarcted hearts. The only measured structural difference observed between the MMP inhibitor treated and control treated MI groups was the amount of collagen deposited in the infarcted LV. Reduced collagen deposition increases the compliance of the infarctzone, which results in mechanical disadvantages compared to control mice, where extensive collagen deposition produces a stiffer infarct ${ }^{20,203}$. Cardiac function in infarcted $\mathrm{uPA}-/$ - and $\mathrm{Plg} /$ - mice was also depressed. This reduction probably also relates to the reduction in collagen deposition and to the large necrotic myocardial segments in these infarcts. These findings 
indicate that interference in the healing process after infarction, using proteinase inhibitors, may have negative effects on cardiac function. Therefore, despite the positive effects on LV dilatation and rupture, caution should be exerted to administer MMP inhibitors to patients at risk for heart failure or cardiac rupture after MI.

\subsection{Concluding remarks and outlook}

We have identified the plasminogen system as a new and important regulatory system in the onset of cardiac wound healing. By degrading ECM molecules, directly and wia the activation of MMPs, plasmin-mediated proteolysis facilitates the migration of inflammatory cells and fibroblast-like cells, a prerequisite for adequate infarct healing. At the same time, by disrupting the collagen network, plasmin-mediated proteolysis weakens the infarcted wall and consequently contributes to infarct expansion, LV dilatation and cardiac rupture.

The MMP inhibitor used in this thesis is a "first generation" MMP inhibitor, a representative of the hydroxamates. The usefulness for clinical application will be limited by extremely poor water solubility. "Second generation" MMP inhibitors are now available, which have overcome the problem of low oral bioavailability. Another critical note is that most MMP inhibitors suppress TNF- $\alpha$ release by inhibition of TNF convertase $e^{81,83,248}$. Inhibition of this proinflammatory cytokine after infarction might have contributed to the delayed infarct healing seen after MMP inhibitor treatment. However, the observations that the delayed inflammatory and healing response could also be achieved after adenoviral TIMP transfer or in MMP-9-/-, uPA-/- and Plg-/- mice, strongly suggest that the effect of GM6001 on infarct healing was accomplished by inhibiting the activity of MMPs and not TNF- $\alpha$.

Our in vivo experiments also demonstrated that broad range inhibition of MMP activity after infarction attenuates LV dilatation and prevents fatal cardiac rupture. Unfortunately, through interference in the cardiac wound healing response, MMP inhibition additionally impairs cardiac function. A possible approach to overcome the deterioration in cardiac function is to selectively inhibit those classes of MMPs that only contribute to the weakening of the infarctzone, but not those that are involved in the migration of fibroblasts and thus scar tissue formation. In this regard, selective and transient inhibition of MMP-9 and possibly also MMP-13 during the early stage of infarct healing might have favourable effects on $L V$ dilatation and rupture without affecting scar tissue formation and cardiac function.

The issue of selective versus broad range MMP inhibition has been adressed in other fields of research as well. In dermal wound healing, selective inhibition of MMPs seems desirable, because non-specific MMP inhibition would most likely impair teepithelialization, due to inhibition of MMP-1. Inhibition of MMP-13 would be more favourable in dermal wound healing, since MMP-13 has been held responsible for the degradation of type I and III collagen and may play a role in the pathogenesis of chronic cutaneous wounds ${ }^{249}$. In cancer research, selective inhibition of the gelatinases (MMP-2 and MMP-9) has been demonstrated to prevent tumor growth and invasion ${ }^{250}$.

Furthermore, our experiments in $\mathrm{Plg} /$ - mice have shown that interference in the onset of infarct healing also has profound consequences for the continuation of the wound healing process, e.g. formation of granulation tissue and scar tissue. The absence 
of macrophages in Plg $/$ - infarcts suggests that the attraction, activation and migration of macrophages is a critical step in the onset of wound healing. Macrophage attraction and activation is regulated by factors, like macrophage colony stimulating factor (M-CSF) and monocyte chemoattractant protein-1 (MCP-1), while macrophage migration is under the control of the plasminogen system. In future experiments it would be interesting to test the hypothesis that abrogation of macrophage attraction and activation has similar profound effects on infarct healing as the abrogation of macrophage migration. The regulation of early wound healing will be the scope of future research.

In conclusion, both MMPs and the plasminogen system play a central role in infarct healing. In addition, due to the positive effects on LV dilatation and rupture, proteinase inhibitors could develop into a new approach to treat patients at risk for heart failure after MI. However, caution should be exerted since proteinase inhibitors may depress cardiac function. 
References 


\section{REFERENCES}

1. Pei $D$. Identification and characterization of the fifth membrane-type matrix metalloproteinase MT5-MMP. J Biol Chem 1999, 274:8925-8932

2. Cossins J, Dudgeon T], Catlin $\mathrm{G}$, Gearing AJ, Clements JM: Identification of MMP-18, a putative novel matrix metalloproteinase. Biochem Biophys Res Commun 1996, 228:494-498

3. Pendas AM, Knauper V, Puente XS, Llano E, Mattei MG, Apte S, Murphy G, Lopez-Otin C. Identification and characterization of a novel human matrix metalloproteinase with unique structural characteristics, chromosomal location, and tissue distribution. J Biol Chem 1997, $272: 4281-4286$

4. Matrisian LM: Metalloproteinases and their inhibitors in matrix remodeling. Trends Genet 1990, 6:121-125

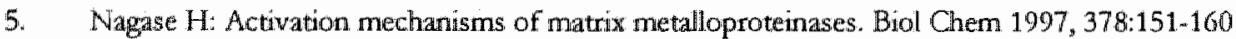

6. Ito $A$, Sato $T$, Iga $T$, Mori $Y$ : Tumor necrosis factor bifunctionally regulates matrix metalloproteinases and tissue inhibitors of metalloproteinases (TIMP) production by human fubroblasts. FEBS lett 1990, 269:93-95

7. Fabunmi RP, Sukhova GK, Sugiyama $S_{3}$ Libby P: Expression of tissue inhibitor of metalloproteinases-3 in human atheroma and regulation in lesionmassociated cells. Circ Res 1998, 83:270-278

8. Fabunmi RP, Baker $\mathrm{AH}$, Murray EI, Booth RFG, Newby AC: Divergent regulation by growth factors and cytokines of $95 \mathrm{kDa}$ and $72 \mathrm{kDa}$ gelatinases and tissue inhibitors of metalloproteinases- $1,-2$ and -3 in rabbit aortic smooth muscle cells. Biochem J 1996, 315:33534.2

9. Wang $\mathrm{H}$, Keiser $\mathrm{JA}$. Vascular endothelial growth factor upregulates the expression of matrix metalloproteinases in vascular smooth muscle cells: role of flt-1. Circ Res 1998, 83:832-840

10. Malik N, Greenfield BW, Walal AF, Kiener PA: Activation of human monocytes through CD40 induces matrix metalloproteinases. J Immunol 1996, 156:3952-3960

11. Zhang $Y$, McCluskey $K$, Fujii $K$, Wahl LM: Differential regulation of monocyte matrix metalloproteinase and TIMP-1 production by TNF-alpha, granulocyte-macrophage CSF, and IL1 beta through prostaglandin-dependent and -independent mechanisms. J Immunol 1998, $161: 3071-3076$

12. Mauviel $A$, Chung $K Y$, Agarwall $A$, Tamai $K$, Uitto $J$ : Cell-specific induction of distinct oncogenes of the jun family is responsible for differentiall regulation of collagenase gene expression by transforming growth factor beta in fibroblasts and keratinocyes. J Biol Chem 1996, $271: 10917.10923$

13. Makela M, Salo T, Larjava H: MMP-9 from TNF $\alpha$-stimulated keratinocytes binds to cell membranes and type I collagen: a cause for extended matrix degradation in inflammation. Biochem Biophys Res Commun 1998, 253:325-335

14. Mauviel A: Cytokine regulation of metalloproteinase gene expression. J Cell Biochem 1993, $53: 288-295$

15. Gomez DE, Alonso DF, Yoshiji $\mathrm{H}$, Thorgeirsson UP: Tissue inhibitor of metalloproteinases: structure, regulation and biological functions. Eur J Cell Biol 1997, 74:111-122

16. Vassalli JD, Sappino AP, Belin D: The plasminogen activator/plasmin system. J Clin Invest 1991, 88:1067-1072

17. Reuning U, Dixon EP, Little SP", Bang NU: Mitogen crosstalk accompanying urokinase receptor expression in stimulated vascular smooth muscle cells. FEBS lett 1996, 392:125 128

18. Treichel JA, Reddington M, Kreutzberg GW: Regulation of plasminogen activator inhibitor-1 mRNA accurmulation by basic fibroblast growth factor and transforming growth factor-beta1 in cultured rat astrocytes. J Neurochem 1998, 71:1944-1952 
19. Georg B, Helseth E, Lund LR, Skandsen $T$, Riccio A, Dano K, Unsgaard $G$, Andreasen $\mathbb{P A}$ Tumor necrosis factor-alpha regulates mRNA for urokinase-type pllasminogen activator and type1 plasminogen activator inhibitor in human neoplastic cell lines. Mol Cell Endocrinol 1989, 61:87-96

20. Yoshida $E$, 'Tsuchiya $K$, Sugiki $M$, Sumi $H$, Mhara $H$, Maruyama M: Modulation of the receptor for urokinase-type plasminogen activator in macrophage-like 4937 cells by inflammatory mediators. Inflammation 1996, 20:319-326

21. van Hinsbergh VW, Kooistra T, van den Berg EA, Princen HM, Fiers W, Emeis II: Tumor necrosis factor increases the production of plasminogen activator inhibitor in hunadn endothelial cells in vitro and in rats in vivo. Blood 1988, 72:1467-73

22. Lu H, Mirshahi MC, Krief $P$, Soria $C$, Soria J, Mishal $Z$, Bertrand O, Perrot JY, Li $H$, Picot $C$, Pujade E, Bemadou A, Caen JP: Parallel inducrion of fibrinolysis and and receptors for plasminogen and urokinase by interferon gamma on U937 cells. Biochem Biophys Res Commun $1988,155: 418-422$

23. Gallichio M, Hufnagl P, Wojta J, Tipping P: IFN-gamma inhibits thrombin- and endotoxininduced plasminogen activator inhibitor type I in human endothelial cells. J Immunol 1996, $157: 2610-2617$

24. Wang W, Chen H], Giedd KN, Schwartz A, Cannon PJ, Rabbani LE: T-cell lymphokines, interleukin-4 and gamma interferon, modulate the induction of vascular smooth muscle cell tissue plasminogen activator and migration by serum and platelet derived growth factor. Circ Res $1995,77: 1095-1106$

25. Mandriota SJ, Seghezzi G, Vassalli ]D, Ferrara N, Wasi $S$, Mazzieri $\mathbb{R}$, Mignatti P, Pepper MS: Vascular endothelial growth factor increases urokinase receptor expression in wascular endothelial cells. J Biol Chem 1995, 270:9709

26. Olofsson $B_{*}$ Korpelainen E, Pepper E, Pepper MS, Mandriota SJ, Aase K, Kunar V, Gunji Y, Jeltsch MM, Shibuya M, Alitalo K, Eriksson U: Vascular endothelial groth factor B (VEGF-B) binds to VEGF receptor-1 and regulates plasminogen activator activity in endothelial cells.s. Proc Natl Acad Sci U S A 1998, 95:11709-11714

27. Mandriota SJ, Pepper MS: Vascular endothelial growth factor-induced in vitro angiogenesis and plasminogen activator expression are dependent on endogenous basic fibroblast growth factor. Joumal of Cell Science 1997, 110:2293-2302

28. Stoppelli $M P$, Verde $\mathbb{P}$, Grimaldi $G$, Locatelli EK, Blasi F: Increase in urokinase plasminogen activator mRNA synthesis in human carcinoma cells is a primary effect of the potent tumor promotor, phorbol myristate acetate. J Cell Biol 1986, 102:1235-1241

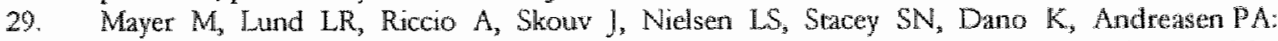
Plasminogen activator inhibitor type-1 protein, mRNA and gene transcription are increased by phorbol esters in human rhabdomyosarcoma cells. I Biol. Chem 1988, 263:15688-15693

30. Vaughan DE: The renin-angiotensin system and fibrunolysis. Am J Candiol 1997, 79:12-16

31. Allan EH, Hamilton JA, Medcalf RL, Kubota M, Martin TJ: Cyclic AMP-dependent and. independent effects on tissue-type plasminogen activator activity in osteogenic sarcoma cells; evidence from phosphodliesterase inhibition and parathyroid hormone antagonists. Biochim Biophys Acta 1986, 888:199-207

32. Pei XH, Nakanishi $Y$, Takayama $K$, Bai F, Kawasaki $M$, Hara N: G-CSF increases secretion of urokinase-type plasminogen activator by human lung cancer cells. Clin Exp Metastasis 1998, 16:551-558

33. Medcalf RL, Richards RI, Crawford RJ, Hamilton JA: Suppression of urokinase-type plasminogen activator mRNA levels in human fibrosarcoma cells and synovial fibroblasts by anti-inflammatory glucocorticoids. Embo J 1986, 92217-2222

34. Lund LR, Riccio A, Andreasen PA, Nielsen LS, Kristensen P, Laiho M, Saksela O, Blasi F, Dano $\mathrm{K}$ : Transforming growth factor-beta is a strong and fast acting positive regulator of the level of type-1 plasminogen activator inhibitor mRNA in WI-38 liuman lung fibroblasts. Enbo J 1987, $6: 1281-1286$ 
35. Rudker PM, Gaboury CL, Condin PR, Seely EW, Willams GH, Vaughan DE: Stimulation of plasminogen activator inhibitor in wivo by infusion of angiotensin II. Evidence of a potential interaction between the renin-angiotensin system and fibrinolytic function. Circulation 1993, $87: 1969-1973$

36. Bevilacqua MP, Schleef RR, Gimbrone MA, Loskutoff DJ: Regulation of the fibrinolytic system of cultured human vascular endothelium by interleukin 1. J Clin Invest 1986, 78:587-591

37. Paysant J, Vasse M, Soria J, Lenomand B, Pourtau J, Vannier JP, Soria C: Regulation of the UPAR/UPA system expressed on monocytes by the deactivating cytokines, $I L-4, \mathrm{~L}-10$ and IL-13: consequences on cell adhesion to vitronectin and fibrinogen. British Joumal of Haematology $1998,100: 45-51$

38. Graham CH, Fitzpatrick TE, McCrae KR: Hypoxia stimulates urokinase receptor expression through a heme protein-dependent pathway. Blood 1998, 91:3300-3307

39. Pinsky DJ, Liao $H$, Lawson CA, Yan SF, Chen J, Carmeliet $P$, Loskutoff DJ, Stem DM: Coordinated induction of plasminogen activator inhibitor-1 (PAI-1) and inhibition of plasminogen activator gene expression by hypoxia promotes pulmonary vascular fibrin deposition. J Chin Invest 1998, 102:919-928

40. Deng $\mathrm{G}$, Curriden $\mathrm{SA}$, Wang $\mathrm{S}$, Rosenberg $\mathrm{S}$, Loskutoff $\mathrm{D}$ : Is plasminogen activator inhibitor-1 the molecular switch that govems urokinase receptor-mediated cell adhesion cell adhesion and release? ] Cell Biol 1996, 134:1563-1571

41. Koning-Dalstra JAA, Reitsma JB (Eds.): Hartw en vaatziekten in Nedexland 1999, cijfers over ziekte en sterfte. Den Haag, Nederlandse Hartstichting, 1999, pp.

42. Kostuk WJ, Kazamias TM, Gander MP, Simon AL, Ross J: Left ventricular size after acute myocardial infarction: Serial changes and their prognostic significance. Circulation 1973, 47:11741179

43. Whittaker $P$, Boughner DR, Kloner RA: Role of collagen in acute myocardial infarct expansion. Circulation 1991, 84:2123-2134

44. Cleutjens JPM: The role of matrix metalloproteinases in heart disease. Cardiovasc Res 1996, $32: 816-821$

45. Weber KT, Sun Y, Tyagi SC, Cleutjens JPM: Collagen network of the myocardium: function, structural remodeling and regulatory mechanisms. I Mol Cell Cardiol 1994, 26:279-292

46. Bishop JE, Laurent GJ: Collagen turnower and its regulation in the nomal and hypertrophying heart. Eur Heart ] 1995, 16 Suppl C:38-44

47. Caulfield JB, Borg TK: The collagen network of the heart. Lab Invest 1979, 40:364-372

48. Mignatti P, Rifkin DB: Biology and biochemistry of proteinases in tumor invasion. Physiol Rev $1993,73: 161-195$

49. Dollery $C M$, McEwan JR, Henney AM: matrix metalloproteinases and cardiovascular disease. Circ Res 1995, 77,863-868

50. Everts $V$, van der Zee E, Creeners $L$, Beertsen W: Phagocytosis and intracellular digestion of collagen, its role in turnover and remodeling. Histochem J 1996, 28:229-245

51. Exckhout $Y$, Vaes $G$ : Further studies on the activation of procollagenase, the latent precursor of bone collagenase: effects of lysosomal cathepsin B, plasmin and kallikrein, and spontaneous activation. Biochem ] 1977, 166:21-31

52. Bond IS, Butler PE: Intracellular proteinases. Ann Rev Biochem 1987, 56:333-364

53. Tyagi SC: Proteinases and myocardial extracellular matrix turnover. Mol Cell Biochem 1997, $168: 1-12$

54. Okada $Y$, Nara K., Kawamura $\mathrm{K}$ : Localization of matrix metalloproteinase $9(92 \mathrm{kDa}$ gelatinase/type IV collagenase=gellatinase B) in osteoclasts: implications for bone resorption. Lab Invest $1995,72311-322$

55. Aimes RT, Quigley JP: Matrix metalloproteinase-2 is an interstitial collagenase. Inhibitor-free enzyme catalyzes the cleavage of collagen fibrils and soluble native type I collagen generating the specific 3/4 and 1/4-length fragments. J Biol Chem 1995, 270:5872-5876

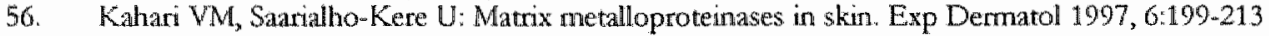

57. Woessner JF Jr: The family of matrix metalloproteinases. Alnn N Y Acad Sci 1994, 732:11-21 
58. Park AJ, Matrisian LM, Kells AF, Pearson $R_{3}$ Yuan $Z$, Nave $M$ : Mutational aralysis of the transin (rat stromelysin) autoinhibitor region demonstrates a fole for residues surrounding the "cysteine switch". J Biol Chem 1991, 266:1584 1590

59. Murphy $G$, Knauper V: Relating matrix metalloproteinase structure to function: why the hemopexin domain? Matrix Biol 1997, 15:511-518

60. Ye $S$, Humphries $S$, Henney A: Matrix metalloproteinases: implication in vascular remodeling during atherogenesis. Clinical Science 1998, 94:103-110

61. Sato H, Takino T, Okada $Y$, Cao J, Shinagawa A, Yamamoto E, Seiki M: A matrix metalloproteinase expressed on the surface of invasive tumour cells. Nature 1994, 370:61-65

62. Schonbeck U, Mach F, Sukhova GK, Murphy C, Bonnefoy JY, Fabunmi RP, Libby P: Regulation of matrix metalloproteinase expression in human wascular smooth muscl cells by $T$ lymphocytes. Circ Res 1997, 81:448-454

63. Wassenaar A, Verschoor T, Kievits F, Den Hartog MT, Kapsenberg ML: CD40 engagement modulates the production of matrix metalloproteinases by gingival fibroblasts. Clin Exp Immunol 1999, 115:161-167

64. Angel $\mathrm{P}$, Baumann $I$, Stein $B$, Delius $H$, Rahmsdorf $H$ J, Herrlich P: TPA induction of the human collagenase gene is mediated by an inducible enhancer element located in the $5^{\text {' }}$-flanking region. Mol Cell Biol 1987, 7:2256-2266

65. Gutman A, Wasylyk B: The collagenase gene promoter contains a TPA and oncogene-responsive unit encompassing the PEA3 and AP-1 binding sites. Embo $\int 1990,92241-2246$

66. Benbow U, Brincerhoff $C E$ : The AP-1 site and MMP gene regulation: what is all the fuss about. Matrix Biol 1997, 15:519-526

67. Jonat $C$, Rahmsdorf HJ, Park KK, Cato ACB, Gebel S, Ponta H, Herrlich P: Antitumor promotion and antiinflammation: down-modulation of AP-1 (fos/jun) activity by glucocorticoid hormone. Cell 1990, 62:1189-1204

68. Bond M, Fabunmi RP, Baker AH, Newby AC: Synergistic upregulation of metalloproteinase- 9 by growth factors and inflammatory cytokines: an absolute requirement for transcription factor NFkappaB. FEBS lett 1998, 435:29-34

69. Huhtala $P$, Chow LT, Tryggvason $K$ : Stnucture of the human type IV collagenase gene. J Biol Chem 1990, 265:11077-11082

70. Murphy $\mathrm{G}$, Willenbrock $\mathrm{F}$, Crabbe $\mathrm{T}$, O'Shea $\mathrm{M}$, Ward $\mathrm{R}$, Atkinson S, O'Connell $]$, Docherty A: Regullation of matrix metalloproteinase activity. Ann N Y Acad Sci 1994, 732:31-41

71. Sato $H$, Takino T, Kinoshita $T$, Imai $K$, Okada $Y$, Stetler Stevenson WG, Seiki M: Cell surface binding and activation of gelatinase $A$ induced by expression of membrane-type-1-matrix metalloproteinase (MT1-MMP). FEBS lett 1996, 385:238-240

72. Knauper V, Cowell S, Smith B, Lopez-Otin C, OShea M, Morris H, Zardi L, Munplyy G The role of the C-terminal domain of human collagenase-3 (MMP-13) in the activation of procollagenase-3, substrate specifity, and tissue inhibitor of metalloproteinase interaction. J Biol Chem 1997, 272:7608-7616

73. Pei $D$, Weiss SJ: Furin-dependent intracellular activation of the human stromelysin-3 zymogen. Nature 1995, 375:244:247

74. Sato $H$, Kinoshita $T$, Takino $T$, Nakayama $K$, Seiki $M$ : Activation of a recombinant membrane type 1umatrix metalloproteinase (MT-MMP) by furin and its interaction with tissue inhibitor of metalloproteinases (TIMP)-2. FEBS lett 1996, 393:101-104

75. Liu YE, Wang $M$, Greene J, Su J. Ullrich S, Li H, Sheng S, Alexander P, Sang QA, Shï YE: Preparation and characterization of recombinant tissue inhibitor of metalloproteinase 4 (TIMP4). \Biol Chem 1997, 272:20479-20483

76. Greene 1, Wang M, Liu YE, Raymond LA, Rosen C, Shi YE: Molecular cloning and characterization of human tissue inhibitor of metalloproteinase 4.J Biol Chem 1996, 271:3037530380

77. Hayalkawa $\mathrm{T}$, Yamashita $\mathrm{K}$, Ohuchi $\mathrm{E}$, Shinagawa A: Cell growth-promoting activity of tissue inhibitor of metalloproteinases-2 (TIMP-2). J Cell Sci 1994, 107:2373-2379 
78. Hayakawa $T$, Yamashica $K$, Tanzawa $K$, Uchijima $E$, Iwata $K$ : Growh promoting activity of tissue inhibitor of metalloprotemases-1 (TMM-1) for a wide range of cells. A possible new growth factor in serum. FEBS lett 1992, 298:29-32

79. Thorgeirsson U1, Yoshij H, Sintia CC, Gomez DE: Breast cancer, tumor neovasculature and the effect of tissue inhibitor of metalloproteinases-1 (TIMP-1) on angiogenesis. In Vivo 1996, $10: 137-144$

80. Baker AH, Zaltsman AB, George SJ, Newby AC: Divergent effects of tissue inhibitor of metalloproteinase-1, -2 or -3 overexpression on rat vascular smooth muscle cell invasion, proliferation, and death in witro. TTMP-3 promotes apoptosis. J Clin Invest 1998, 101:1478-1487

81. Gearing AJH, Beckett $P$, Christodoulou $M$, Churchill $M$, Clements I, Davidson $A H$, Drummond AH, Galloway WA, Gibert R, Gordon JL, Leber TM, Mangan M, Miller K, Nayee P, Owen $K$, Patel S, Thomas W, Wells G, Wood LM, Woolley $\mathrm{K}$. Processing of tumour necrosis factor-alpha precursor by metalloproteinases. Nature 1994, 370:555-557

82. Schonbeck U, Mach F, Libby P: Generation of biologically active IL-1 beta by matrix metalloproteinases: a novel caspase-1-independent pathway of IL-1 beta processing. I Immunol $1998,161: 3340-3346$

83. Hodggon J: Remodeling MMPIs. Biotechnology 1995, 13:554-557

84. Taraboletti $G$, Garofalo $A$, Belotti D, Drudis T, Borsotti $P$, Scanziani $\mathbb{E}$, Brown PD, Giavazzi $\mathbb{R}$ : Inhibition of angiogenesis and murine hemangioma growth by batimastat, a synthetic inhibitor of metalloproteinases. Natl Cancer Inst 1995, 87:293-298

85. Lewis EJ, Bishop J, Bottomley KMK, Bradshaw D, Brewster $M$, Broadhurst M], Brown PA, Budd JM, Elliott L, Greentham AK, Johnson WH, Nixon JS, Rose F, Sutton B, Wilson K: Ro 323555 , and orally active collagenase inhibitor, prevents cartilage breakdown in vitro and in viwo. British Journal of Pharmacology 1997, 121:540-546

86. Witte MB, Thomton F], Kiyana $T$, Efron DT, Schultz GS, Moldawer LL, Barbul A: Metalloproteinase inhibitors and wound healing: a novel enhancer of wound strength. Surgery $1998,124: 464470$

87. Galardy RE, Cassabonne ME, Giese C, Gilbert JH, Lapierre F, Lopez H, Schaefer ME, Stack R, Sullivan $M$, Summers $B$, Tressler $R$, Tyrrell D, Wee J, Allen SD, Castellot JJ, Barletta JP, Schultz GS, Fernandez LA, Fisher S, Cui T, Foellmer HG, Grobelny D, Holleran WM: Low molecular weight inhibitors in comeal ulceration. Ann N Y Acad Sci 1994, 732:315-323.

88. Bigatel DA, Elmore JR, Carey DJ, Cizmeci-Smith $G$, Franklin DP, Youkey JR: The matrix metalloproteinase inhibitor BB-94 limits expansion of experimental abdominal aortic aneurysms. J Vasc Surg 1999, 29:1301-139

89. Bendeck MP, Irvin C, Reidy MA: Inhibition of matrix metalloproteinase activity inhibits smooth muscle cell migration but not neointimal thickening after arterial injury. Circ Res 1996, 78:38-43

90. Strauss BH, Robinson R, Batchelor WB, Chisholm RJ, Ravi G, Natarajan MK, Logan RA, Mehta SR, Levy DE, Ezrin AM, Keelley EW: In viwo collagen turnover following experimental balloon angioplasty injury and the role of matrix metalloproteinases. Circ Res 1996,79:541-550

91. Forough $R$, Koyama $N$, Hasenstab $D$, Lea $H$, Clowes $M$, Nikkari ST, Clowes AW: Overexpression of tissue inhibitor of matrix metalloproteinase-1 inhibits vascular smooth muscle cell function in vitio and in vivo. Circ Res 1996, 79:812-820

92. Forough $R$, Lea $H$, Starcher $B$, Allaire $B$, Clowes $M$, Hasenstab $D$, Clowes AW: Metalloproteinase blockade by local overexpression of TIMP -1 increases elastin accumulation in rat carotid artery intima. Arterioscler Thromb Vasc Biol 1998, 18:803 807

93. Allaire $\mathrm{E}_{\mathrm{x}}$ Forough $\mathrm{R}$, Clowes $\mathrm{M}_{\mathrm{x}}$ Starcher $\mathrm{B}$, Clowes $\mathrm{AW}$ : Local overexpression of TMMP-1 prevents aortic aneurysm degeneration and nupture in at rat model. J Clin Invest 1998, 102,14131420

94. George SJ, Baker AH, Angelini GD, Newby AC: Gene transfer of tissue inhibitor of metalloproteinase-2 inhibits metalloproteinase activity and neointima formation in human saphenous veins. Gene Ther 1998, 5:1552-1560

95. Montfort I, Perez-Tamayo R: The distribution of collagenase in nomal rat tissues. J Histochem Cytochem $1975,23: 910-920$ 
96. Cleutiens JPM, Kandala JC, Guarda $E$, Guntaka RV, Weber KT: Regulation of collagen degradation in the rat myocardium after infarction. J Mol Cell Cardiol 1994, 27:1281-1292

97. Coker MS, Thomas CV, Doscher MA: Matrix metalloproteinase expression and activity in adult ventricular myocytes: influence of basement membrane adhesion. Circulation 1997, 96 (Suppll. 1) 1 - 689

98. Tyagi SC, Matsubara L, Weber KT: Direct extraction and estimation of collagenase(s) activity by zymography in microquantities of rat myocardium and uterus. Clin Biochem 1993, 26:191-198

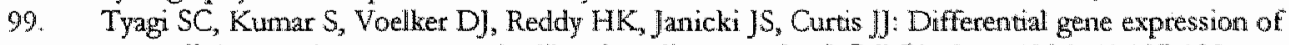
extracellular matrix components in dilated cardiomyopathy. J Cell Biochem 1996, 63:185-198

100. D'Armiento JM, Kim HE, O'Byme TK, Chen CT, Weisfeldt ML, Dalal SS: Myocardial overexpression of collagenase in the transgenic mouse produces left ventricular hypertrophy and hypercontractility. Circulation 1997, 96:1-520

101. Tyagi SC, Kumar SG, Haas SJ, Reddy HK, Voelker DJ, Hayden MR, Demmy TL, Schmaltz RA, Curtis J]: Post-transcriptional regulation of extracellular regulation of extracellular matrix metalloproteinase in human heart end-stage failure secondary to ischemic cardionyopathy. I Mol Cell Cardiol 1996, 28:1415-1428

102. Herzog $E$, Gu A, Kohmoto $T$, Burkhoff $D$, Hochman JS: Early activation of metalloproteinases after experimental myocardial infarction occurs in infarct and non-infarct zones. Cardiovasc Pathol 1998,7:307-312

103. Carlyle WC, Jacobson AW, Judd DL, Tian B, Chu C, Hauer KM, Harman MM, McDonald KM: Delayed reperfusion alters matrix metalloproteinase activity and fibronectin mRNA expression in the infarct zone of the ligated rat heart. J Mol Cell Cardiol 1997, 29:2451-2463.

104. Sato S, Ashraf M, Millard RW, Fujwara H, Schwartz A: Connective tissue changes in early ischemia of porcine myocardium: an ultrastructural study. J Mol Cell Cardiol 1983, 15:261.275

105. Danielsen CC, Wiggers $\mathrm{H}$, Andersen HR: Increased amounts of collagenase and gelatinase in porcine myocardium following ischemia and reperfusion. J Mol Cell Cardiol 1998, 30:1431-14.42.

106. Rohde LE, Ducharme A, Arroyo LH, Aikawa M, Sukhova GH, Lopez-Anaya A, McClure KF, Mitchell PG, Libby P, Lee RT: Matrix metalloproteinase inhibition attenuates early left ventricular enlargement after experimental myocardial infarction in mice. Circulation 1999, 99-3063-3070

107. Li YY, Feldman AM, Sun Y, McTiernan CF: Differential expression of tissue inhibitors of metalloproteinases in the failing human heart. Circulation 1998, 98:1728-1734

108. Cameliet P, Collen D: Genetic analysis of the plasminogen and coagulation system in mice. Haemostasis 1996, 26:132-153.

109. Mayer M: Biochemical and biological aspects of the plasminogen activation system. Clin Biochem $1990,23: 197-211$

110. Wiman $B$, Collen $D$ : Molecular mechanism of physiological fibrinolysis. Nature $1978,272549$. 550

111. Ponting CP, Marshall JM, Cederholm-Williams SA: Plasminogen: a strucrural rewiew. Blood Coagulation and Fibrinolysis 1992, 3:605-614

112. Ji WR, Castellino FJ, Chang $Y$, Deford ME, Gray H, Villarreal X, Eghtedarzadeh K, Marti DN, Llinas $M$, Schaller ], Kramer RA, Trail $\mathbb{P} A$ : Characterization of kringle domains of angiostatin as antagonists of endothelial cell migration, an important process in angiogenesis. Faseb J 1998, $12: 1731-1738$

113. OrReilly MS, Holmgren $L$, Shing $Y$, Chen $C$, Rosenthal RA, Moses M, Lane WS, Cao $Y$, Sage $\mathrm{EH}$, Folkman J: Angiostatin: a novel angiogenesis inhibitor that mediates the suppression of metastases by a Lewis lung carcinoma. Cell 1994, 79:315-328

114. Gately S, Twardowski P, Stack MS, Cundiff DL, Grella D, Castellino FJ, Enghild J, Kwaan HC, Lee: $\mathbb{F}$, Kramer RA, Volpert $O$, Bouck $N$, Soff GA: The mechanism of cancer-mediated conversion of plasminogen to the angiogenesis inhibitor angiostatin. Proc Natl Acad Sci U S A 1997, 94:10868-10872

115. Mignatti $P_{3}$ Rifkin DB: Plasminogen activators and matrix metalloproteinases in angiogenesis. Enzyme Protein 1996, 49:117-137

116. Lijnen HR: Pathophysiology of the plasminogen/plasmin system. Int J Clin Lab Res 1996, 26:1-6 
117. Cammeliet $P$, Collen $D$ : Gene targeting and gene transfer studtes of the biological role of the plasminogen/plasmin system. Thromb Haemost 1995, 74:429-436

118. Hajjar $\mathrm{KA}$, Jacowina $\mathrm{AT}$, Chacko J: An endothelial cell receptor for plasminogen/tissue plasminogen activator 1. identity with annexin II. I Biol Chem 1994, 269:21191-21197

119. Cesamann GM, Guevara CA, Hajjar KA: An endothelial cell receptor for plasminogen/tissue. plasminogen activator ( $I P A)$. II. Annexin II-mediated enhancement of $t P A$ dependent plasminogen activation. J Biol Chen 1994, 269:21198-21203

120. Moser TL, Enghild J], Pizzo SV, Stack MS: The extracellular matrix proteins laminin and fibronectin contain binding domains for human plasminogen and tissue plasminogen activator. J Biol Chem 1993, 268:18917-18923

121. Eitzman DT; Ginsburg D: Of mice and men: the function of plasminogen activator inhibitors (PAIs) in vivo Adv Exp Med Biol 1997, 425:131-141

122. Dear AE, Medcalf RL: The cellular and molecular biology of plasminogen activator inhibitor- 2 . Fibrinolysis $1995,9.321$

123. Dougherty KM, Pearson JM, Yang AY, Westrick R], Baker MS, Girasburg D: The plasminogen activator inhibitor-2 gene is not required for nomal murine development or survival. Proc $\mathbb{N a t}$. Acad Sci U S A 1996), 96:686-691

124. Ploug $M$, Kjalker M, Ronne $E_{s}$ Weidle $U$, Hoyer-Hansen $G$, Dano $K$ : Localization of the disulfide bonds in the NH2-terminal domain of the cellulat receptor for human urokinase-type plasminogen activator. A domain structure belonging to a novel superfamily of giycolipidanchored membrane proteins. J Biol Chem 1993, 268:17539-17546

125. Cubellis MV, Wun TC, Blasi F: receptor mediated internalization and degradation of urokinase is caused by its specific inhibitor PAI-1. Embo J 1990, 9:1079-1085

126. Wei $\mathrm{Y}$, Waltz DA, Rac N, Drummond RJ, Rosenberg $S$, Chapman HA: Identification of the urokinase receptor as an adhesion receptor for vitunectin. ] Bioll Chem 1994, 269:32380-32388

127. Wei $Y$, Lukashev M, Simon DI, Bodary SC, Roseenberg S, Doyle MV, Chapman HA: Regulation of integrin function by the urokinase receptor. Science 1996, 273:1551-1555

128. Tang $h$, Kerins DM, Hao Q. Inagami " $T$, Vaughan DE: The urokinase-type plasminogen activator receptor mediates tyrosine phosphorylation of focal adhesion proteins and activation of mitogenactivated protein kinase in cultured endothelial cells. J Biol Chem 1998, 273:18268-18272

129. Mizukami IF, Faulkner NE, Gyetko MR, Sitrin RG, Todd RF: Enzyme-linked immunoabsorbent assay detection of a soluble form of urokinase plasminogen activator receptor in vivo. Blood $1905,86: 203$

130. Patterson BC, Sang QA: Angiostatin-converting enzyme activities of human matrilysin (MMP-7) and gelatinase B/type IV collagenase (MMP-9). I Biol Chem 1997, 272:28823-28825

131. Dong ZY, Kumar R, Yang XI, Fidler IJ: Macrophage derived metalloelastase is responsible for the generation of angiostatin in Lewis lung carcinoma. Cell 1997, 88:801-810

132. Lijnen $H R$, Ugwu $F$, Bini $A$, Collen $D$ : Generation of an angrostatin-like fragment from plasminogen by stromelysin-1 (MMP-3). Biochemistry 1998, 37:4699.4702

133. Cao Y, Ji RW, Davidson D, Schaller J, Marti D, Sohndel S, McCance SG, O'Reilly MS, L Linas M, folkman I: Kringle donains of human angiostatin; claracterization of the anti-proliferative activity on endothelial cells. J Biol Chem 1996, 271:29461-29467

134. Brooks WW, Bing OHL, Conrad CH, ONeill L, Crow MT, Lakatta EG, Dostal DE, Baker KM, Boluyt MO: Captopril modifies gene expression in hypertrophied and failing hearts of aged spontaneously hypertensive rat. Hypertension 1997, 30:1362-1368

135. Griscelli F, Li H, Bennaceur-Griscelli A, Soria J, Opolon P, Soria C, Perricaudet M, Yeh P, Lu H: Angiostatin gene transfer: inhibition of tumor growth in vivo by blockage of endothelial cell proliferation associated with a mitosis arrest. Proc Natl Acad Sci US A 1998, 95:6367-6372

136. Claesson-Welsh L, Welsh M, Ito N, Anand-Apte B, Soker S, Zetter B, O'Reilly, Folkman J: Angiostatin induces endothelial cell apoptosis and activation of focal adhesion kinase independently of the integrin-binding motif RGD. Proc Natl Acad Sci U S A 1998, 95:5579-5585

137. Moser TL, Stack MS, Asplin I, Enghild JJ, Hojrup P, Everitt L, Hubchak S, Schnaper $\mathbb{H W}$, Pizzo SV: Angiostatin binds ATP synthase on the surface of human endothelial cells. Proc Nat Acad Sci U S A $1999,96: 2811-2816$ 
138. Stathakis $P$, Fitzgerald $M$, Matthias $L$, Chesterman $C N$, Hogg PJ: Generation of angiostatin by reduction and proteolysis of plasmin. Catalysis by a plasmin reductase secreted by cultured cells.) Biol Chem 1997, 272:20641-20645

139. Cao $Y$, Chen $A$, An SSA, Ji $R W$, Davidson $D$, Cao $Y$, Llinas $M$ : Kringle 5 of plasminogen is a novel inhibitor of endothelial cell growth. J Biol Chem 1997, 272:22924-22928

140. Botteri FM, Ballmer-Hofer $\mathrm{K}$, Rajput B, Nagamine Y: Disruption of cytoskelletal structures result. in the induction of the urokinase-type plasminogen activator gene expression. J Biol Chem 1990, 265:13327-13334

141. Vaughan DE: Fibrinolytic balance, the renin-angiotensin system and atherosclerotic disease. Eur Heart J 1998, 19:G9-12

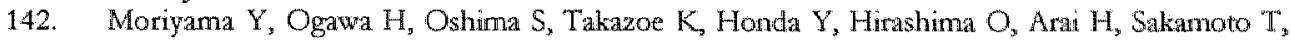
Sumida $H$, Suefuji $H$, Kaikita $K$, Yasue $H$ : Captopril reduces plasminogen activator inhibitor activity in patients with acure myocardial infarction. Jpn Circ ] 1997,61:308-314

143. Oikawa $T$, Freeman $M$, Lo W, Vaughan DE, Fogo A: Modulation of plasminogen activator imhibitor-1 in vivo: a new mechanism for the anti-fibrotic effect of renin-angiotensin unhibition. Kidney Int 1997, 51:164-172

144. Cameliet P, Collen D: Gene manipulation and transfer of the plasminogen and coagulation. system in mice. Thromb Haenost 1996, 22:525-542

145. Estreicher $A$, Muhlhauser J, Carpentier JL, Orci L, Vassalli JD: The receptor for urokinase type plasminogen activates polarizes expression of the protease to the leading edge of migrating monocytes and promotes degradation of enzyme inhibitor complexes. J Cell Bioll 1990, 111:783792

146. Kjoller L, Kanse SM, Kirkegaard $T$, Rodenburg KW, Ronne $\mathrm{E}_{\mathrm{x}}$ Goodman SL, Preissner KT, Ossowski L, Andreasem PA: Plasminogen activator inhibitor-1 represses integrin- and vitronectin mediated cell migration independently of its function as an inhibitor of plasminogen activation. Exp Cell Res 1997, 232:420-429

147. Singer SJ, Kupfer A: The directed migration of eukaryotic cells. Annu Rev Cell Biol 1986, 2:337. 365

148. Stefansson S, Haudenschild CC, Lawrence DA: Beyond fibrinolysis: The role of plasminogen activator inhibitor-1 and vitronectin in vascular wound healing. Trends Cardiovasc Med 1928, 8:175-180

149. Cameliet P, Moons L, Lijnen $R$, Janssens S, Lupu F, Collen D, Gerard RD: Inhibitory role of plasminogen activator inhibitor-1 in arterial wound healing and neointima formation. Circulation $1997,96: 3180-3191$

150. Blasi F: UPA, UPAR, PAI-1: key intersection of proteolytic and adhesive and chemotactic highways? Immunology Today 1997, 18:415-417

151. Waltz DA, Natkin LR, Fujita RM, Wei Y, Chapman HA: Plasmin and plasminogen activator inhibitor type 1 promote cellular motility by regulating the interaction between the urokinase receptor and vitronectin. J Clin Invest 1997, 100:58 67

152. Conese $M$, Blasi $F$ : Urokinase/urokinase receptor system: intemalization/degradation of urokinase-serpin complexes: mechanism and regulation. Biol Chem Hoppe-Seyler 1995, 376:143155

153. Schmitt $M$, wilhelm $O$, Janicke $F$, Magdolen $V$, Reuning $U$, Ohi $M$, Moniwa $N$, Kobayashi $\mathbb{H}$, Weidle $U$, Graeff $H$ : Urokinase-type plasminogen activator (UPA) and its receptor (CDBT): a new

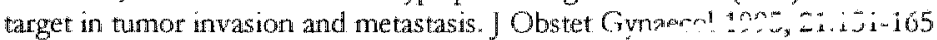

154. Carmeliet P, Moons L, Dewerchin M, Rosenberg S, Herbert JM, Lupu F, Collen D: Receptorindependent role of urokinase-type plasminogen activator in pericellular plasmin and matrix metalloproteinase proteolysis dwring vascular wound healing in mice. I Cell Birll 1998, 140:233245

155. Salksela $\mathrm{O}$, Rifkin DB: Release of basic growth factor-heparan sulfate complexes from endothelial cells by plasminogen activator-mediated proteolytic activity. J Cell Biol 1990, 110:767-775

156. Mignatt $P$, Mazzieri $R$, Rifkin $D B$ : Expression of the urokinase receptor in vascular endothelial cells is stimulated by basic fibroblast growth factor. I Cell Biol 1991, 113:1193-1201 
157. Lyons RM, Gentry LE, Purchio AF, Moses HL: Mechanism of activation of latent recombinant transforming growth factor- $\beta 1$ by plasmin. I Cell Biol 1990; 110:1361-1367

158. Ploplis $\mathrm{VA}$, Carmeliet $\mathrm{P}$, Vazirzadeh V, Vlaenderen van I, Moons L, Plow EF, Collen D: Effects of disruption of the plasminogen gene on thrombosis, growth, and health in mice. Circulation $1995,922585-2593$

159. Carmeliet P. Moons L, Ploplis V, Plow E, Collen D: Impaired arterial neointima formation in mice with disruption of the plasminogen gene. J Clin Invest 1997, 99:200-208

160. Lijnen HR, yan Hoef $B$, Lupu $F_{\text {s }}$, Moons $L$, Cameliet $P_{\text {, Collen }} D$ : Function of the plusminogen/plastmin and matrix metalloproteinase systems after vascular injury in mice with targeted inactivation of fibrinolytic system genes. Arterioscler Tromb Vasc Biol 1998, 18:10351045

161. Romer J, Bugge TH, Pylke C, Lund LR, Flick MJ, Degen JL, Dano K. Impaired wound healing in mice with a disrupted plasminogen gene. Nat Med 1996, 2:287-292

162. Ploplis VA, French EL, Cameliet $P$, Collen D, Plow EF: Plasminogen deficiency differentially affects recruitment of inflammatory cell population in mice. Blood 1998, 91:2005-2009

163. Takahashi $S$, Barry AC, Factor SM: Collagen degradation in ischaemic rat hearts. Biochem I] 1990, 265:233-241

164. Weber $\mathrm{KT}^{*}$, Sun $\mathrm{Y}$, Cleutjens JPM: Structural remodeling of the myocardium postinfarction: potential mechanisms and influence of therapy. Cardiol Rev 1995, 3:53-65

165. Jugdutt BI, Amy RW: Healing after myocardiall infarction in the dog: changes in infarct hydroxyproline and topography. J Am Coll Cardiol 1986, 9:91-102

160. Willems IE, Havenith MG, De Mey JG, Daemen MIAP: The alpha-smoath muscle actin-positive cells in heading human myocardial scars. Am J Pathol 1994, 145:868-875

167. Weisman HF, Bush DE, Mannisi JA, Weisfeldt ML, Healy B: Cellular mechanisms of myocardial expansion. Circulation 1988,78:186-201

168. Pfeffer MA, Braunwald E: Ventricular remodeling after myocardial infarction: experimental observations and clinical implications. Circulation 1990, 81:1161-1172

169. Jugdutt BI, Khan MI: Impact of increased infarct transmurality on remodeling and function during healing after anterior myocardial infarction in the dog. Can ] Physiol. Pharmacol 1992, $70.949-958$

170. Caulfield JB, Norton P, Weaver RD: Cardiac dilatation associated with collagen alterations. Mol Cell Biochem 1992, 118:171-179

171. Janicki $\$, Brower $G L$, Henegar $\llbracket R$, Wang $L$ : Ventricular remodeling in heart failure: the role of myocardial collagen. Adw Exp Med Biol 1995, 382:239-245

172. Hammetmatn $H$, Kloner $R A$, Schoen $F$, Hale $S$, Braunwald $E$ : Indomethacin-induced scar thinning atter experimental myocardial infarction. Circulation 1983, 67:1290-1295

173. Jugdut BI: Delayed effects of early infarct-limiting therapies on healing after myocardial inlarction. Circulation 1985, 72:907-914

174. Brown EJ, Klone RA, Schoen FJ, Hammerman H, Hale S, Braunwald E: Scar thinning due to ibuprofen administration after experimental myocardial infarction. Am J Cardiol 1983, 51:877883

175. Jugdutt BI, Basualdo CA: Myocardial infarct expansion during indomethacin or buprofen therapy for symptomatic postinfarction pericarditis: Influence of other pharmacological agents during remodeling. Can J Cardiol 1989, 5:211-221

176. Weber KT: Monitoring tissue repair and fibrosis from a distance. Circulation 1997, 96:2488-2492

177. Weber $\mathrm{KT}$, Brilla $\mathrm{CG}$, Janicki JS: Myocandial fibrosis: functional significance and regulatory factors. Cardiovasc Res 1993, 27,341-348

178. Kato $S$, Spinale $\mathbb{F G}$, Tanaka $R$, Johnson W, Cooper $G$ th, Zile MR: Inhibition of collagen crosslinking: effects on fibrillar collagen and ventricular diastolic function. Am J Physiol 1995, 269:-1:-1863-H868

179. Cleutjens JPM, Verluyten MJA, Smits JFM, Daemen MJAP: Collagen remodeling after myocardial infarction in the rat heart. Am J Pathol 1995, 147:1-14 
180. Campbell SE, Diaz-Arias AA, Weber KT: Myocardial nupture postinfarction. Wound healing in cardiowascular disease. Edited by Weber RT. New York, Futura Publishing Company, 1995, pp. 49-60.

181. Tyagi SC, Campbell SE, Reddy HK, Tjahia E, Voelker DJ: Matrix metalloproteinase activity expression in infarcted, noninfarcted and dilated cardiomyopathic human hearts. Mol Cell Biochem 1.996, 155:13-21

182. Spinale $F G$, Coker ML, Thomas CW, Walker JD, Mukheriee R, Hebbar L: Time-dependent changes in matrix metalloproteinase activity and expression during the progression of congestive heart failure. Circ Res 1998, 82:482-495

183. Zhang J, Fujimoto $N$, Iwata $K$, Sakai $T$, Okada $Y$, Hayakawa T: A onewstep sardwich enzyme immunoassay for human matrix metalloproteinase 1 (interstitial collagenase) using monoclonal antibodies. Clin Chim Acta 1993,219:1-14

184. Obata $K$, Iwata $K$, Okada $Y$, Kohrin $Y$, Ohuchi $\mathbb{E}$, Yoshida S, Shinmei M, Hayakawa $T$ : A onestep sandwich enzyme immunoassay for human matrix metalloproteinase 3 (stromelysin-1) using monoclonal antibodies. Clin Chim Acta 1992, 211:59-72

185. Laszlo A, Sohar I, Sagi I, Kovacs ], Kovacs A: Activity of cathepsin $\mathrm{H}, \mathrm{B}$ and metalloproteinase in the serum of patients with acute myocardial infarction. Clin Chim Acta 1992, 210:233-235

186. Weber KT, Pick R, Janicki JS: Inadequate collagen thethers in delated cardiopatlyy. Am Heart J $1988,116: 1641-1640$

187. Knox JB, Sukhova $G K$, Whattemore $A D$, Libby $P$ : Evidence for altered balance between matrix metalloproteinases and their inhibitors in human aortic diseases. Circulation 1997, 95:205-212

188. Galis ZS, Sukhova GK, Lark MW, Libby P: Increased expression of matrix metalloproteinases and matrix degrading activity in vulnerable regions of human atherosclerotic plaques. J Clin Invest 1994, 94:2493-2503

189. Cannon RO, Butany JW, McManus BM, Speir E, Kravitz AB, Bolli $R$, Ferrans V]: Early degradation of collagen after acute myocardial infarction in the rat. Am J Cardiol 1983,52:390395

190. Cameliet P, Moons L, Lijnen R, Baes M, Lemaitre V, Tipping P, Drew A, Eeckhout Y, Shapiro $S$, Lupu $F$, Collen $D$ : Urokinase-generated plasmin activates matrix metalloproteinases during aneurysm formation. Nat Gen 1997, 17:439-444

191. Lewis JL, Burchell $H B$, Titus JL: Clinical and pathological features of postinfarction cardiac tupture. Am J Cardiol 1969, 23:43-53

192. Dellborg $M$, Held $P$, Swedberg $K$, Vedin A: Rupture of the myocardium: occurence and risk factors. Br Heart J $1985,54: 11-16$

193. Mann JM, Roberts WC: Rupture of the left wentricular free wall during acute myocardial infarction: analysis of 138 necropsy patients and comparision with 50 necropsy patients with acute myocardial infarction without rupture. Am J Cardiol 1988, 62:847-859

194. Thompson RW, Parks WC: Role of matrix metalloprotenases in abdominal aortic aneurysms. Ann N Y Acad Sci 1996, 800:157 174

195. Lunseth $\mathrm{JH}$, Ruwaldt $\mathrm{M}$. Pathogenesis of cardiac nupture due to myocardial infarction: a study of twenty-six cases. Dis Chest 1956, 30:499-507

196. Thomas CV, Coker ML, Zellner JI, Handy JR, Crumbley AI 3rd, Spinale FG. Increased matrix metalloproteinase activity and selective upregulation in LV myocardium from patients with endstage dilated cardiomyopathy. Circulation 1998, 97:1708-1715

197. Jugdutt BI: Prevention of ventricular remodelling post myocardial infarction: timing and duration of therapy. Can J Carctiol 1993, 9:103-114

198. Spinale FG, Coker ML, Krombach SR, Mukherjee R, Hallak H, Houck WV, Clair MJ, Kribbs SB, Johnson LL, Peterson JT, Zile MR: Matrix metalloproteinase inhibition during the development of congestive heart failure: effects on left ventricular dimensions and function. Circ Res 1999, 85:364-376

199. Lutgens E, Daemen MJAP, de Muinck ED, Smits JFM: Chronic myocardial infarction in mice: structural and functional consequences. Cardiovasc Res 1999, 41:586-593.

200. Bendeck MP, Zempo N, Clowes AW, Galardy RE, Reidy MA: Smooth muscle cell migration and matrix metalloprotenase expression after arterial injury in the rat. Circ Res 1994, 75.539-545 
201. Hanemaijer $R$, Visser $H$, Kontinen $Y T$, Koolwijk $P$, Verheifen $J H$ : A novel and simple immunocapture assay for determination of gelatinase-b (mmp-9) activities in biological fluids: saliva from patients with Sjorgen's syndrome contain increased latent and active gelatinase-b levels. Matrix Biol 1998; 17:657-665

202. Leenen PJ, de Bruin $\mathrm{Ml}^{-7}$, Voeman $\ \mathrm{~S}$, Campbell PA, van Exwijk W: Markers of mouse macrophage devellopment detected by monoclonal antibodies. J Immunol Meth 1994, 174:5-19

203. Pfeffer MA, Pfeffer JM, Fishbein $M C$, Fletcher PJ, Spadaro J, Kloner RA, Braunwald E: Myocardial infarct size and ventrieular function in rats. Circ Res 1979, 44:503-512

204. Heymans $S$, Luthun A, Nuyens D, Theilmeier $G$, Cremers E, Moons L, Dyspersin GD, Cleutjens JPM, Shipley M, Angellilo A, Levi M, Nube O, Baker A, Keshet E, Lupu F, Herbert JM, Smits JE, Shapiro SD, Baes $M$, Borgers $M$, Collen $D$, Daemen $M$, Carmeliet $P$ : Inhibition of plasminogen activators or matrix metalloproteinases prevent cardiac rupture but impairs therapeutic angiogenesis and causes cardiac failure. Nat Med 1999, 10:1135-1142

205. Narayanan AS, Page RC, Swanson J: Collagen synthesis by human fibroblasts. Regullation by transforming growth factor-beta in the presence of other inflammatory mediators. Biochem J $1989,260: 463-469$

206. Creemers EEJM, Daemen MJAP, Cleutjens JPM, Srnits JFM, Collen D, Carmeliet P: Complete inhibition of cardiac wound healling after myocardial infarction in plasminogen deficient mice. Circulation 1998, 98:1-553

207. Przyklenk K, Connelly CM, McLaughlin RJ, Kloner RA, Apstein CS: Effect of myocyte necrosis on strenght, strain, and stiffness of isolated myocardial strips. Am Heart J 1987, 114:1349-1359

208. Swan HJC, Forrester IS, Diamond G, Chatterjee K, Parmley Ww: Hemodynamic spectrum of myocardial infarction and cardiogenic shock: a conceptual model. Circulation 1972, 45:10971103

209. Cameliet P, Schoonjans I, Kieckens L, Ream B, Degen \, Bronson R, De Vas R, Van den Oord J], Collen D, Mulligan RC: Physiological consequences of loss of plasminogen activator gene function in mice. Nature 1994, 368:419-424

210. Gawaz M, Neumann FJ, Dickfeld T, Reininger A, Adelsberger H, Gebhardt A, Schomig A: Vitronectin receptor $(\alpha \mathrm{V} \beta 3$ ) mediates platelet adhesion to the luminal aspect of endothelial cells. Circulation 1997, 96:1809-1818

211. Weber $\mathrm{Kr}(\mathbb{E} \mathrm{d})$ : Wound healing in cardiovascular disease. New York, Futura Publishing Company, 1995, pp.

212. Vaalamo $M$, Weckroth $M$, Puolakkainen P, Kere J, Saarinen P, Lauharanta J, Saarialho-Kere UK: Patterns of matrix metalloproteinase and TIMP-1 expression in chronic and normally healing human cumaneous wounds. Br J Dematol 1996, 135:52-59

213. Quax PHA, Lamfers ML, Grimbergen $J \mathrm{G}$, Verheijen $J \mathrm{H}$, wan Hinsbergh Vx: Inhibition of neointima formation in cultured human saphenous vein segments by an adenovirus expressing an urokinase receptor binding plasmin inhibitor. Circulation 1997, $96(8): 1669$

214. Lozier JN, Metzgiger ME, Donahue RE, Morgan RA: Adenovirus-mediated expression of human coagulation factor IX in the rhesus macaque is associated with dose-limiting toxicity. Blood 1999, $94: 3968-3975$

215. Dai Y, Schwarz EM, Gu D, Zhang WW, Sarvetnick N, Verma IM: Cellular and humoral immune responses to adenoviral vectors containing factor IX gene: tolerization of factor IX and vector antigens allows for long time expression. Proc Nat Acad Sci U S A 1995, 92:1401-1405

216. Brenner M: Gene transfer by adenovectors. Blood 1999, 94:3965-3967

217. Kuizinga MC, Smits JFM, Arends JW, Dhemen MJAP: AT-2 Receptor blockade reduces cardiac interstitial cell DNA synthesis and cardiac function after rat myocardial infarction. J Mol Cell Cardiol 1998, 30:421-434

218. Cleutiens JPM, Havenith $M G$, Beek $C$, Vallinga $M$, ten Kate J, Bosman FT: Origin of basement membrane type-IV collagen in xenografted human epithelial numor cell lines. Am J Pathol 1990, 136:1165-1172

219. Kockx MM, Muhring J, Bortier H, De Meyer GRY, Jacob W: Biotin- or digoxigenin-conjugated nucleotides bind to matrix vesicles in atherosclerotic plaques. Am J Pathol 1996, 148:1771-1777 
220. Smits JFM, van Krimpen C, Schoemaker RG, Cleutjens JPM, Daemen MAP: Angiotensin II receptor blockade after myocardial infarction in rats: effects on hemodynamics, myocardial DNA synthesis, and interstitial collagen content. J Cardiovasc Pharmacol 1992, 20:772-778

221. Reddy SG, Roberts WC. Frequency of rupture of the left ventricular free wall or ventricular septum among necropsy cases of fatal acute myocardial infaretion since introduction of coronary care units. Am J Cardiol 1989, 63:906-911

222. Varbella $F$, Biongioanni $S$, Sibona Masi $A$, Iazzolino $E$, Alunni $G$, Conte MR, Brusca $A$ : Subacute left ventricular free-wall rupture in early course of acute myocardial infarction. Clinical report of two cases and review of the literature. G Ital Cardiol 1999, 29:163-170

223. Dalrymple-Hay MJ, Monro IL, Livesey SA, Lamb RK: Postintarction ventricular septal rupture: the Wessex experience. Semin Thorac Cardiovasc Surg 1998, 10:111w116

224. Zahger D, Milgalter E, Pollak A, Hasin Y, Merin G, Beeri R, Gotsman MS: Left ventricular free wall rupture as presenting manifestation of acute myocardial infarction in diabetic patients. Am J Cardiol 1996, 78:681-682

225. Peuhikurinen $\mathrm{K}$, Risteli $\mathrm{L}$, Jounela $\mathrm{A}$, Risteli J: Changes in interstitial collagen metabolism during acute myocardial infarction treated with streptokinase or tissue plasminogen activator. Am Heart ] 1996, 131:7-13

226. Knoepfler PS, Bloor CM, Carroll SM: Urokinase plasminogen activator activity is increased in the myocardium during coronary artery occlusion. J Mol Cell Cardiol 1995, 27:1317-1324

227. Robert V, Besse $S$, Sabri A, Silvestre JS, Assayag P, Van Thiem N, Swyngedauw B, Delcayre C: Differential regulation of matrix metalloproteinases associated with aging and hypertension in the rat heart. Lab Invest 1997, 76:729-738

228. "Tyagi SC, Kumar S, Cassatt S, Parker JL: Temporal expression of extracelluar metal loproteinases and tissue plasminogen activator in the development of collateral vessels in the canine model of coronary occlusion. Can J Physiol Pharmacol 1996, 74:983-995

229. Cameliet $P$, Collen $D$ : Development and disease in proteinase-deficient mice: role of the plasminogen, matrix metalloproteinase, and coagulation system. Thromb Res 1998, 91:255-285

230. George SJ, Johnson JL, Angelini GD, Newby AC, Baker AH: Adenovirus-mediated gene transfer of the human TIMP-1 gene inhibits smooth muscle cell migration and neointima formation in human saphenous vein. Hum Gene Ther 1998, 9:867.877

231. Alcom JL, Gao E, Chen Q, Smith ME, Gerard RD, Mendelson CR: Genomic elements involved in transcriptional regulation of the rabbit surfactant protein-A gene. Mol Endo 1993, 7:10721085

232. Nunes [, Munger JS, Harpel JG, Nagano $Y$, Shapiro RL, Gleizes PE, Rifkin DB: Structure and activation of the large latent transforming growth factor-beta complex. Int J Obes Relat Metab Disord 1996, 20:S4-S8

233. Schaffer CJ, Nanney LB: Cell biology of wound healing. Int Kev Cytol 1996, 169:151-181

234. Koyama $\mathrm{H}$, Raines EW, Bomfeldt KE, Roberts JM, Ross R: Fibrillar collagen inhibits arterial smooth muscle proliferation through regulation of Cdk2 inhibitors. Cell 1996, 87:1069-1078

235. Plesner T, Behrendt N, Ploug M: Structure, function and expression on blood and bone marrow cells of the urokinase-rype plasminogen activator receptor, UPAR. Stem Cells 1997, 15:398-408

236. KJeiner DE, Stetler-Stevenson WG: Matrix metalloproteinases and metastasis. Cancer Chemother Pharmacol 1999, 43:S42-51

237. Chapman HA: Plasminogen activators, integrins and the coordinated regulation of cell adhesion and migration. Cur Opin Cell Biol 1997, 9:714-724

238. Rifkin DB, Mazzieri R, Munger JS, Noguera I, Sung J: Proteolytic contral of growth factor availability. APMIS 1990, 107:80-85

239. Borregaard N, Cowland JB: Granules of the human neutrophilic polymorphoruclear leukocyte. Blood 1997, 89:3503-3521

240. Lee $\ K$, Zaidi SHE, Li $\mathbb{P}$, Dawood F, Cheah AYL, Wen WH, Saiki Y, Rabinowitch M: A serine elastase inhibitor reduces inflammation and fibrosis and preserves cardliac function after experimentally-induced murine myocarditus. Nar Med 1998, 4:1383-1391 
241. Zhang B, Ye S, Hermann SM, Eriksson P, de Maat M, Evans A, Arveiler D, Luc G, Cambien F, Hamstem A, Wathins $H$, Henney AM: Functional polymorphism in the regulatory region of gelatinase $B$ gene in relation to severity of coronary atherosclerosis. Circulation $1999,99: 1788$

242. Lifnen $\mathrm{HR}$, Collen $\mathrm{D}$ : Congenital and accuired deficiencies of components of the fibrinolytic system and their relation to bleedingt and thrombosis. Fibrinolysis $1989,367-77$

243. Hamsten $A_{\text {, de }}$ Faire $U$, Walldius $G$, Dahelen $G$, Szamosi $A$, Landou $C$, Blomback $M$, Wiman $B$ : Plasminogen activator inhibitor in plasma: risit factor for recurrent myocardial infarction. The Lancet $1987,3-8$

244. Heriry M, Tregowet DA, Alessi MC, Aillaud MF, Visvikis $S$, Siest $G$, Tiret $L$, Juhan-Vague I: Metabolic determinants are much more important than genetic polymorphisms in determining the PAI-1 activity and antigen plasma concentrations: a family study with part of the Stanislas Cohort. Arterioscler Tromb Vasc Biol 1998, 18:84-91

245. Carmeliet P, Collen D: Vascular development and disorders: molecular analysis and pathogenetic insights. Kidney Int 1998, 53:1519-1549

246. Keski-Oja ل, Lyons RM, Moses HL: Inactive secreted forms of transfoming growth factor-beta: activation by proteolysis. I] Cell Biochem 1987, 11a:60

247. Preissner KT, May AE, Germer M. Kanse SM: Molecular crosstalk between adhesion receptors and proteolytic cascades in vascular remodeling. Thrombosis and Haemostasis 1997, 78:88-95

248. Solorzano $\mathrm{CC}$, Ksontini $\mathrm{R}$, Pruitt JH, Auffenberg T, Tannahill $\mathrm{C}$, Galardy $\mathrm{RE}$, Schultz GP, MacKay SLD, Copeland EM, Moldawer LL: A matrix metalloproteinase inhibitor prevents processing of tumor necrosis factor alpha and abrogates endotoxin-induced lethality. Shock 1997 , $7: 427-431$

249. Vaalamo M, Matula L, Johansson $N$, Karmiemi AL, Karjalainen-Lindsberg ML, Kahari VM, Saarialho-Kere U: Distinct populations of stromal cells express collagenase-3 (MMP-13) and collagenase-1 (MMP-1) in chronic ulcers but not in normally healing wounds. I lnvest Dermatol $1997,109: 96-101$

250. Koivunen E, Arap W, Valtanen H, Rainisalo A, Medina OP, Heikkila P, Kantor C, Gahmberg

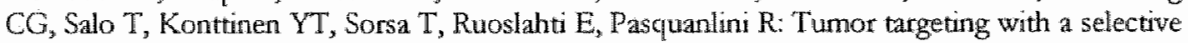
gelatinase inhibitor. Nature $1999,17: 768-774$

251. Hackel DB, Jennings RB. The heart. In: Pathology. Ed: Rubin and Farber, 1988.

252. Koolwijk $P$, Vanerck MGM, Devree WJA, Vermeer MA, Weich $H A$, Hanemaaijer $\mathbb{R}$, Varhinsbergh VWM: Cooperative effect of TNFa, bFGF, and VEGF on the formation of tubular structures of human microvascular endothelial cells in a fibrin matrix. Role of urokinase activity. J Cell Biol 1996, 132:1177-1188 
Summary

Samenvatting

Dankwoord

Curriculum vitae 


\section{SUMMARY}

Heart failure is a common syndrome with an increasing incidence and prevalence. One of the major causes of heart failure is myocardial infarction. Understanding of the pathophysiology of heart failure is important for an adequate approach to therapy. Most studies on this subject have focused on the limitation of muscle injury and the progressive ventricular dilatation that occurs in the months to years after infarction. In contrast, little attention has been paid to the healing process of the myocardium after infarction. The infarct appears to be more than just dead tissue and infarct healing turns out to be an active well controlled process. More importantly, interventions in infarct healing appear to affect the architecture of the heart, an important determinant of survival after infarction. One of the determinants of left ventricular remodeling is damage to and loss of the myocardial extracellular matrix during the healing process after infarction. This thesis focuses on the healing process of the heart after infarction, with special attention to two enzyme systems that are able to degrade components of the extracellular matrix, i.e. matrix metalloproteinases (MMPs) and the plasminogen system. The main hypothesis of the present thesis is that proteinases, in particular MMPs and plasmin, are the main regulators of the wound healing process after infarction. Second, we hypothesized that interference in this healing process modulates $\mathrm{LV}$ remodeling and cardiac function.

In Chaper 2 we studied the localization and time course of MMP-1, $-2,-3$ and -9 immunoreactivity in cardiac autopsy tissue of patient who died after myocardial infarction. A subgroup of patients, who developed cardiac rupture after infarction was included to test the hypothesis that MMP over-activation contributes to rupture of the heart following MI. We found that: 1) tissue MMP immunoreactivity decreases as early as a few hours after infarction, through loss of MMP-1, -2 and -3 immunoreactivity of ischemic cardiomyocytes, 2) 12 hours after infarction, MMP immunoreactivity begins to increase again as a result of infiltration of MMP- $1,-2,-3$ and -9 containing inflammatory cells into the infarcted myocardium, 3) in early granulation tissue MMP $-1,-2,-3$ and -9 are extensively present in fibroblast-like cells and endothelial cells, implying a further role for $M M P_{s}$ in the structural remodeling process and the angiogenic response of the infarcted myocardium during wound healing, and 4) no differences in localization of MMPs were found between the infarct and rupture group.

After describing the localization of MMPs in human infarcts, we investigated the mRNA expression (using RT-PCR) and activity (using zymography) of MMPs in a mouse model of myocardial infarction in Chapter 3. Within the first week, the activities of MMP-2, -3 and -9 were upregulated in the infarcted LV. Already the first day postMI, MMP-13 mRNA expression was significantly upregullated, whereas the mRNA levels of $\mathrm{MMP}^{-2},-3$ and -9 remained fairly high, but constant over the first 5 weeks. The main objective of the study described in chapter 3 was to assess the role of MMPs in LV remodeling, infarct healing and cardiac function in vivo. We used the same mouse model of myocardial infarction and studied the effects of a broad range MMP inhibitor (GM6001) on LV remodeling, infarct healing and cardiac function. Infarcted mice allocated to GM6001 treatment had comparable infarct sizes, but less LV dilatation and 
thicker infarcted LV walls, 7 days after MI. In these infarcts, necrotic areas were latger, cell densities lower and collagen contents reduced. These effects of MMP inhibition were most prominent 7 days after MI and showed a trend towards normalization after 14 days. Cardiac output, measured 14 days after surgery, yielded a lower cardiac index after maximal stimulation of the hearts in the GM6001 treated mice. In conclusion, in the infarcted mouse heart, MMP inhibitor treatment attenuates $\mathrm{LV}$ remodeling, reduces the rate of infarct healing and depresses cardiac function. Thus, the present study indicates that the use of MMP inhibitors as potential therapeutic agents for heart failure should be applied with caution, since they may depress cardiac function.

The next three chapters of this thesis focus on the role of the plasminogen system, an important activator for most MMPs, in the healing process of the heart after infarction. In chapter 4 we used a recombinant adenovirus (adATF.BPTI), encoding a hybrid protein consisting of the receptor binding domain of uPA, linked to a potent plasmin inhibitor, and injected it 7 days before coronary artery ligation in mice. Both control and ad.ATF.BPTI injection resulted in high mortality, mainly during the first few hours after coronary artery ligation. Nevertheless, analysis of the hearts from mice that survived the complete experiment demonstrated that infarct healing was not affected at 7 days after infarction by adA TF.BPTI infection. In conclusion, these preliminary observations on the effects of systemic adenoviral gene transfer of a plasmin inhibitor during the healing phase of the heart after myocardial infarction, indicate high mortality, but no effect on infarct healing. However several kinetic issues related to gene delivery remain to be addressed.

In chapter 5 myocardial infarction was induced in plasminogen deficient mice ( $\mathrm{Plg} /-$ ) and in wild-type controls (Plg $+/+$ ). Structural analysis 1,2 and 5 weeks after infarction, revealed that infarct healing was virtually abolished in $\mathrm{Plg}-/$ - mice, indicating that the plasminogen system is required for the repair process of the heart. In the absence of plasminogen, inflammatory cells did not migrate into the infarcted myocardium. Necrotic cardiomyocytes were not removed and the formation of granulation tissue and fibrous tissue did not occur. In these non-healing infarcted hearts, $L V$ dilatation was not altered. In addition, gelatinolytic activity of MMP-2 and MMP-9 was depressed in the Plginfarcted hearts, suggesting that the plasmin effect on infarct healing may be mediated by MMPs. Surprisingly, cardiac function was only attenuated to a rather small extent in the $\mathrm{Plg}$-/ - infarcted mice when compared to the wild-types. In conclusion, this study provides direct proof that plasmin mediated proteolysis plays a central role in cardiac wound healing after myocardial infarct in mice.

In chapter 6 we investigated other components of the plasminogen system in the same murine model of myocardial infarction. It turned out that uPA deficiency, but not tPA or UPAR deficiency resulted in impaired healing, although the phenotype was less pronounced than in the PIg-/ mice (chapter 5). In addition, uPA deficiency or adenoviral PAI-1 overexpression protected against cardiac rupture. Since temporary administration of PAI-1 or TIMP-1 completely protected wild-type mice against cardiac rupture, but did not abort infarct healing to a large extent, ptoteinase inhibitors may constitute a new approach to prevent cardiac nupture after myocardial infarction. 
In conclusion, both MMPs and the plasminogen system play a central role in infarct healing. Our data show dual effects. By degrading extracellular matrix components, these proteolytic enzyme systems allow cells (inflammatory and fibroblast-like cells) to infiltrate in the infarct, a prerequisite for adequate infarct healing. At the same time, by disrupting the collagen network, MMP activity weakens the infarcted wall and consequently contribute to infarct expansion and cardiac rupture. Due to the positive effects on $\mathrm{LV}$ dilatation and cardiac rupture, proteinase inhibitors could develop into a new approach to treat patients at risk for heart failure. However caution should be exerted since proteinase inhibitors may depress cardiac function. 


\section{SAMENVATTING}

Hartfalen, een syndroom met toenemende incidentie, wordt gekenmerkt door een afgenomen pompfunctie van het hart. De klachten van de patiènt bestaan 0. a. uit kortademigheid bij inspanning, en naarmate de pompfunctie verder achteruit gaat, ook in rust. Een van de meest voorkomende oorzaak wan hartfalen is het hartinfarct. Een hartinfarct wordt veroorzaakt door afsluiting van een van de kransslagaders door atherosclerose (aderverkalking). Hierdoor wordt het gedeelte van de hartspier, dat nomaliter van zuurstof voorzien wordt door de betreffende kransslagader, geconfronteerd met een zuurstof tekort. Er zal een gedeelte van de hartspier afsterven, wat afhankelijk van de grootte van het infatct, de hartfunctie nadelig beinvloedt.

Therapièen tegen de gevolgen van een hartinfarct zijn voormamelijk gericht op het zo snel mogelijk weer openen van de afgesloten kransslagader, waardoor de schade aan de hartspier enigzins beperkt blifft. Anderzijds zijn veel onderzoeken gericht op het voorkomen van de progressieve verwijding van de linker hartkamer (dilatatie), die optreedt in de maanden tot jaren na het infarct. Weinig aandacht is er tot op heden besteed aan het wondgenezingproces van de hartspier na het infarct. Het infarct blijkt echter meer te zijn dan een dode massa cellen, en het wondgenezingproces blijkt een actief en goed georganiseerd proces te zijn. Studies hebben aangetoond dat interventie in dit wondgezingsproces invloed kan hebben op de dilatatie van het hart, een belangrijke determinant voor het ontstaan van hartfalen. Een van de processen die ten grondslag ligt aan de progressieve verwijding van de linker hartkamer na infarct is schade an de extracellulaire matrix gedurende het wondgenezingsproces van het hart. De studies, beschreven in dit proefschrift, bestuderen het wondgenezingsproces van het hart, met speciale aandacht voor 2 enzymsystemen die in staat zijn om componenten van de extracellulaire matrix af te breken: matrix metalloproteinases (MMPs) en het plasminogeen systeem. De hoofd-hypothese van het proefschrift is dat proteases, in het bijzonder MMPs en plasmine, een belangrijke rol spelen bij de regulatie van het wondgenezingsproces na een hartinfarct. Daarnaast hebben we onderzocht of ingripen in het wondgenezingsproces middels remming van de activiteit van deze enzymsystemen, de dilatatie van de linker hartkamer en de hartfunctie beinvloedt.

In hoofdstuk 2 hebben we, m.b.v immunohistochemische technieken de lokalisatie van verschillende MMPs bestudeerd in het humane hart op verschillende tijdstijpen na een infarct. Hiervoor is gebruik gemaakt van autopsie weefsel van patienten die ovetleden zijn aan een hattinfarct. Om de hypothese te testen dat over-activatie van MMPs bijdtagt aan de ontwikkeling van een ruptuur is tevens een subgroep patiënten in deze studie opgenomen, die overleden zijn aan een tuptuur van het hart na infarct. Resultaten van deze studie waren dat: 1) de MMP immunoreactiveit afneemt reeds enkele uren na infarct, door verlies van MMP-1, -2 en -3 immunoreactiviteit uit ischemische hartspiercellen, 2) 12 uur na infarct de MMP immunoreactiviteit is toegenomen, door inflitratie van MMP-1, -2 , -3 en -9 bevattende ontstekingscellen in het geinfarceerde myocard, 3) in granulatie weefsel, MMP-1, -2 en -3 voornamelijk aanwezig zijn in macrofagen, fibroblasten en endotheelcellen, wat een rol voor MMPs suggereert in het verdiere proces van littekenweefselworming en de vorming van nieuwe vaten in de geinfarceerde hartspiet, en 
4) geen verschillen gevonden zïn in lokalisatie van MMPs tussen de geinfarceerde en geruptureerde harten.

$\mathrm{Na}$ de lokalisatie van MMPs in harten van patiênten met hartinfarct onderzocht te hebben, helbben we in hoofdstuk 3 de mRNA expressie (m.b.v RT-PCR) en activiteit (m.b.v. zymografie) van MMPs onderzocht in een muizen model van het hartinfarct. Gedurende de eerste week na inductie wan het infarct blijkt de activiteit van MMP-2, -3 en -9 verhoogd te zijn. De mRNA expressie van MMP-2, -3 en -9 bleek echter niet verhoogd na infarct, hetgeen suggereert dat de verhoogde MMP activiteit niet het gevolg is van verhoogde synthese van $M M P s_{\text {, }}$ maar van verhoogde activatie van latente MMPs. Alleen de mRNA expressie van MMP-13 was verhoogd op dag 1 na infarct, en met name in het geinfarceerde myocard. De belangrijkste doelstelling van dit hoofdstuk was echter om de rol van MMPs te bestuderen in het wondgenezingsproces van het hart na infarct en de gevolgen woor de functie van het hart. Dit werd bewerkstelligd door toediening van een breed spectrum MMP remmer aan geinfarceerde muizen. In deze MMP remmer behandelde muizen werd geen verschil gevonden in infarct-grootte, t.ov. de controle groep. Wel werd gevonden dat, 7 dagen na inductie van het hartinfarct de verwijding van de linkerkamer was afgenomen en dat de wanddikte van de geinfarceerde linkerkamer minder was afgenomen, vergeleken met de dieren die de placebo behandeling hadden gekregen. In deze 7 dagen oude infarcten werden tevens grotere gebieden met necrotische hartspiercellen aangetroffen, was de infiltratie van ontstekingscellen lager, en de collageen afzetting afgenomen. 14 dagen na inductie van het hartinfarct werd de hartfunctie gemeten, welke verslechterd bleek in de MMP remmer groep. Uit de bevindingen in hoofstuk 3 concluderen we dat remming van MMP activiteit na een infarct de progressieve verwijding van de linker hattkamer vermindert, het wondgenezingsproces vertraagt en de hartfunctie verslechtert. Deze studie impliceert dus dat voorzichtigheid geboden is voor gebnuik van MMP remmers als een potentiële therapie voor hartfalen omdat deze de hartfunctie nadelig beïnvloedt.

De volgende 3 hoofdstukken van dit proefschrift beschrijven de rol van het plasminogeen systeem, wat o.a. een belangrijke activator is voor MMPs, in het wondgenezingsproces van het hart na infarct. In hoofdstuk 4 hebben we gebruik gemaakt van een recombinant adenovirus (adATF.BPTI), wat codeert voor een hybride eiwit bestaande uit het receptor bindend domein van uPA en een potente plasmine remmer. Het adenovirus werd intraveneus toegediend, 7 dagen voor infarct operatie in muizen. Zowel het controle adenovirus als adATF.BPTI resulteerde in een hoge mortaliteit, de muizen stierven voomamelijk de eerste paar uur na infarct operatie. Analyse van de harten van de muizen die de operatie wel overleefden liet desalniettemin zien dat de infarctgenezing niet veranderd was na adATF.BPTI infectie. Concluderend liet deze pilot studie zien dat infarctgenezing niet beïnloed wordt door de adenovirale gentherapie met een plasmine remmer. Voordat geconcludeerd kan worden dat plasmine geen rol speelt in het wondgenezingsproces van het hart na infarct zullen enkele zaken m.b.t. de wijze van adenovirus toediening, de toegankelijkheid van het virus in het infarctgebied en de toxiciteit van het adenoviraal construct, nog verder onderzocht moeten worden. 
In hoofdstuk 5 beschrijven we het wondgenezingsproces tha een hartinfarct in plasminogeen deficiënte muizen $(\mathrm{Plg}-/-)$ and wild-type controle muizen $(\mathrm{Plg}+/+)$. Structurele analyse van de harten, 1,2 en 5 weken na infarct, liet zien dat het wondgenezingsproces in de $\mathrm{Plg}$ - / infarcten niet op gang was gekomen. In de afwezigheid van plasminogeen, infiltreerden ontstekingscellen niet naar het geinfarceerde myocard, werden necrotische hartspiercellen niet gefagocyteetd en werd de vorming van granulatie weefsel en litteken weefsel voorkomen. In deze niet genezende infarcten was de dilatatie van de linker kamer niet anders dan in de controle harten, maar was de hartfunctie wel enigszins verslechterd. De activiteit van MMP-2 en MMP-9 was afgenomen in Plg-/infarcten, wat suggereert dat het effect van plasminogeen op infarct genezing gemedieerd wordt door MMPs. Concluderend bewrist deze studie dat plasmine gemedieerde proteolytische activiteit een centrale rol speelt in cardiale wondgenezing na een infarct in de muis.

In hoofdstuk 6 hebben we in hetzelfde muizenmodel andere componenten van het plasminogeen systeem onderzocht in relatie met infarct genezing. De resultaten laten zien dat $\mathrm{UPA}$, en niet $\mathrm{TPA}$, de plasminogeen activator is die plasminogeen activeert tot plasmine in het geinfarceerde hart. Infarct genezing was namelijk totaal afwezig in uPA deficiënte muizen, maat niet in $\mathrm{tPA}$ deficiënte muizen. Bovendien bleek uPA deficiëntie, adenovirale PAI-1 overexpressie en adenovirale TIMP-1 overexpressie te beschermen tegen het ontstaan van een cardiale ruptuur na infarct. In dit licht zouden protease remmers in de toekomst gebruikt kunnen worden als therapie tegen cardiale rupturen.

Concluderend kunnen we stellen dat zowel MMPs als het plasminogeen systeem een belangrijke rol spelen in het wondgenezingsproces van het hart na een infarct. Onze resultaten zijn echter tweeledig. Door de afbraak van extracellulaire matrix componenten, vergemakkelijken deze twee enzym-systemen de infiltratie van verschillende cel typen in het infarct gebied, een vereiste voor adequate wondgenezing. Tegelijkertijd leidt afbraak/beschadiging van het collageen netwerk tot verzwakking van de geinfarceerde wand. Dit draagt op haar beurt bij aan verwijding van de linker hartkamer en aan het ontstaan van cardiale rupturen. Dankzij de positieve effecten op LV dilatatie en cardiale rupturen zouden protease remmers in de toekomst gebruikt kunnen worden als therapie voor patiënten na een hartinfarct. Toch is enige voorzichtigheid geboden omdat het gebruik van protease remmers de hartfunctie nadelig beïnloedt. 


\section{DANKWOORD}

Begin 1995, toen ik nog nooit van MMPs gehoord had, begon ik aan een groot avontuur dat promotie-onderzoek heet. $\mathrm{Nu}, 5$ jaar later besef ik, met de afronding van lhet proefschrift; dat het avontuur er echt op lijkt te zitten en dat ik in deze tussenliggende periode toch wel het een en ander opgestoken heb. De mensen die mij tijdens deze reis begeleid, geholpen en voor vertier gezorgd hebben wil ik graag langs deze weg bedanken.

Allereerst wil ik mijn promotoren Mat Daemen en Jos Smits en co-promotor Jack Cleutjens bedanken.

Beste Mat, als 'reisleider' van mijn promotie-avontuur heb ik veel van je geleerd. Jouw positieve kijk en snelle maniet van werken waren erg motiverend voor me. Gelukkig wist je me op de juiste momenten uit mijn dal te praten om me vervolgens tijdens mijn pieken wijselijk mijn gang te laten gaan. Bedankt voor de goede begeleiding en voor de katitjes Nederland-Belgie.

Beste Jos, je bent tevens een belangrijk persoon voor mijn onderzoek geweest. Altijd aanwezig op de achtergrond, en gelukkig op belangrijke kritische momenten wat meer op de voorgrond, was je altijd bereid te helpen. Je kritische commentaar op mijn manuscripten waren soms verhelderend, soms verwarrend maar desondanks zeer nuttig. Ik heb veel van je geleerd en hoop dat in de toekomst aok nog te mogen doen.

Beste Jack, zonder jou was dit project en dus dit boekje er nooit geweest. Bedankt voor het me wegwijs maken in het land der MMPs.

De analisten van het dierenlab: Jacques, Peter, Nicole en sinds kort Catleen, jullie zijn waarschijnlijk degenen die het meeste praktisch werk voor mij verzet hebben. Bedankt voor alle infarct-operaties (ofwel mietjes, zoals Nicole ze noemt), cardiac output metingen en de gezellige uurtjes bij de farmacologie.

De meiden van het 'ons' lab wilde ik tevens bedanken voor hun praktische bijdrage.

Petra, de kleuringen uit hoofdstuk 2 zijn grotendeels van jouw hand. De vraagbaken Anique en Monique, zonder jullie zou het lab, mede door mij hoor, maar een zooitje zijn. Jullie geotganiseerdheid heeft zeker een positieve invloed gehad op mijn onderzoek. Waar zou ik anders alle antilichamen, blokjes en primers terug hebben kunnen vinden? Loes wil ik bedanken voor alle BrdU's en Githa voor het opzetten van de RT-PCR voor MMP-1 en MMP-2. En last but not least, Kim, hartelijk dank voor je grote inzet tijdens je stage. We waren een geweldig (mutsen) team! Ik vind het fijn dat je als paranimf aan mijn zijde staat.

De (ex-en adoptie-) bewoners van onze werkkamer. Sylvia, de langstzittende onder ons, bedankt voor je hulp bij god-weet-wat-allemaal. 'Lopend woordenboek' Esther en 'alltijd vrolijke' Cherida, bedankt voor het telkens weer geduldig aanhoren van mijn klaagzang, en oh ja voor de soms te prettige sfeer. Beste Meindert, adoptickind 1, om tegen de invasie van al die vaat-mensen weerstand te kunnen bieden moeten wij, als echte cardio's, elkaar natuurlijk blijven steunen! Richard en Robert, ook jullie bedankt voor de gezellige goede 
oude tijd... Susan, ons tweede adoptiekind, ze waren inderdaad gedenkwardig! Kitty; bedankt voor je hulp bij de tot stand koming van mijn nieuwe baan.

De mensen uit Leuven: Peter Carmeliet, Stephane Heijmans en Liteve Moons, hartelijk dank voor de tips, muizen en de goede samenwerking.

Uit Leiden ben ik Paul Quax en Jan Willem Lardanoije dankbaar voor de prettige samenwerking. Paul, bedankt voor je verbazingwekkende snelle reacties als ik weet eens wat van je vroeg over de e-mail.

Twee collega"s hebben mijn promotie-awontuur veraangenaamd, door zich plotseling te ontpoppen als 'goede vriendin'. Marielle, bedankt voor de vele gezellige kletsavondjes en je peptalks tajdens mijn schrijfdipjes. En Birgit, dankzij jou weet ik dat mensen uit Eindhoven best aardig kunnen zijn. Op naar jullie promotie!

RPBS, avondjes uit met jullie werden altijd weer legendarisch.

Gouden Lepel, bedankt voor de broodnodige vitamines en de gezelligheid in de vele gouden aftakkingen. Krijg ik nu dan eindelijk mijn A-status?

Carla, en de andere leden van de Ongelagdje Ei-jer, bedankt voor de nodige afleiding in 'good old' Weert. Nu zien jullie eindelijk wat ik al die tijd in Maastricht gedaan heb.

Mijn ouders ben ik dankbaar voor het geduld, de interesse en de steun die ze me de afgelopen 5 jaar gegeven hebben. En Eric, ik heb het maar getroffen met een broet als jij! 


\section{CURRICULUM VITAE}

\section{Esther Creemers}

1969

Geboren te Geldrop

1983-1990

VWO-B, Bisschoppelijk College Weett

1990-1995

Studie gezondheidswetenschappen

afstudeerrichting biologische gezondheidskunde

Universiteit Maastricht

1995-1999

Assistent in Opleiding, Academisch Ziekenhuis Maastricht, afdeling Pathologie

1999

Post-doctoraal medewerker bij dezelfde vakgroep

\section{LIST OF PUBLICATIONS}

Heymans, S; Luttun, A; Nuyens, D; Theilmeier, G; Creemers, E; Moons, L; Dyspersin, GD; Cleutjens, JPM; Shipley, M; Angellilo, A; Levi, M; Nube, O; Baket, A; Keshet, E; Lupu, F; Herbert, JM; Smits, JF; Shapiro, SD; Baes, M; Borgers, M; Collen, D; Daemen, MJ; Carmeliet, P. Inhibition of plasminogen activators or matrix metalloproteinases prevent cardiac rupture but impairs therapeutic angiogenesis and causes cardiac failure. (1999). Nature Meditime. 10, 1135-1142.

Creemers, E; Heymans, S; Cleutjens, J; Smits, J; Moons, L; Collen, D; Daemen, M; Carmeliet, P: Disruption of the plasminogen gene in mice abolishes wound healing following myocardial infarction. Ams. J. Pathol. (in press).

Creemers, E; Daemen, $\mathrm{M}$; Cleutjens, J. Time-dependent localization of matrix metalloproteinases in the healing human heart after infarction (subsuitted).

Creemers, E; Cleutjens, J; Savelkouls, K; Hanemaaijer, R; Quax, P; Smits, J; Daemen, M. Inhibition of Matrix Metalloproteinases attenuates left ventricular remodeling, delays infarct healing and depresses cardiac function after myocardial infarction in mice (subromitted)

Creemers, E; Cleutjens, J; Smits, J; Daemen, M. Wound healing after myocardial infarction. A focus on the matrix metalloproteinases and the plasminogen system (Review). (In preparation) 